\title{
Updated Application of Spatial Data Modeling and Geographical Information Systems (GIS) for Identification of Potential Siting Options for Small Modular Reactors
}

September 2012

Prepared by

R. J. Belles

G. T. Mays

O. A. Omitaomu

W. P. Poore

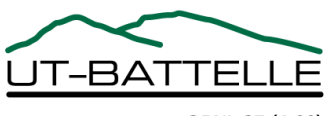




\section{DOCUMENT AVAILABILITY}

Reports produced after January 1, 1996, are generally available free via the U.S. Department of Energy (DOE) Information Bridge.

Web site http://www.osti.gov/bridge

Reports produced before January 1, 1996, may be purchased by members of the public from the following source.

National Technical Information Service

5285 Port Royal Road

Springfield, VA 22161

Telephone 703-605-6000 (1-800-553-6847)

TDD 703-487-4639

Fax 703-605-6900

E-mailinfo@ntis.gov

Web site http://www.ntis.gov/support/ordernowabout.htm

Reports are available to DOE employees, DOE contractors, Energy Technology Data Exchange (ETDE) representatives, and International Nuclear Information System (INIS) representatives from the following source.

Office of Scientific and Technical Information

P.O. Box 62

Oak Ridge, TN 37831

Telephone 865-576-8401

Fax 865-576-5728

E-mail reports@osti.gov

Web site http://www.osti.gov/contact.html

This report was prepared as an account of work sponsored by an agency of the United States Government. Neither the United States Government nor any agency thereof, nor any of their employees, makes any warranty, express or implied, or assumes any legal liability or responsibility for the accuracy, completeness, or usefulness of any information, apparatus, product, or process disclosed, or represents that its use would not infringe privately owned rights. Reference herein to any specific commercial product, process, or service by trade name, trademark, manufacturer, or otherwise, does not necessarily constitute or imply its endorsement, recommendation, or favoring by the United States Government or any agency thereof. The views and opinions of authors expressed herein do not necessarily state or reflect those of the United States Government or any agency thereof. 
ORNL/TM-2012/403

Reactor and Nuclear Systems Division

Computational Sciences and Engineering Division

\title{
UPDATED APPLICATION OF SPATIAL DATA MODELING AND GEOGRAPHICAL INFORMATION SYSTEMS (GIS) FOR IDENTIFICATION OF POTENTIAL SITING OPTIONS FOR SMALL MODULAR REACTORS
}

\author{
R. J. Belles \\ G. T. Mays \\ O. A. Omitaomu \\ W. P. Poore \\ Date Published: September 2012 \\ Prepared for \\ U.S. Department of Energy, Office of Nuclear Energy \\ Prepared by \\ OAK RIDGE NATIONAL LABORATORY \\ Oak Ridge, Tennessee 37831-6283 \\ managed by \\ UT-BATTELLE, LLC \\ for the \\ U.S. DEPARTMENT OF ENERGY \\ under contract DE-AC05-00OR22725
}





\section{CONTENTS}

Page

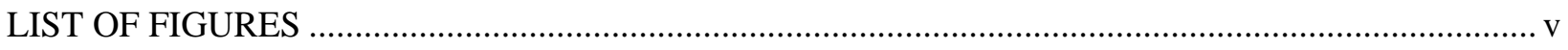

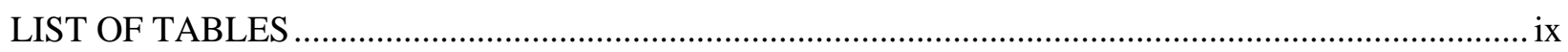

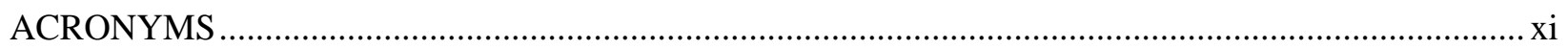

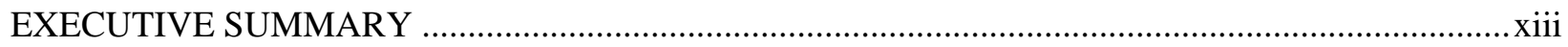

1. BACKGROUND, INTRODUCTION, AND METHODOLOGY …........................................... 1

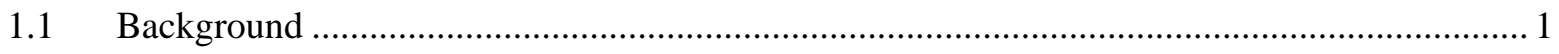

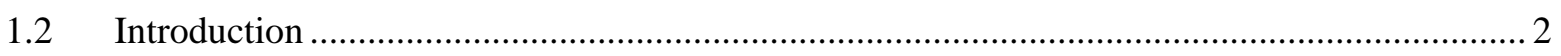

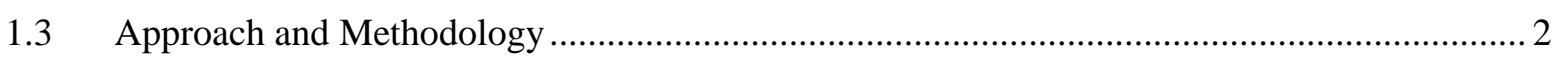

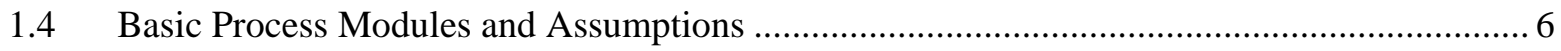

2. BASE CASE SMALL MODULAR REACTOR RESULTS ….................................................. 9

2.1 Nominal SMR Site Selection and Evaluation Criteria ........................................................ 10

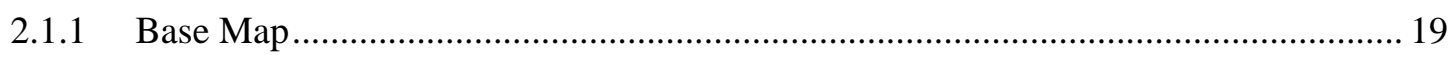

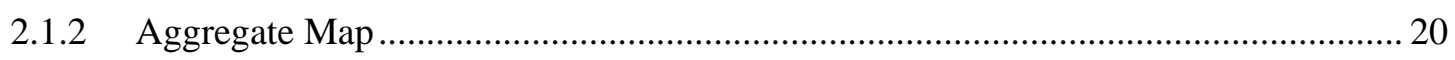

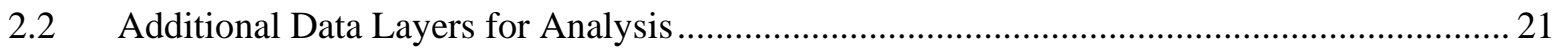

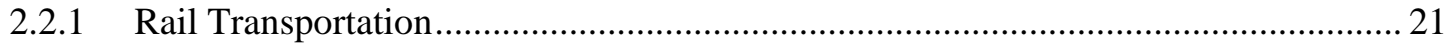

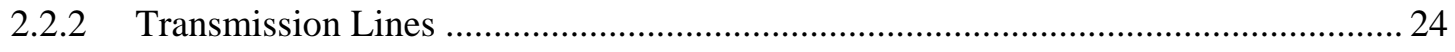

2.3 Additional Stream Flow Layer SSEC Values .................................................................. 25

2.3.1 Stream Flow Requirements for an SMR with an Electrical Capacity of 250 MW(e) 25

2.3.2 Stream Flow Requirements for Minimal Station Water Requirements...................... 26

3. ALTERNATIVE SOURCES OF COOLING WATER MAKEUP ...............................................2 29

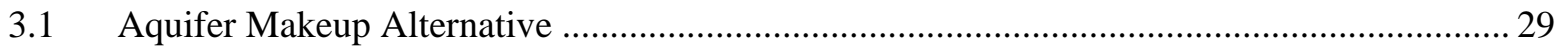

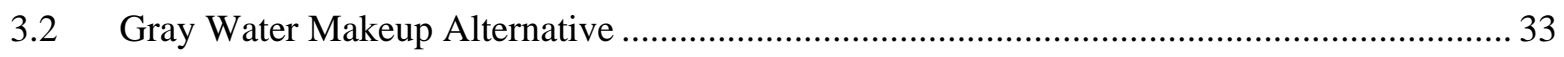

3.3 Ocean and Great Lakes Cooling Alternative ................................................................. 37

3.4 Combined Cooling Source Results.................................................................................... 38

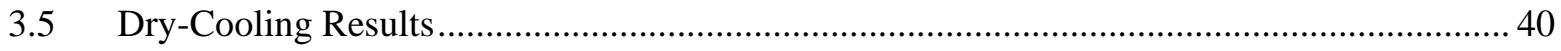

4. CHARACTERIZATION OF AREAS WHERE SCREENING RESULTS INDICATE THAT SMRS CAN BE SITED AND LARGE LWRS CANNOT BE SITED ........................................ 43

4.1 Comparison to EPRI Study Large Reactor Results ............................................................ 43

4.1.1 Effect of Reduced Population Buffer .................................................................... 46

4.1.2 Effect of Increased Slope Tolerance.................................................................... 47

4.1.3 Effect of Reduced Cooling Water Requirement..................................................... 48

4.1.4 Effect of Reduced Hazardous Area Exclusions......................................................... 49

4.1.5 Effect of Greater Seismic Tolerance ……............................................................... 50

4.1.6 Summary of SMR-Only Base Map Area Characterizations...................................... 51 
4.2 Proximity to High Population (and High Electrical Demand) Areas

4.2.1 Proximity to Areas of Projected High Population Growth (and Areas of High Electrical Load Growth)

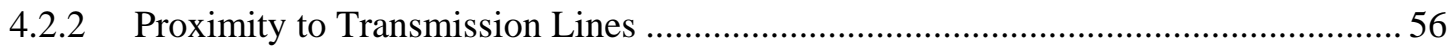

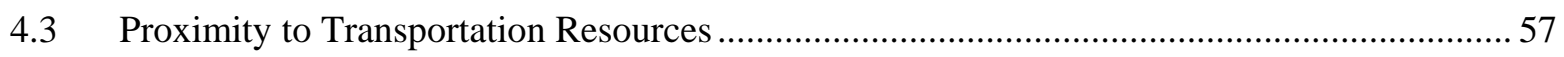

4.4 Replacement of Older Coal Plants in Ohio and Nearby States ............................................. 57

5. CLIMATE, FLOODING, AND FUKUSHIMA CONSIDERATIONS …...................................... 59

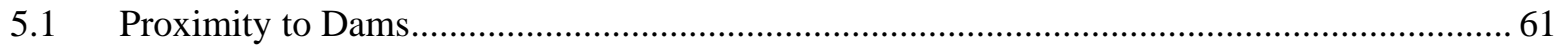

6. CHARACTERIZATION OF SINGLE-ISSUE SCREENING RESULTS ....................................... 63

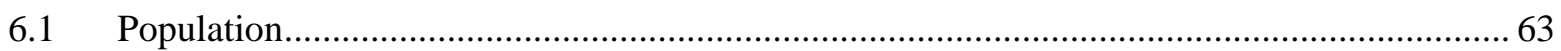

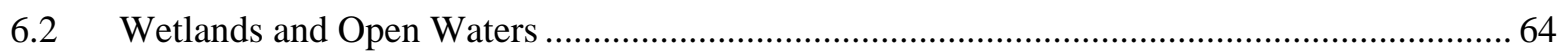

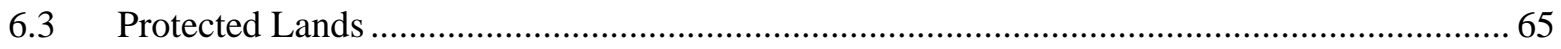

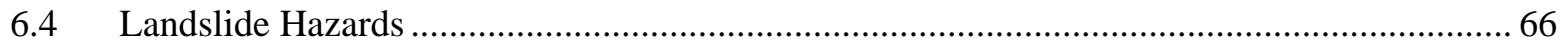

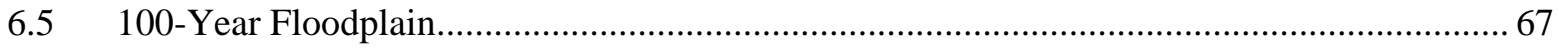

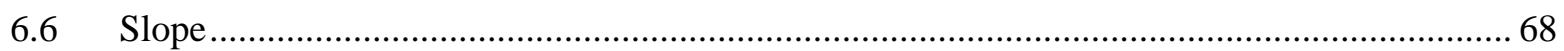

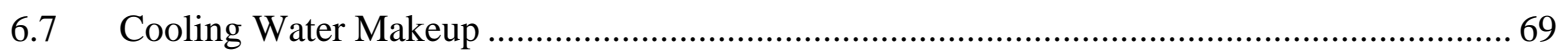

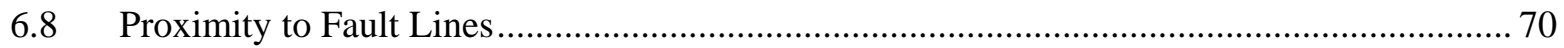

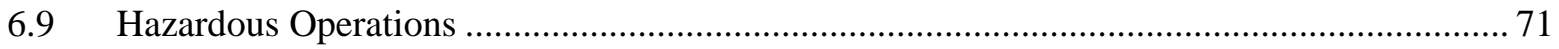

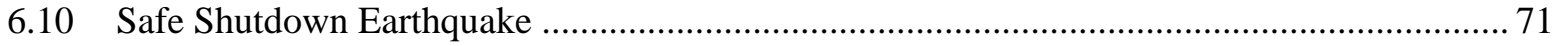

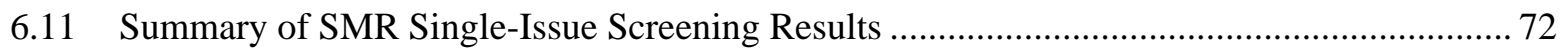

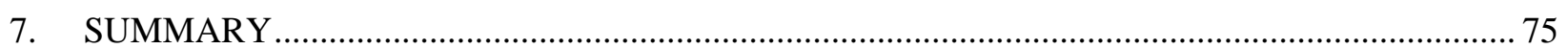

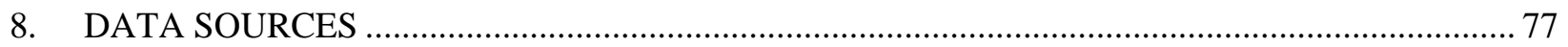




\section{LIST OF FIGURES}

Figure $\quad$ Page

ES-1 SMR aggregate siting map ..................................................................................

ES-2 Southeast SMR-only base map with areas of high population density (2035)...................... Xv

ES-3 SMR composite map detailing siting challenges...............................................................

1 OR-SAGE functions as a visual database ................................................................... 2

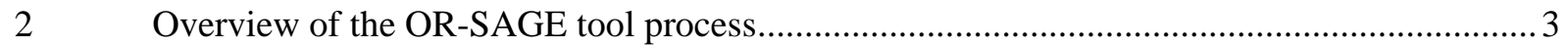

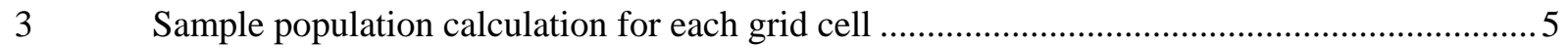

$4 \quad$ Generating a base map with no siting challenges....................................................... 6

$5 \quad$ Comparison of Large PWR Design with iPWR Design for SMRs ....................................... 9

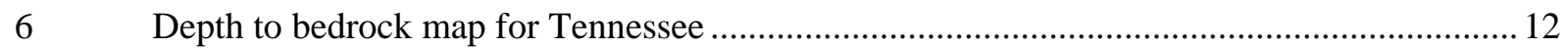

$7 \quad$ Nominal, bounding SMR high-population SSEC layer....................................................... 13

$8 \quad$ Nominal, bounding SMR wetlands and open-water SSEC layer ........................................ 13

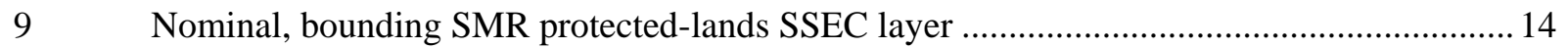

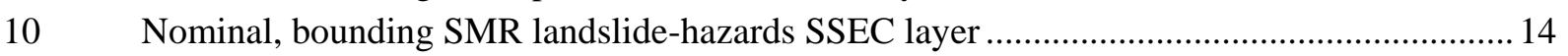

11 Nominal, bounding SMR 100-year floodplain SSEC layer ............................................... 15

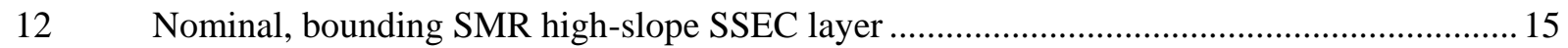

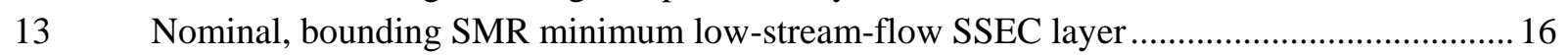

$14 \quad$ Nominal, bounding SMR proximity-to-fault-lines SSEC layer …....................................... 16

$15 \quad$ Nominal, bounding SMR proximity-to-hazards SSEC layer ................................................ 17

16 Nominal, bounding SMR safe-shutdown earthquake SSEC layer ...................................... 17

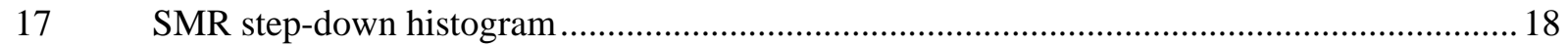

$18 \quad$ Nominal, bounding SMR composite map detailing siting challenges................................... 19

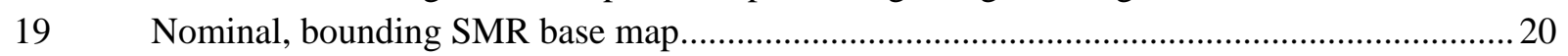

20 Nominal, bounding SMR base map aggregated for 50-acre sites ..................................... 21

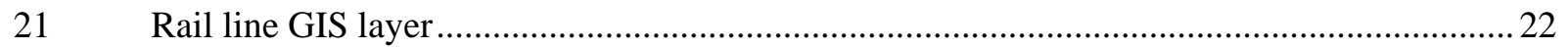

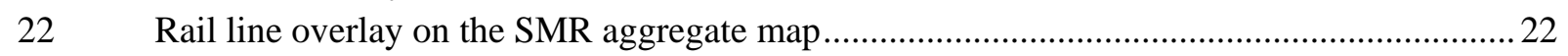

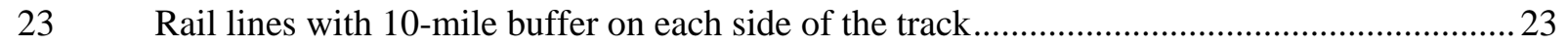

24 Rail lines with 10-mile buffer overlaid on SMR aggregate map.......................................23

25 Transmission line overlaid on the SMR aggregate map..................................................... 24

26 Transmission lines with excess capacity overlaid on the SMR aggregate map .................... 25

27 SMR minimum low stream flow SSEC layer for 30,000 gpm ............................................ 26

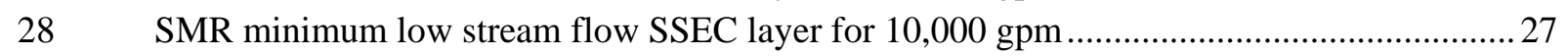

29 SMR aggregate map variants with multiple stream flow values ......................................... 28

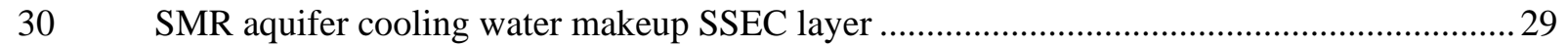

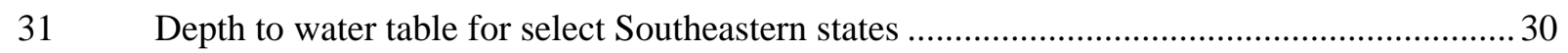

32 SMR composite map utilizing aquifer SSEC layer ......................................................... 31

33 Combined stream flow and aquifer cooling water makeup layer ........................................ 32

34 SMR composite map utilizing combined stream flow and aquifer SSEC layer..................... 32

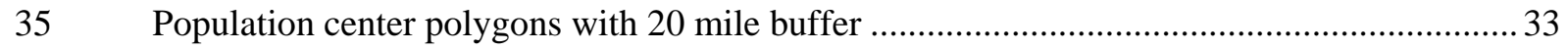

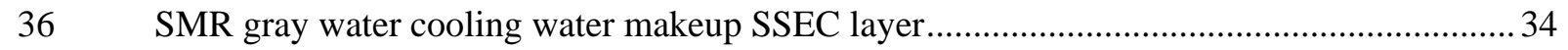

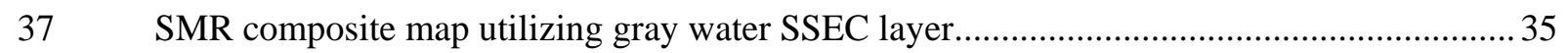

$38 \quad$ Combined stream flow and gray water cooling water makeup layer .................................... 36 
SMR composite map utilizing combined stream flow and gray water SSEC layer ................. 36

$40 \quad$ SMR base map with alternate ocean and Great Lakes cooling ............................................ 37

41 Combined stream flow, aquifer, and gray water cooling water makeup layer ........................ 38

42 SMR composite map utilizing combined stream flow, aquifer, and gray water SSEC layer.. 39

43 SMR composite map utilizing no cooling water (dry cooling) .............................................. 41

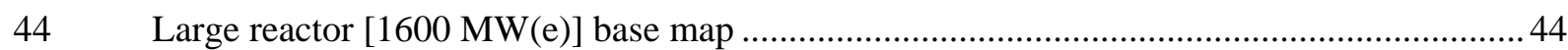

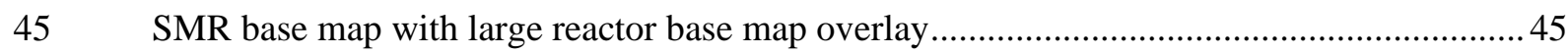

46 Extraction of SMR base map (Fig. 45) where only SMRs (yellow) can be sited................... 45

47 SMR-only base map indicating contribution of increased land from lower population

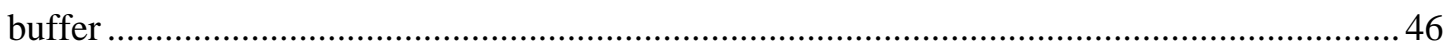

48 Focused SMR-only base map indicating contribution of increased land from lower population buffer

49 SMR-only base map indicating contribution of additional land from increased slope

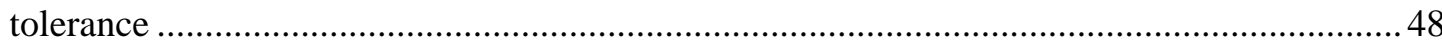

50 SMR-only base map indicating contribution of increased land from lower makeup water

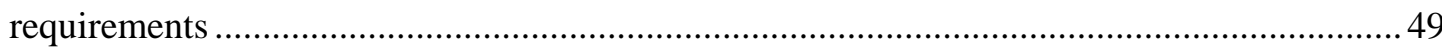

51 SMR-only base map indicating contribution of increased land from military bases and closer proximity to airports

52 SMR-only base map indicating contribution of increased land from relaxed SSE peak

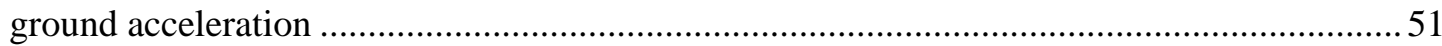

53 SMR step-down histogram detailing effect of SMR centric SSEC values............................52

54 SMR-only base map combined with areas of high population density (2010).......................53

$55 \quad$ SMR-only base map combined with areas of high population density (2035)......................54

56 Southeast SMR base map (yellow and green) with areas of high population density

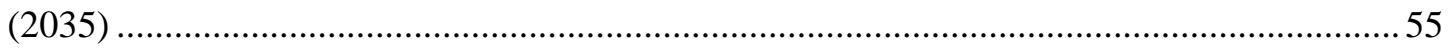

57 Alabama SMR base map (yellow and green) with areas of high population density (2035) .55

58 Transmission lines (110-230 kV) with 10-mile buffer overlaid on SMR-only aggregate

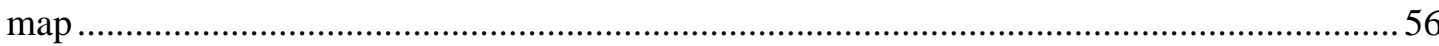

59 Rail lines with 10-mile buffer overlaid on SMR-only aggregate map ..................................57

60 SMR aggregate map colored to show the split between all (green) and SMR-only

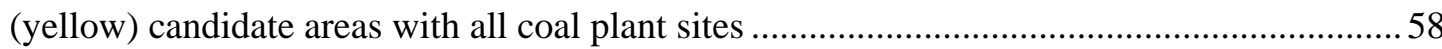

61 Seismotectonic and RLME source zones of the central and eastern United States .................60

62 SMR aggregate map and all U.S. dams with capacity of at least 5000 acre-feet ...................61

63 Dams with capacity of at least 5,000 acre-feet that overlap the SMR aggregate map ...........62

64 Nominal, bounding SMR composite map detailing siting challenges....................................63

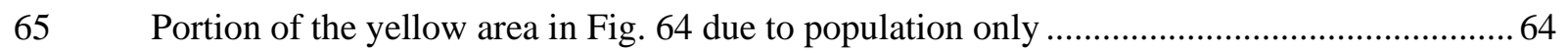

66 Portion of the yellow area in Fig. 64 due to wetlands and open water only ..........................65

67 Portion of the yellow area in Fig. 64 due to protected lands only ...........................................66

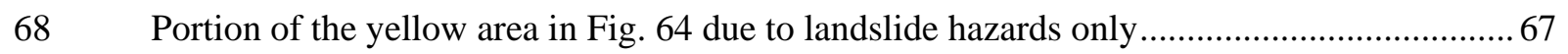

69 Portion of the yellow area in Fig. 64 due to 100-year floodplain only.................................... 68

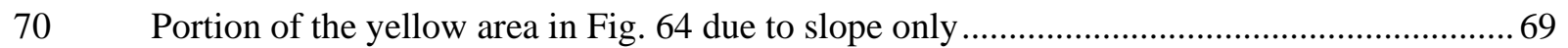

71 Portion of the yellow area in Fig. 64 due to cooling water makeup only .............................. 70 
72 Portion of the yellow area in Fig. 64 due to proximity to faults only

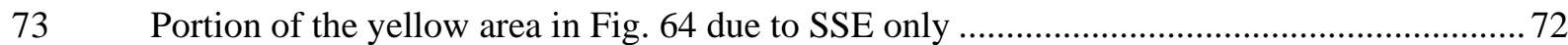





\section{LIST OF TABLES}

Table

Page

1 Comparison of large and small reactor candidate areas (percentage of contiguous

United States)

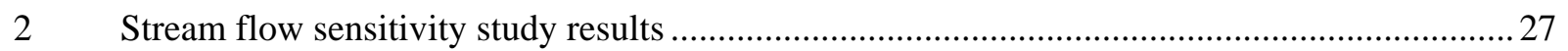

3 Cooling source combinations (percentage of contiguous United States) ................................. 40

4 Comparison of stream flow cooling water makeup and dry cooling ...................................... 41

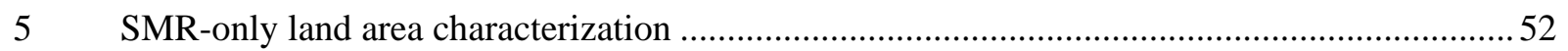

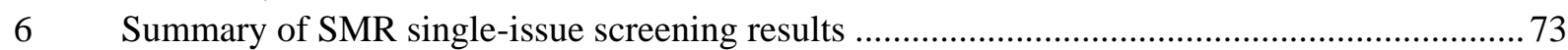





\section{ACRONYMS}

$\begin{array}{ll}\text { BWR } & \text { boiling-water reactor } \\ \text { DOE } & \text { U.S. Department of Energy } \\ \text { EIA } & \text { DOE Energy Information Administration } \\ \text { EPA } & \text { U.S. Environmental Protection Agency } \\ \text { EPRI } & \text { Electric Power Research Institute } \\ \text { ESP } & \text { early site permit } \\ \text { FAA } & \text { Federal Aviation Administration } \\ \text { GIS } & \text { geographic information systems } \\ \text { GW(e) } & \text { gigawatt electrical } \\ \text { iPWR } & \text { integral pressurized-water reactor } \\ \text { LANL } & \text { Los Alamos National Laboratory } \\ \text { LWR } & \text { light-water reactor } \\ \text { MW(e) } & \text { megawatt electrical } \\ \text { NE } & \text { (DOE) Office of Nuclear Energy } \\ \text { NETL } & \text { National Energy Technology Laboratory } \\ \text { NHDPlus } & \text { National Hydrography Database Plus } \\ \text { NRC } & \text { U.S. Nuclear Regulatory Commission } \\ \text { ORNL } & \text { Oak Ridge National Laboratory } \\ \text { OR-SAGE } & \text { Oak Ridge Siting Analysis for Power Generation Expansion } \\ \text { PWR } & \text { pressurized-water reactor } \\ \text { RLME } & \text { repeat large magnitude earthquake } \\ \text { SSE } & \text { safe shutdown earthquake } \\ \text { SSEC } & \text { site selection and evaluation criteria } \\ \text { SMR } & \text { small modular reactor } \\ \text { USGS } & \text { U.S. Geological Survey }\end{array}$





\section{EXECUTIVE SUMMARY}

Beginning in late 2008, Oak Ridge National Laboratory (ORNL) responded to ongoing internal and external studies addressing key questions related to our national electrical energy supply. This effort has led to the development and refinement of Oak Ridge Siting Analysis for power Generation Expansion (OR-SAGE), a tool to support power plant siting evaluations. The objective in developing OR-SAGE was to use industry-accepted approaches and/or develop appropriate criteria for screening sites and employ an array of geographic information systems (GIS) data sources at ORNL to identify candidate areas for a power generation technology application. The basic premise requires the development of exclusionary, avoidance, and suitability criteria for evaluating sites for a given siting application such as siting small modular reactors (SMRs). For specific applications of the tool, it is necessary to develop site selection and evaluation criteria (SSEC) that encompass a number of key benchmarks that essentially form the site environmental characterization for that application. These SSEC might include population density, seismic activity, proximity to water sources, proximity to hazardous facilities, avoidance of protected lands and floodplains, susceptibility to landslide hazards, and others.

The OR-SAGE tool is essentially a dynamic visualization database. The SSEC are the fields of the database, and the GIS data for a given variable represent the values against which searches are performed. The evaluation process divides the contiguous United States into 100- by 100-m (1 hectare) squares (cells), applying successive SMR-appropriate SSEC to each cell. There are just under 700 million cells representing the contiguous United States. If a cell meets the requirements of each SMR criterion, the cell is included as a candidate to be integrated in the possible siting of an SMR. Some SSEC parameters preclude siting a facility because of an environmental, regulatory, or land-use constraint. Other SSEC assist in identifying less favorable areas, such as proximity to hazardous operations. All of the selected SSEC tend to recommend against sites; that is, they tend to identify areas in which there are challenges to using the site for the purpose of interest. The focus of the ORNL SMR siting study is on demonstrating how SMR candidate areas might be identified, stopping short of performing any detailed site evaluations or comparisons. This approach is designed to quickly identify favorable SMR candidate areas. The results shown in this report represent a single static set of results using a specific set of input parameters. In this case, the GIS input parameters were optimized to focus on SMRs. A single set of individual results should not be construed as an ultimate SMR deployment plan or an energy solution, since U.S. energy policy is very complex. However, the strength of the OR-SAGE tool is that numerous alternative scenarios can be quickly generated to provide additional insight into SMR electrical generation or other GIS-based applications.

There are a variety of important assumptions supporting this work. Rules of thumb for the supply of cooling water makeup for thermoelectric power generation are necessary. All cooling is assumed to be provided by a closed-cycle cooling system requiring makeup water to account for evaporation and blowdown. Stream flow is the primary thermoelectric plant cooling water makeup source evaluated in this study. Plants are limited to $10 \%$ of the available stream flow for makeup water to reflect the overall demands on freshwater resources. Stream flow is conservatively based on a composite of calculated 7-day, 10-year low-flow data from the U.S. Geological Survey and existing lake and reservoir data. More readily available average stream flow data over predict available water on an annual basis as opposed to the actual seasonal highs and lows. Limited evaluations of cooling water makeup from aquifers, municipal waste water, shoreline cooling, and air cooling were also performed in this study. A methodology to provide an adequate siting footprint for typical SMR power plant applications is also necessary. In most cases, the actual plant sites selected by a utility would likely be large. However, not all the land owned by the utility or an independent power producer needs to meet all the SMR SSEC. Although most utilities own or control thousands of acres around a nuclear facility, only a nominal SMR footprint will be required to meet all siting criteria based on recognition of unique design features common to many SMRs. 
Political restrictions and social reservations against nuclear power are not considered. These assumptions and OR-SAGE methodologies are discussed at length in a previous ORNL study. ${ }^{1}$

A bounding analysis on current SMR designs indicates that SMR candidate area sites exist in every state of the contiguous United States as shown in Fig. ES-1. The available SMR candidate area land aggregated for 50-acre SMR sites with no siting challenges for SMR facilities is $26.9 \%$ of the contiguous United States, or 460 million acres. This is based on the stated assumptions and selected values for the SMR SSEC, which include an upper bound of 65,000 gpm of cooling water makeup. A previous power plant siting study identified approximately $13 \%$ of the contiguous United States aggregated to 500 -acre sites as candidate areas for a large-scale $[1.6 \mathrm{GW}(\mathrm{e})]$ nuclear power plant. ${ }^{1}$ Therefore, there is more than twice as much land available to site the bounding SMR integral pressurized-water reactor (iPWR) design as there is to site the bounding large reactor plant design.

Green $=>$ No siting challenges

Aggregated land area $\mathbf{2 6 . 9 \%}$

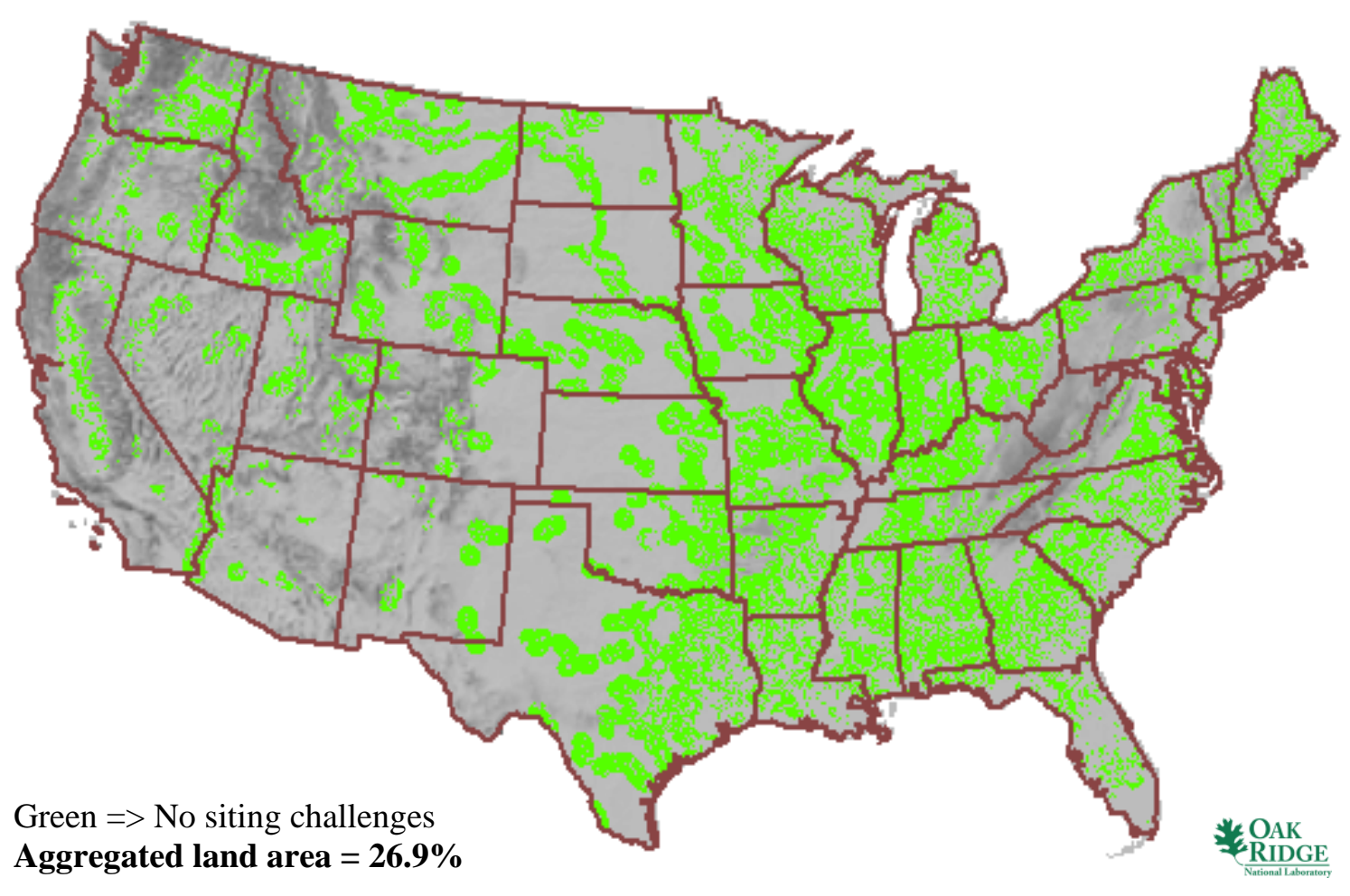

Fig. ES-1. SMR aggregate siting map.

Most SMR designs indicate the intention or possibility to site these reactors below grade. Evaluating local geology would add significant insight into the SMR site evaluation process. Los Alamos National Laboratory (LANL) has been engaged to gather and evaluate potential subsurface SMR SSEC. LANL has prepared a preliminary subsurface evaluation report ${ }^{2}$ focused on the southeastern United States to support future incorporation of subsurface SSEC into the SMR candidate area siting process.

${ }^{1}$ G. T. Mays, R. J. Belles, O. A. Omitaomu, et al., Application of Spatial Data Modeling and Geographical Information Systems (GIS) for Identification of Potential Siting Options for Various Electrical Generation Sources, ORNL/TM-2011/157/R1, May 2012.

${ }^{2}$ F. Perry, R. Kelley, R. Middleton, S. Birdsell, Status Report on Evaluation of Site Suitability, Screening Criteria, and Data for Small Modular Reactors, Los Alamos National Laboratory, LA-UR-12-24495, September 2012. 
Additional evaluations and sensitivity studies examined transportation networks and transmission networks. Based on the selected SSEC criteria, $88 \%$ of the SMR aggregated land is within 20 miles of an available rail line; $93 \%$ is within 20 miles of an available $110-230 \mathrm{kV}$ transmission line; and $72 \%$ is within 20 miles of an available extra high-voltage transmission line.

Use of aquifers and municipal waste water for cooling water makeup has the potential to increase the SMR candidate area by $20 \%$ of the contiguous United States. In this case, more than half of the contiguous United States land area becomes available for potential SMR siting. In addition, some SMR designs are considering air cooled technologies. In this case, almost $60 \%$ of the contiguous U.S. land area becomes available for potential SMR siting.

Approximately 50\% more land is available for siting SMRs than was forecast previously for large reactors. Numerous analyses are quantified relative to this additional land made available by the perceived increased flexibility for SMR siting. Furthermore, areas of population growth and decline out to 2035 have been identified as shown in Fig. ES-2 for the southeastern United States. Typically, the red rings in Fig. ES-2 represent projected population growth outward from current areas of high population density as population expands from 2010 to 2035. Map areas where the red rings abut green or yellow SMR candidate site areas could be well suited for reactor deployment from the perspective of being close to locations of expected load growth. Plant sites close to load can help reduce electrical transmission infrastructure construction and minimize the likelihood of grid-based disturbances associated with longdistance wheeling of power from one area to another. In areas of population growth, this is a specific advantage for SMRs with characteristics that include reduced core damage frequency, elimination of large break loss-of-coolant accident sequences, a smaller source term, reduced early release fraction, reactor vessels and containment vessels that are located entirely underwater or below grade, and reactor buildings that are located partially or totally below grade.

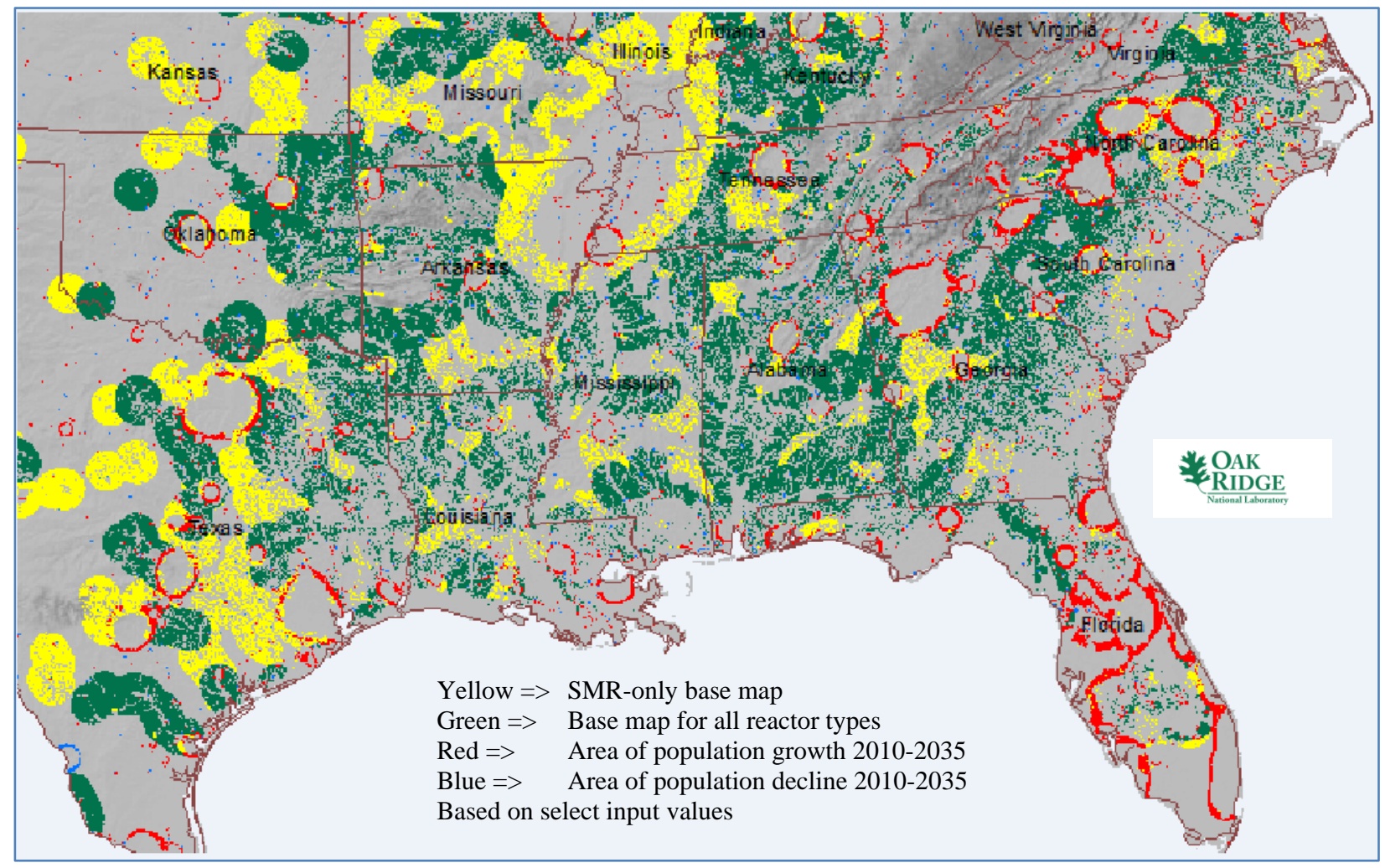

Fig. ES-2. Southeast SMR-only base map with areas of high population density (2035). 
OR-SAGE can visually display the cells that are clear of all the SSEC layer exclusions displayed and can track and display cells that are tripped by one, two, or three or more exclusions. This is known as the "SMR composite map," shown in Fig. ES-3. This is a powerful aspect to the OR-SAGE tool, because it allows areas with a limited number of siting challenges to also be identified. The areas in yellow in Fig. ES-3 makeup 41.3\% of the contiguous United Sates and have just a single siting challenge. Engineering solutions or other accommodations for the individual issues that "block" SMR siting may be available and can yield significant increases in available SMR candidate land areas.

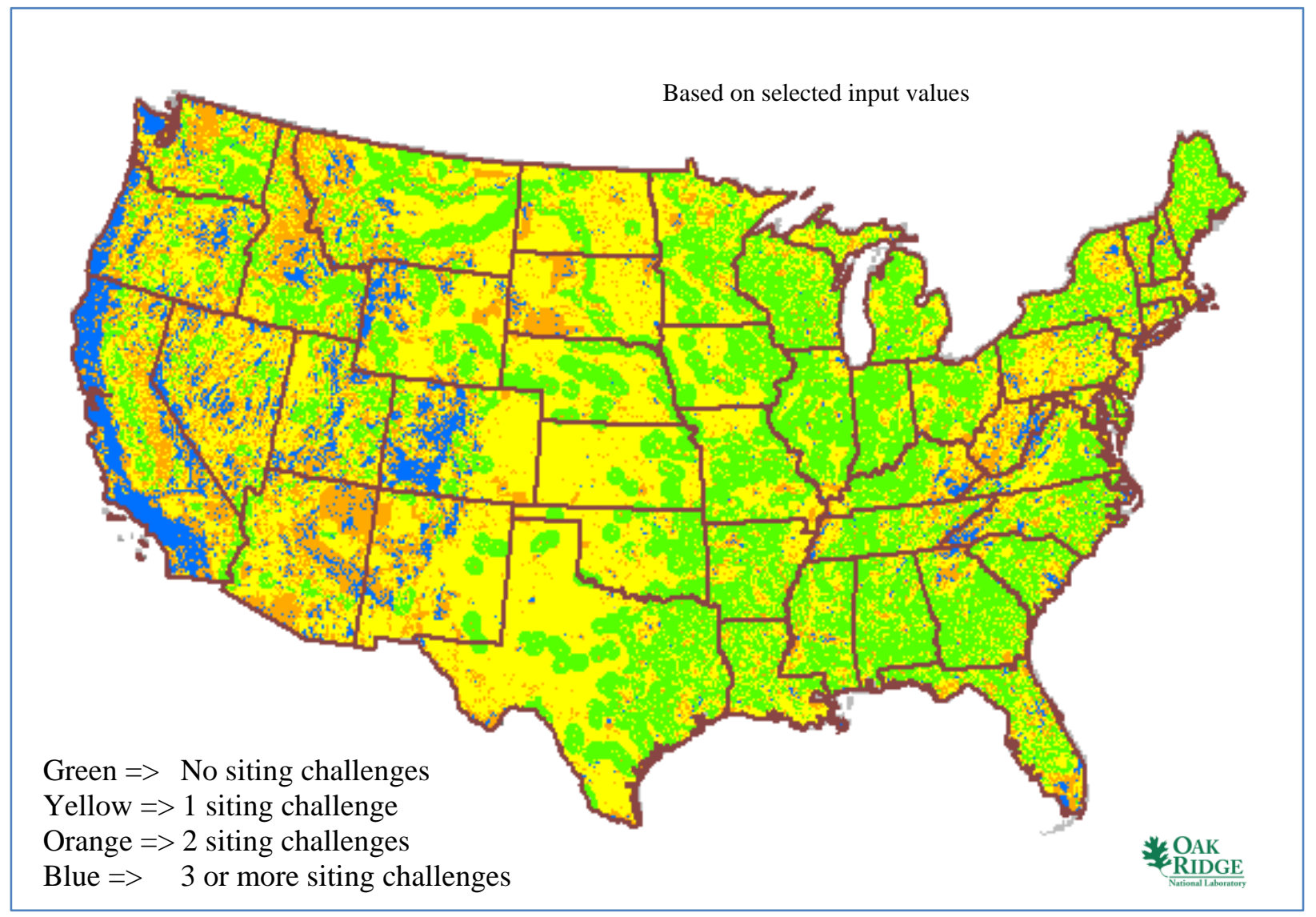

Fig. ES-3. SMR composite map detailing siting challenges.

The most significant contributor to the single-issue area on the nominal SMR composite map is cooling water makeup from existing stream flow. Varying values for stream flow and alternate sources of cooling water and dry cooling are explored in Sect. 2.2 and Chapter 3 of the report, respectively. Other SSEC that provide a noteworthy contribution to the single-issue area on the nominal SMR composite map include population limitations and buffer distance, landslide hazards, and slope. These parameters offer a reasonable possibility of an engineering solution or rule-making decision affecting the screening value as well as providing a significant increase in the amount of land available for SMR candidate areas. ${ }^{1}$ 


\section{BACKGROUND, INTRODUCTION, AND METHODOLOGY}

\section{$1.1 \quad$ Background}

The U.S. Department of Energy (DOE) Office of Nuclear Energy (NE) has tasked Oak Ridge National Laboratory (ORNL) to support identification of candidate sites for new small modular reactor (SMR) power plants using a geographic information system (GIS) based tool that ORNL has developed. ${ }^{3}$ The tool, Oak Ridge Siting Analysis for power Generation Expansion (OR-SAGE), is a flexible system being used to evaluate power plant siting options and considerations for a variety of power sources as well as identify nuclear waste storage siting options. The objective in developing OR-SAGE was to merge industry-accepted approaches for screening sites with the array of GIS data sources at ORNL to identify candidate areas for a particular application.

ORNL has employed the general concepts as presented in the 2002 Electric Power Research Institute (EPRI) Siting Guide 4 methodology developed to support Early Site Permit (ESP) applications for purposes of screening sites for nuclear power plants to develop exclusionary, avoidance, and suitability criteria. The concepts were used to develop exclusionary, avoidance, and suitability criteria for screening sites for various power plants. For a given application, it is necessary to develop site selection and evaluation criteria (SSEC) that encompass a number of key screening criteria that essentially form the site environmental characterization for that application. These SSEC might include population density, slope, seismic activity, proximity to cooling water sources, proximity to hazardous facilities, avoidance of protected lands and floodplains, susceptibility to landslide hazards, and others. OR-SAGE is a visual, relational database. The SSEC are the fields of the database, and the GIS data for a given variable represent the values against which searches are performed. The visual database concept is demonstrated in Fig. 1. The database partitions the contiguous United States, a total of 7.2E8 hectares ( 1.8 billion acres), into 100 - by $100-\mathrm{m}$ ( 1 hectare or $~ 2.5$ acre) cells. Therefore, the database is tracking just under 700 million individual land cells.

ORNL staff previously evaluated screening criteria for large and small nuclear power plants, advanced coal plants with carbon sequestration, wet and dry solar power technologies (excluding photovoltaic cells), and compressed air energy storage for EPRI. ${ }^{5}$ The principal differences between large and small nuclear power plants in the EPRI study were cooling water demand and plant footprint. This report summarizes the initial phase of a more detailed look at SMRs.

\footnotetext{
${ }^{3}$ G. T. Mays, T. J. Harrison, and O. A. Omitaomu, Preliminary Report on Siting Evaluation Tool for Commercial Nuclear Power Plants Developed by Oak Ridge National Laboratory, LTR/DOE-NE/Siting-2010/002, November 2010.

${ }^{4}$ E. Rodwell (Project Manager), Siting Guide: Site Selection and Evaluation Criteria for An Early Site Permit Application, 1006878, Final Report, Electric Power Research Institute, March 2002.

${ }^{5}$ G. T. Mays, R. J. Belles, O. A. Omitaomu, et al., Application of Spatial Data Modeling and Geographical Information Systems (GIS) for Identification of Potential Siting Options for Various Electrical Generation Sources, ORNL/TM-2011/157/R1, May 2012.
} 


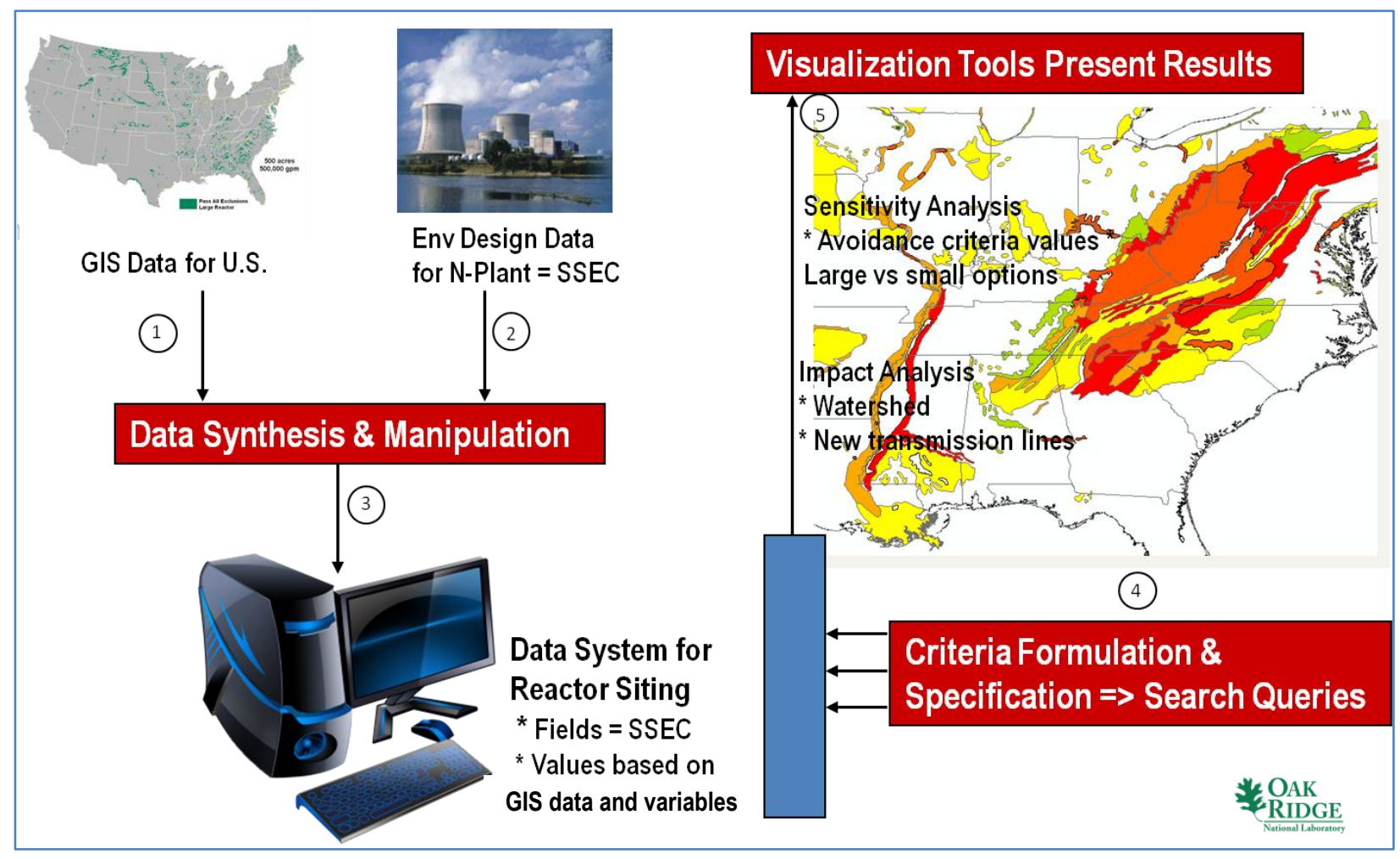

Fig. 1. OR-SAGE functions as a visual database.

\subsection{Introduction}

The objective of this SMR site-screening study is to support DOE-NE to enhance and extend the capability of the ORNL OR-SAGE siting tool to focus on issues related specifically to the siting of SMRs. Applying SMR-centric screening criteria in OR-SAGE will provide the ability to quickly analyze and characterize potential SMR sites from a national deployment perspective as well as from a site specific vantage point.

This report summarizes the initial phase of the approach that ORNL developed for screening the various power supply sites of interest to DOE-NE; the methodology employed, including spatial modeling; and initial results for the contiguous United States. The objective in conducting this type of siting evaluation is to perform early site characterization of the candidate areas to identify any particular issues for power plant siting; it is not intended to be a definitive assessment per se as to the overall suitability of any particular site.

\subsection{Approach and Methodology}

The key to the approach for this study was to use industry-accepted practices in screening sites and then to employ the proper array of data sources and identify candidate areas through the considerable computational capabilities of GIS technology available at ORNL. Initially, ORNL staff (1) adapted and extended the 2002 EPRI Siting Guide ${ }^{4}$ methodology, developed to support ESP applications, for the purpose of screening sites and (2) employed three of the four steps in the Bechtel site evaluation process ${ }^{6}$ for nuclear plant siting. This process was subsequently applied to all SMR sources evaluated in this study.

\footnotetext{
${ }^{6}$ Dominion Energy, Inc., and Bechtel Power Corporation, Study of Potential Sites for the Deployment of New Nuclear Plants in
} the United States, prepared for the U.S. Department of Energy, September 2002. 
The screening process divides the contiguous United States into 100- by $100-\mathrm{m}$ (1 hectare) squares (cells), applying successive suitability SSEC to each cell. If a cell meets the requirements of each criterion, the cell is deemed a candidate area for siting an SMR power plant of a particular size in terms of power [MW(e)]. Some SSEC parameters preclude siting a plant because of an environmental, regulatory, or land-use constraint. Other SSEC assist in identifying less-favorable areas such as proximity to hazardous operations. All of the selected SSEC tend to recommend against sites; that is, they tend to identify areas in which there are challenges to using the site for the purpose of interest. At this point, the suitability criteria are employed to assist in evaluating the acceptability of candidate areas and sites. The Bechtel evaluation process includes a successive four-step approach: (1) examining regions of the country, (2) examining regions of interest based on electricity and market projections,(3) identifying candidate areas, and (4) identifying candidate sites using various scoring and weighting factors.

The focus of the ORNL electrical generation source siting study is on identifying candidate areas from which potential SMR sites might be selected, stopping short of performing any detailed site evaluations or comparisons. This approach is designed to quickly screen for and characterize candidate areas. In consideration of the EPRI Siting Guide and Bechtel's Study of Potential Sites; data presented in the 1992 ESP Demonstration Program; ${ }^{7}$ and the ESP applications for North Anna, Clinton, and Grand Gulf sites, ORNL staff first developed a subset of SSEC for nuclear plant siting that were considered to have the most impact on the viability of any given site and were directly amenable to application of GIS techniques. This process is readily applicable to other forms of power generation. An overview of the OR-SAGE tool application is detailed in Fig. 2.

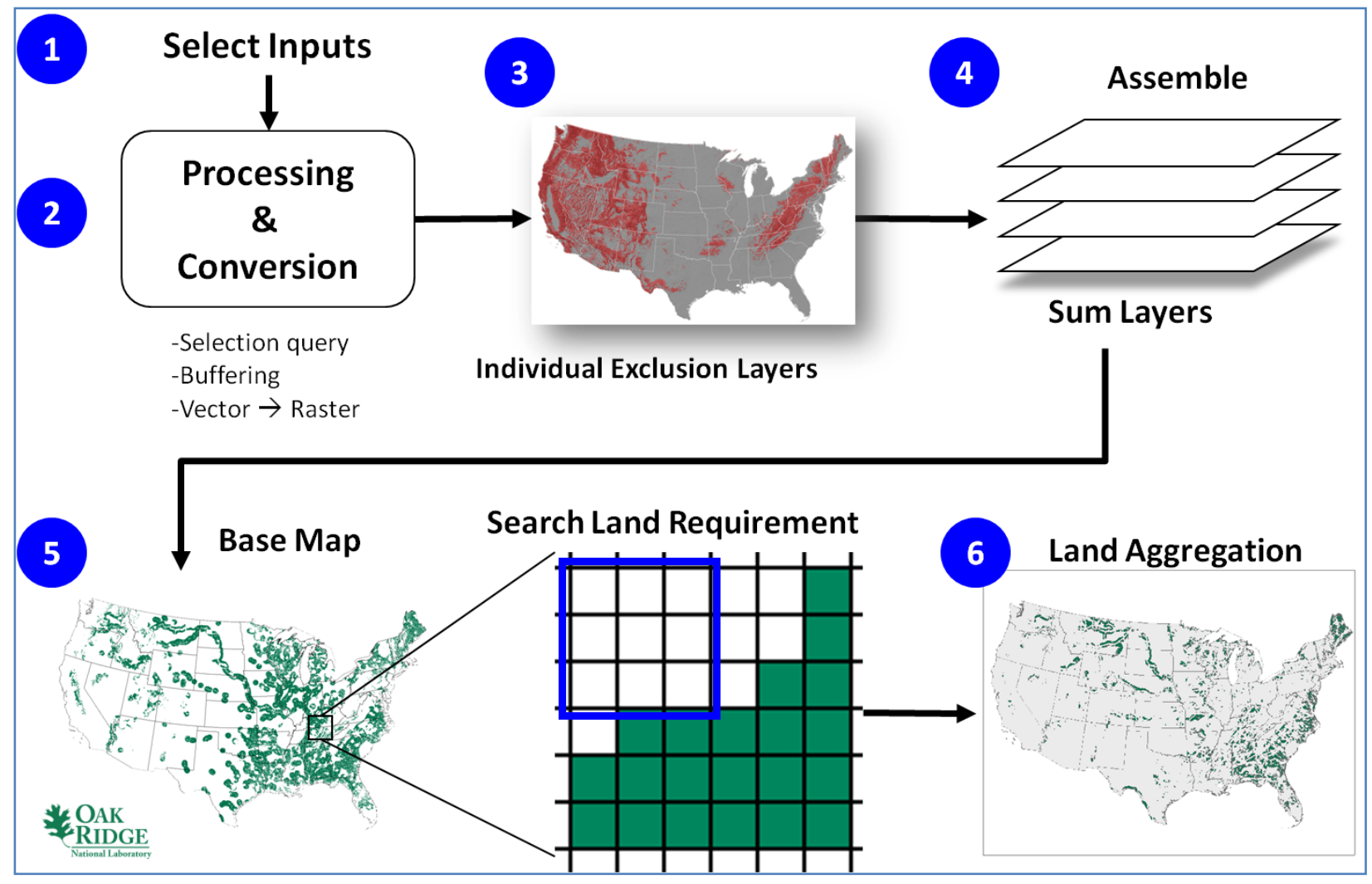

Fig. 2. Overview of the OR-SAGE tool process.

\footnotetext{
${ }^{7}$ Bechtel Power Corporation, Early Site Permit Demonstration Program, Plant Parameter Envelopes, Comparison with Ranges of Values for Four Hypothetical Sites, Gaithersburg, MD, 1992.
} 
A discussion of the OR-SAGE process steps is available from the EPRI GIS report. ${ }^{5}$ Datasets that provide national or greater coverage with attributes matching the desired SSEC are selected. The specific SSEC identified for each power source are detailed as part of the results discussion for each power source. Greater than national coverage is preferred to prevent map "edge-effects." Appropriate scaling and resolution of each dataset must be considered before using a dataset in the study. There are 22 datasets supporting the SMR evaluations. The dataset sources include:

- U.S. Geological Survey (USGS),

- U.S. National Park Service,

- U.S. Forest Service,

- U.S. Fish and Wildlife Service,

- U.S. Department of Transportation,

- Federal Emergency Management Agency,

- Federal Aviation Administration (FAA),

- U.S. Census Bureau,

- ORNL LandScan ${ }^{\mathrm{TM}}$ data (a high-resolution population distribution database developed by ORNL),

- ORNL 7-Day, 10-Year Low Flow Calculated Data, and

- other commercial sources.

Some data layers involve generating an appropriate selection query and applying a buffer zone. The application of the buffer zone can be a complex process. For example, one of the SMR power plant SSEC is population density of less than 500 people per square mile. U.S. Nuclear Regulatory Commission (NRC) Regulatory Guide $4.7^{8}$ indicates that "a reactor should preferably be located such that, at the time of initial site approval and within about 5 years thereafter, the population density, including weighted transient population, averaged over any radial distance out to 20 miles (cumulative population at a distance divided by the circular area at that distance), does not exceed 500 persons per square mile." To meet the guidance, each cell in the database is queried for ambient population, which considers the weighted transient population. If a cell population is greater than 500 people per square mile, it is immediately excluded. If a cell population is less than 500 people per square mile, the surrounding area is evaluated by calculating the population density in an expanding set of rings out to a maximum of 20 miles (in simple terms, a buffer zone). If any ring is calculated to have a population density above 500 people per square mile, then the center cell is excluded. If no ring around the central cell exceeds a population density of 500 people per square mile, then the cell remains viable with regard to population. Figure 3 shows a representative result of a population dataset query with a buffer distance considered. The maximum search radii can be set to any value to create alternate buffer distances. For instance, the SMRs considered a buffer distance of 10 miles for population to reflect the industry contention of smaller source terms and other favorable design attributes of an SMR.

${ }^{8}$ Regulatory Guide 4.7, General Site Suitability Criteria for Nuclear Power Stations, Nuclear Regulatory Commission, April 1998. 


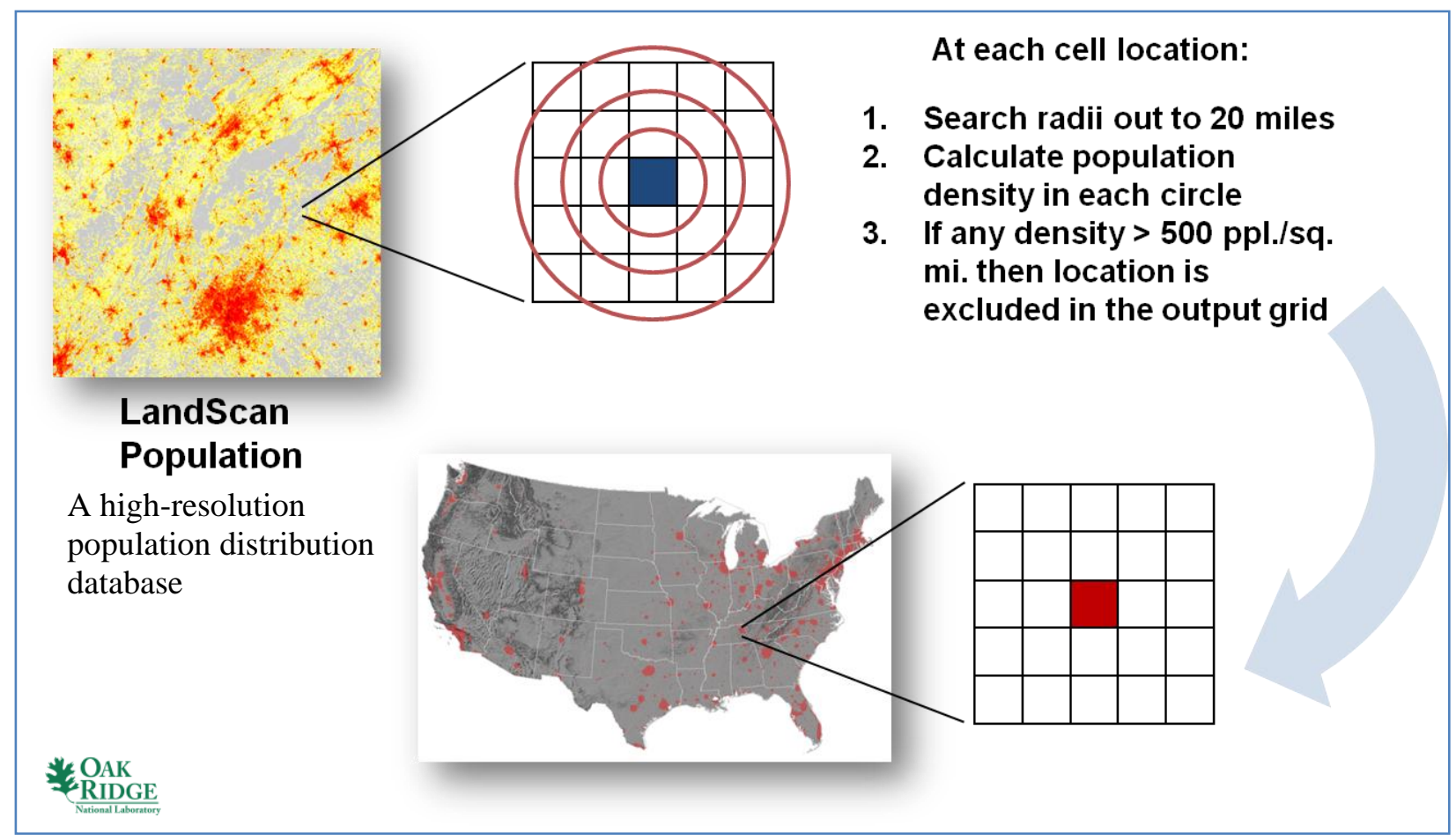

Fig. 3. Sample population calculation for each grid cell.

Individual SMR SSEC layers are assembled into a single output. Essentially, the applicable layers are summed cell-by-cell. The result is a highlighted map of all the areas that do not pass one or more of the envelope criteria for the power source under consideration. Individual layers can be moved in and out of the study to conduct sensitivity analyses. The limits associated with any SMR SSEC layer can also be adjusted to conduct sensitivity analyses. Since the desired result is to identify candidate areas where an SMR is viable, the highlighted portions of the map are inverted to reveal an alternately highlighted map of all areas that have no siting challenges based on the chosen site selection and evaluation criterion. The result is considered to be the SMR "base map" for the nominal case. In effect, it is a static look in time at a set of criteria that are thought to bound the placement of an SMR. Each 100- by 100-m cell that passes every SMR SSEC is typically highlighted in green on the base map. The overall concept, as shown in Fig. 4, depicts the general application of OR-SAGE methodology by applying the individual SMR SSEC as GIS datasets to exclude areas (red map) leading to the identification of candidate areas (green map). Other considerations are available for map areas that have one or more siting challenges. 


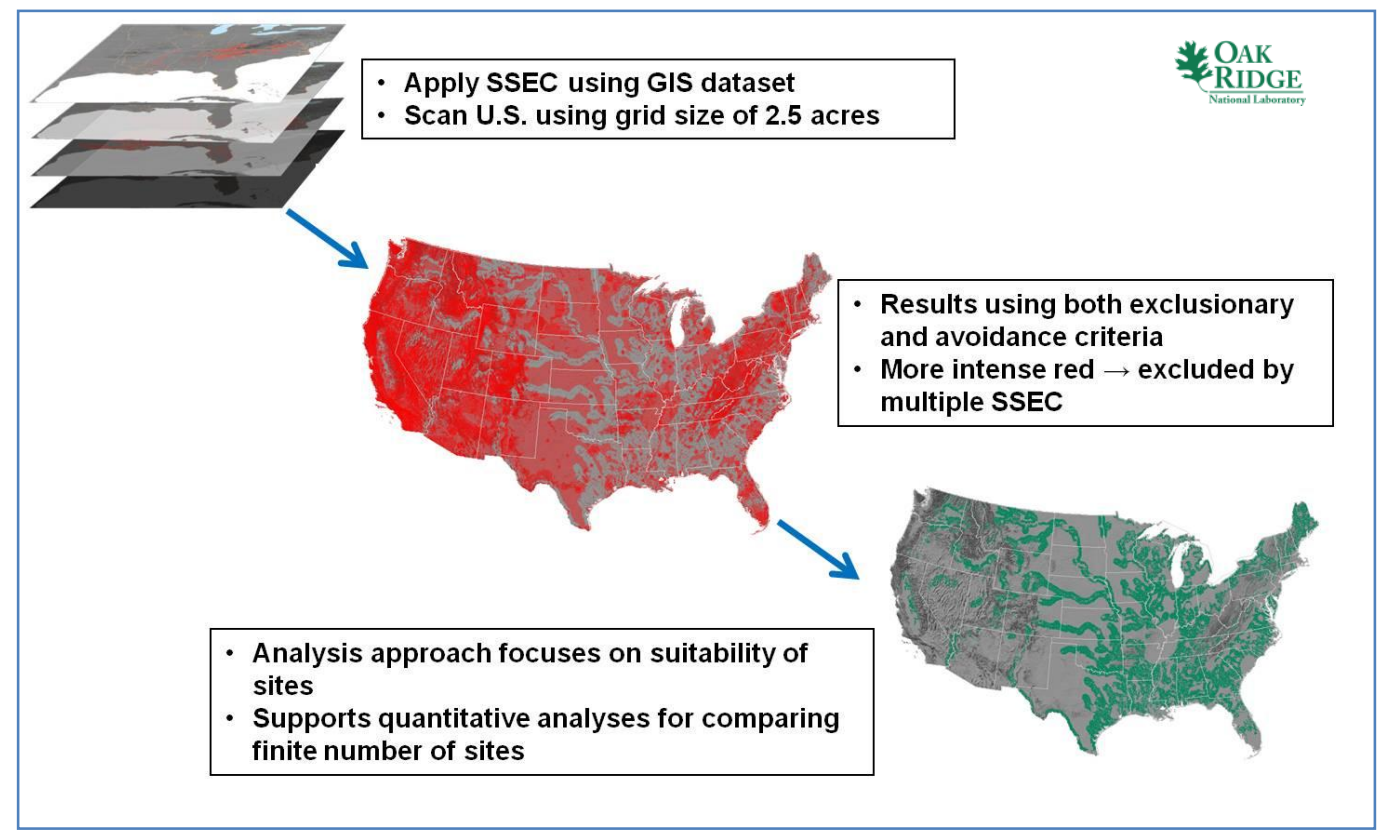

Fig. 4. Generating a base map with no siting challenges.

Given that a single cell represents approximately 2.5 acres of land, a land search must be conducted to identify realistically sized, connected plots of land that can support the typical size of an SMR. A typical size for a given power source can be highly subjective, but the essential footprint of the SMRs under consideration for the near term is typically accepted to be 50 acres or less, so the land aggregation process is considered to be the initial sensitivity study for any given power source. Cells that cannot be combined into a larger (50-acre) plot of land to support an SMR are "turned off" in the output display. The result is a pared-down base map or aggregate map identifying candidate areas where the power source of interest could realistically be sited. This land aggregation process is discussed in more detail in the EPRI GIS report. ${ }^{5}$

It must be stressed that the net result is a visualization of the candidate areas that could support SMR plants. Little is known of the underlying land ownership, except that the land is generally not in a highpopulation area, nor in most cases is the land situated on protected land such as a national park or forest. Results are generally stated in the percentage of land amenable to the SMR power source on a contiguous basis, a state basis, or a water basin basis. However, despite these caveats, these candidate area maps are extremely useful because strong estimations of how much energy could subsequently be produced by SMRs are possible using reasonable assumptions. Insights into where an SMR power source is most practical in various parts of the contiguous United States are also brought out in this study.

\subsection{Basic Process Modules and Assumptions}

There are numerous processes required to support the calculations made by the OR-SAGE tool:

- a methodology to calculate the available supply of cooling water to thermoelectric power generation;

- a methodology to analyze an adequate siting footprint for typical power plant applications;

- a methodology to estimate cumulative thermoelectric plant capacity while accounting for and debiting available cooling water throughout the various national watersheds; and

- a methodology to account for future siting limitations as population increases, load demands shift, and demands on freshwater sources change. 
These process modules are discussed in more detail in the EPRI GIS report. ${ }^{5}$

Likewise, there are numerous basic assumptions required to simplify the results computed by the OR-SAGE tool.

- Political restrictions against nuclear power are not considered. For example, some states have laws prohibiting the use of nuclear power to generate electricity, and other states have nuclear bans until trigger events are reached, such as establishment of a spent fuel repository. Likewise, those states with negative public opinion toward nuclear power are not factored into the results. However, incorporating a screening layer to model public opinion is certainly possible in OR-SAGE.

- In most cases, the actual plant sites selected by a utility would likely be large. However, not all the land owned by the utility or an independent power producer needs to meet all the SMR SSEC. Although most utilities own or control thousands of acres around a nuclear facility, only a nominal SMR footprint will be required to meet all siting criteria.

- Plants are limited to $10 \%$ of the available stream flow ${ }^{4}$ for makeup water to reflect the overall demands on freshwater resources by the general population.

- Stream flow is based on a composite of 7-day, 10-year low-flow data from the $\mathrm{USGS}^{5}$ and existing lake and reservoir data. Average stream flow data over predicts available water on an annual basis as opposed to the actual seasonal highs and lows.

- Aggregation of GIS land cells into 50-acre parcels requires only $90 \%$ or more of the individual cells to pass SSEC. ${ }^{5}$ This allows for small imperfections in a 50 -acre parcel without requiring that the parcel be discarded from consideration. 


\section{BASE CASE SMALL MODULAR REACTOR RESULTS}

This analysis characterizes suitable areas for near-term SMRs. Near-term SMRs are based on light-water reactor (LWR) technology with compact design features that are expected to offer a host of safety, siting, construction, and economic benefits. These smaller plants are ideally suited for small electric grids and for locations that cannot support large reactors, thus providing utilities with the flexibility to scale power production as demand changes by deploying the additional power by adding more modules or reactors in phases. The near-term SMR designs are based on existing pressurized-water reactor (PWR) technology. They are characterized as "integral" PWRs (iPWRs) since these plants will have major equipment such as pumps, steam generators, and pressurizers all located within the pressure vessel in an integrated, compact design. Individual reactor units in these designs are typically in the 25- to 250-MW(e) power range. In 2012, DOE initiated the "SMR Licensing Technical Support Program" through a funding opportunity announcement to accelerate the deployment and commercialization of near-term SMR technologies. This program represents a 5 year cost-share industry partnership in which the DOE contribution will total $\$ 452 \mathrm{M}$ for two SMR vendors to support licensing activities to obtain a design certification with the overall goal of having electricity from an SMR on the grid by 2022 .

The principal design differences between an iPWR and a loop-type PWR are shown in Fig. 5. The schematic in Fig. 5 shows that the coolant loop piping for the large PWR, with two, three, or four loops (only one pictured) is eliminated; piping that penetrates the reactor vessel is significantly smaller in the iPWR; and the major equipment for the iPWR is located within the pressure vessel. Another distinguishing design feature that is not illustrated in Fig. 5 is the elongated (taller) core design for the iPWR. The vessel height-to-diameter ratio for the near term iPWRs will likely exceed 6.0 while that of a PWR and boiling-water reactor (BWR) are on the order of 2.5 and 2.0, respectively. This increase in the aspect ratio greatly facilitates the formation of gravity-driven natural convection circulation of the coolant, which enhances heat removal from the core and allows the plant to cool down safely in the event of a loss of off-site power without a requirement for emergency power (diesels or batteries) to drive circulation pumps. ${ }^{9}$

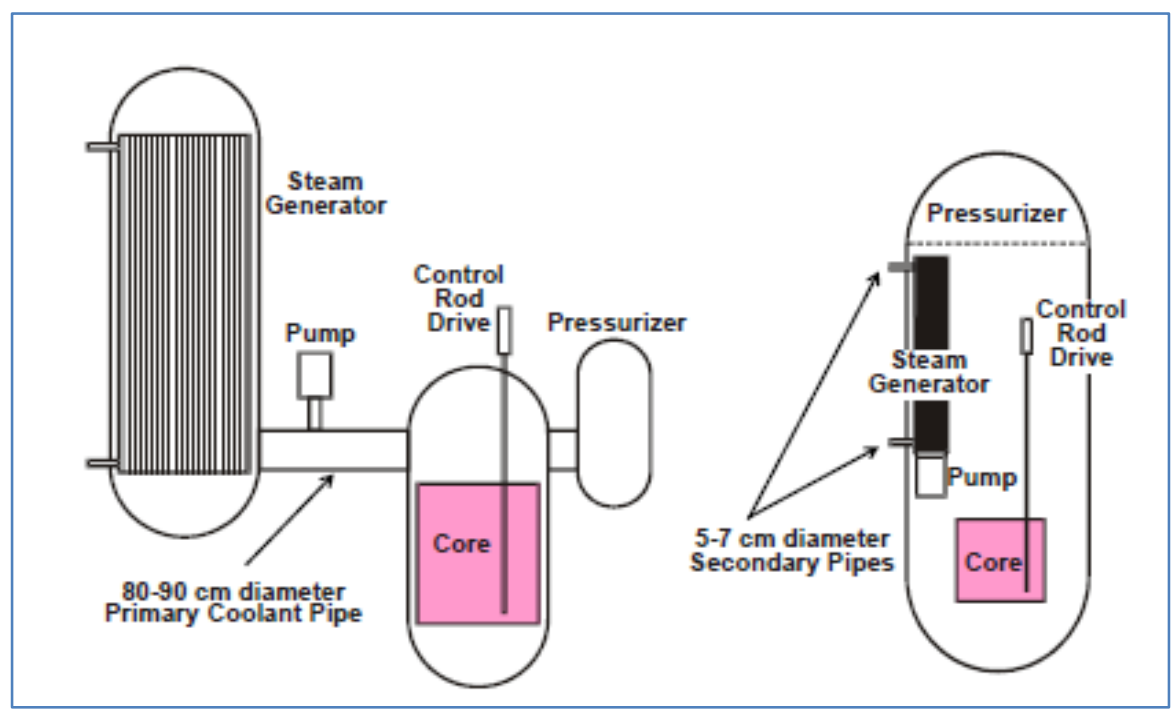

Fig. 5. Comparison of Large PWR Design with iPWR Design for SMRs.'

\footnotetext{
${ }^{9}$ Ingersoll, D. T., An Overview of the Safety Case for Small Modular Reactors, Proceedings of the ASME 2011 Small Modular Reactors Symposium, Washington, DC, September 28-30, 2011.
} 
The four SMR vendors whose integral designs are based on PWR technology include:

- Babcock and Wilcox mPower SMR: $180 \mathrm{MW}(\mathrm{e})$ per reactor module with the plan to deploy two $180 \mathrm{MW}(\mathrm{e})$ modules/units at a time;

- NuScale SMR: 45 MW(e) per reactor module with the plan to deploy these modules/units 6 or 12 at a time;

- Westinghouse SMR: 200 MW(e) per reactor with the plan to deploy one or more units individually; and

- Holtec SMR-160: $160 \mathrm{MW}(\mathrm{e})$ per reactor.

All of these near-term SMR designs feature underground siting as well for safety and security reasons. All four vendors presently indicate submitting applications for design certification in the 2013-2015 time range.

For the purposes of this study, the largest SMR has a nominal output of $540 \mathrm{MW}(\mathrm{e})$, representative of a 12-module NuScale SMR. The power output is used to determine the necessary stream flow to supply makeup water for cooling, which is subsequently reflected in the SSEC modeling application. A $540 \mathrm{MW}(\mathrm{e})$ nominal plant will bound the cooling water needs for all of the near-term SMR designs with respect to the "standard" design installation (e.g., 12 units, 2 units, single unit). Plant cooling in all cases is provided by a closed-cycle mechanical-draft cooling tower with makeup water required for evaporation and blowdown.

Other longer-term advanced SMR designs, such as high-temperature gas reactors, liquid metal reactors, and molten-salt reactors are not discussed or analyzed in this phase of the SMR study. The screening parameters selected for the near-term iPWR reactors are expected to also encompass these advanced SMRs.

\subsection{Nominal SMR Site Selection and Evaluation Criteria}

There is well defined regulatory guidance for siting a nuclear power plant in the United States. Approximately 50 potential SSEC were identified in various sources related to health and safety, environment, socioeconomic, and engineering factors. The selected SMR SSEC for the nominal SMR power plants operating at $540 \mathrm{MW}(\mathrm{e})$ are based on providing a high level of discrimination and readily available data. A summary of the SSEC selected for SMR siting is provided here and a more detailed discussion of each individual SSEC follows below.

- Land with a population density greater than 500 people per square mile (including a 10 mile buffer) is excluded.

- Wetlands and open water are excluded.

- Protected lands (e.g., national parks, historic areas, wildlife refuges) are excluded.

- Land with a moderate or high landslide hazard susceptibility is excluded.

- Land that lies within a 100-year floodplain is excluded.

- Land with a slope greater than $18 \%\left(\sim 10^{\circ}\right)$ is excluded.

- Land areas that are more than 20 miles from cooling water makeup sources with at least $65,000 \mathrm{gpm}$ are excluded for nominal SMR plant applications.

- Land too close to identified fault lines is excluded (the length of the fault line determines the standoff distance).

- Land located in proximity to hazardous facilities (airports and oil refineries) is avoided.

- Land with safe shutdown earthquake (SSE) peak ground acceleration (2\% chance in a 50 year return period) greater than $0.5 \mathrm{~g}$ is excluded. 
Based on preliminary design information and expert judgment, it is assumed that the SMR iPWR base design package (single unit or multi-module) from each vendor can easily be accommodated on a 50-acre footprint.

Population densities of greater than 500 people per square mile begin to transition into an urban setting. NRC siting guidance ${ }^{8}$ recommends calculating the population density within 20 miles of the site and excluding population densities of greater than 500 people per square mile. However, one of the advantages of SMR iPWR designs is the ability to replace smaller, aging coal plants with a similar capacity and footprint. In order to meet this requirement, SMRs will need to be located closer to population centers where many of these coal plants already exist. Arguments for allowing SMRs to be closer to population centers typically include a reduced core damage frequency, elimination of largebreak loss-of-coolant accident sequences, smaller source term, reduced early release fraction, reactor vessels and containment vessels that are located entirely underwater or below grade, and reactor buildings that are located partially or totally below grade. Thus, the appropriate evacuation zone for SMR iPWR designs is an issue still under discussion with the NRC staff. For the purposes of this study, a 10-mile buffer was deemed possible for SMR siting. This value is variable within the database and can be adjusted to simulate other values for the buffer zone distance.

In addition, nuclear plants must consider seismic restrictions, proximity to fault lines, and nearby hazardous facilities as public safety issues. Many SMR designs are expected to call for an underground installation. In addition, the smaller structures associated with these designs should allow greater flexibility in designing to higher seismic conditions. Therefore, where earlier studies ${ }^{5}$ limited siting consideration to less than $0.3 \mathrm{~g}$ safe shutdown earthquake peak ground acceleration, this study permitted an increased limit of $0.5 \mathrm{~g}$ safe shutdown earthquake peak ground acceleration. Again, this value is variable within the database and can be adjusted. Also, previous studies ${ }^{5}$ excluded military facilities as a subset of hazardous facilities. Since the U.S. Department of Defense is looking at the possibility of using SMRs to remove some defense installations from the grid, military installations were not excluded for this study.

Protected lands include national parks, national monuments, national forests, wilderness areas, wildlife refuges, wild and scenic rivers, state parks, county parks, American Indian lands, hospitals, colleges, schools, and correctional facilities. These lands are excluded based on their public nature.

Steeper slopes are avoided based on the economic cost of preparing the site for construction. Previous studies $^{5}$ for large reactor sites limited the slope to $12 \%$ based on 2002 EPRI $^{4}$ guidance. Since the SMR designs have a much smaller footprint, this value was relaxed to $18 \%$, recognizing that more extensive site work to prepare a relatively small site may be justifiable. This allows the size of the candidate areas for potential SMR siting to be expanded and makes this a significant scoring factor in choosing an actual site. This value is variable within the database and can also be adjusted.

Cooling water makeup requirements are based on rules of thumb for cooling water makeup required per megawatt of generation. ${ }^{10}$ These rules of thumb are consistent with environmental analyses supporting site evaluations submitted to the NRC. The value of 65,000 gpm was selected based on the largest MW(e) rating of the nominal vendor configuration of the SMR iPWR designs under consideration - the bounding SMR. Any of the SMR designs with a lower installed capacity would require less stream flow and thus would increase the candidate areas available for siting. This is explored through a series of sensitivity studies. Additionally, it was assumed that cooling water makeup should be limited to taking no more than $10 \%$ of the available stream flow. ${ }^{4}$ This limited the siting of reactor plants to the vicinity of streams with sufficient flow volumes. Twenty miles was considered to be within reasonable proximity to a cooling water source, allowing for piping and pumps. ${ }^{4}$

\footnotetext{
${ }^{10}$ National Energy Technology Laboratory, Water Requirements for Existing and Emerging Thermoelectric Plant Technologies, DOE/NETL-402/080108, prepared for the U.S. Department of Energy, August 2008 (Revised April 2009).
} 
The remaining SMR SSEC are related to design and risk considerations.

Since most SMR designs are planned for underground installation, it may be appropriate to consider geology in the mix of SSEC at some point in the future. Los Alamos Nation Laboratory (LANL) has begun to explore and compile data geological features such as water table, bedrock, and unconsolidated sediment thickness and characteristics. ${ }^{11}$ For example, a graphic detailing the depth to bedrock in Tennessee is shown in Fig. 6. A future SMR SSEC criterion may focus on selecting a maximum depth to bedrock.

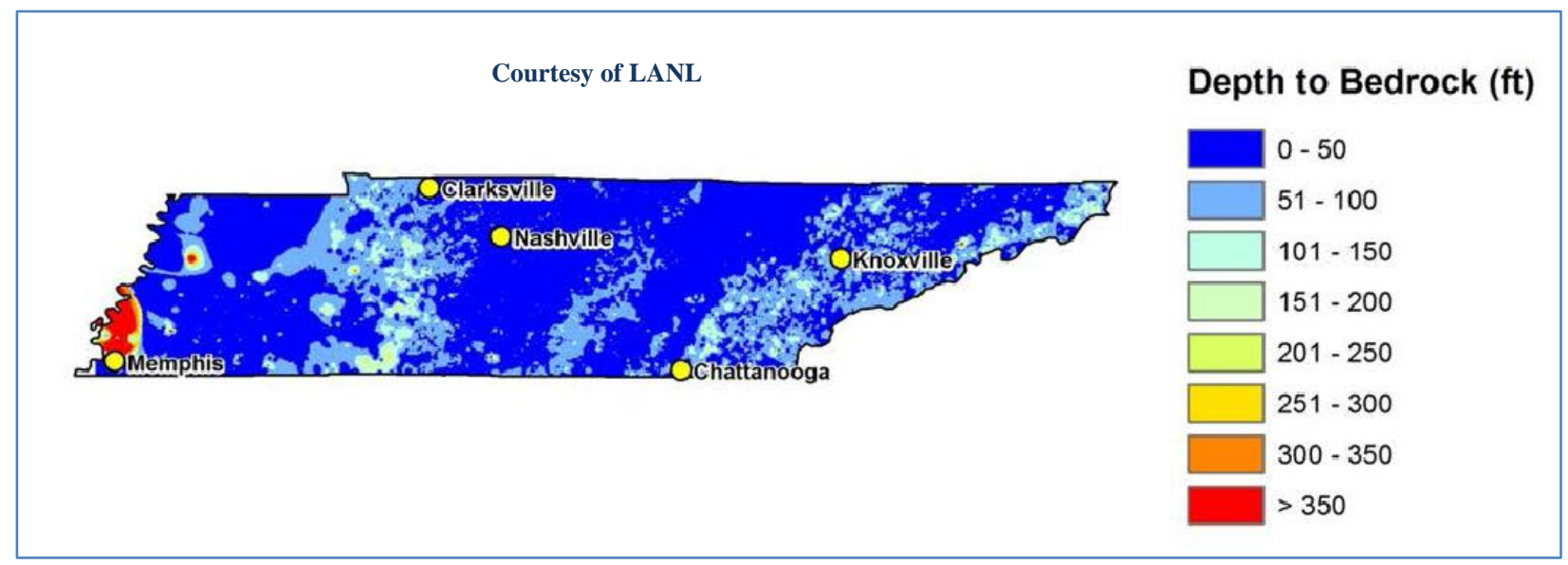

Fig. 6. Depth to bedrock map for Tennessee. ${ }^{11}$

The following figures (Figs. 7-16) show the individual SSEC layers for the nominal SMR plant based on the values provided in the above list. Areas shown in magenta represent a siting challenge and are excluded based on the selected input parameter value, while areas shown in gray are acceptable. Excluded areas in each layer can be modified based on different assumptions or requirements for the SSEC, which would change the individual map areas depicted in magenta and the subsequent multi-layered analysis.

\footnotetext{
${ }^{11}$ F. Perry, R. Kelley, R. Middleton, S. Birdsell, Status Report on Evaluation of Site Suitability, Screening Criteria, and Data for Small Modular Reactors, Los Alamos National Laboratory, LA-UR-12-24495, September 2012.
} 


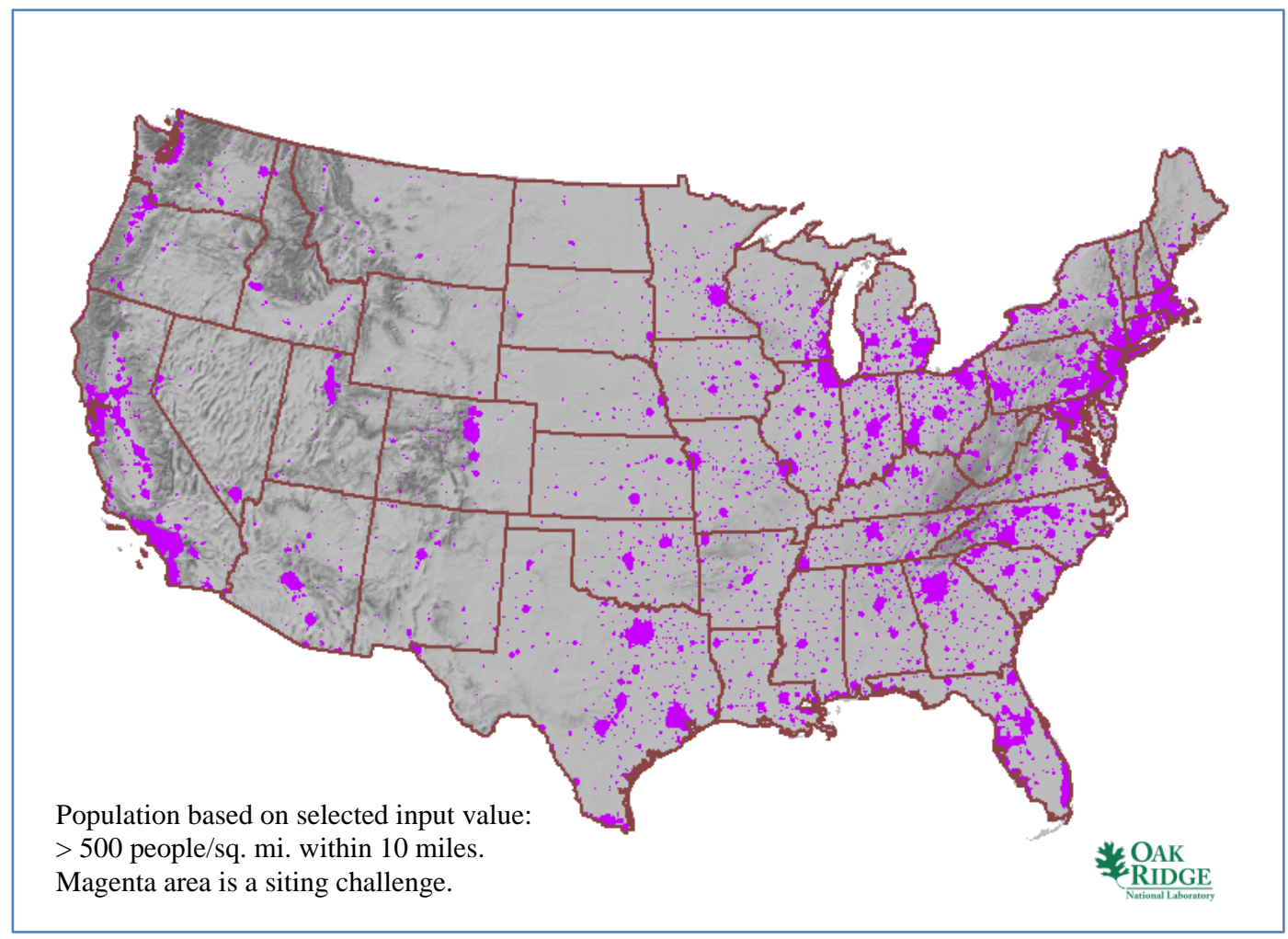

Fig. 7. Nominal, bounding SMR high-population SSEC layer.

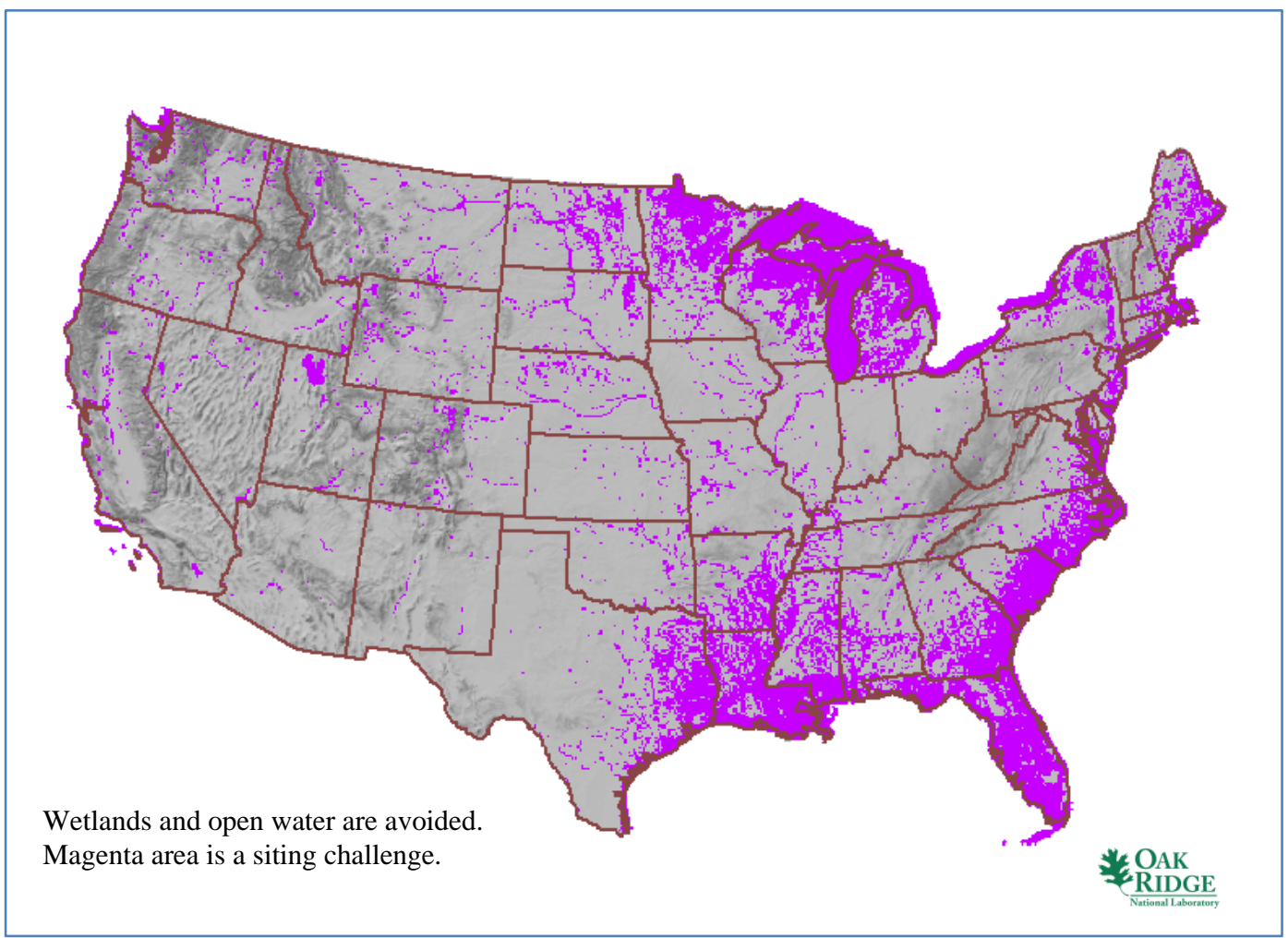

Fig. 8. Nominal, bounding SMR wetlands and open-water SSEC layer. 


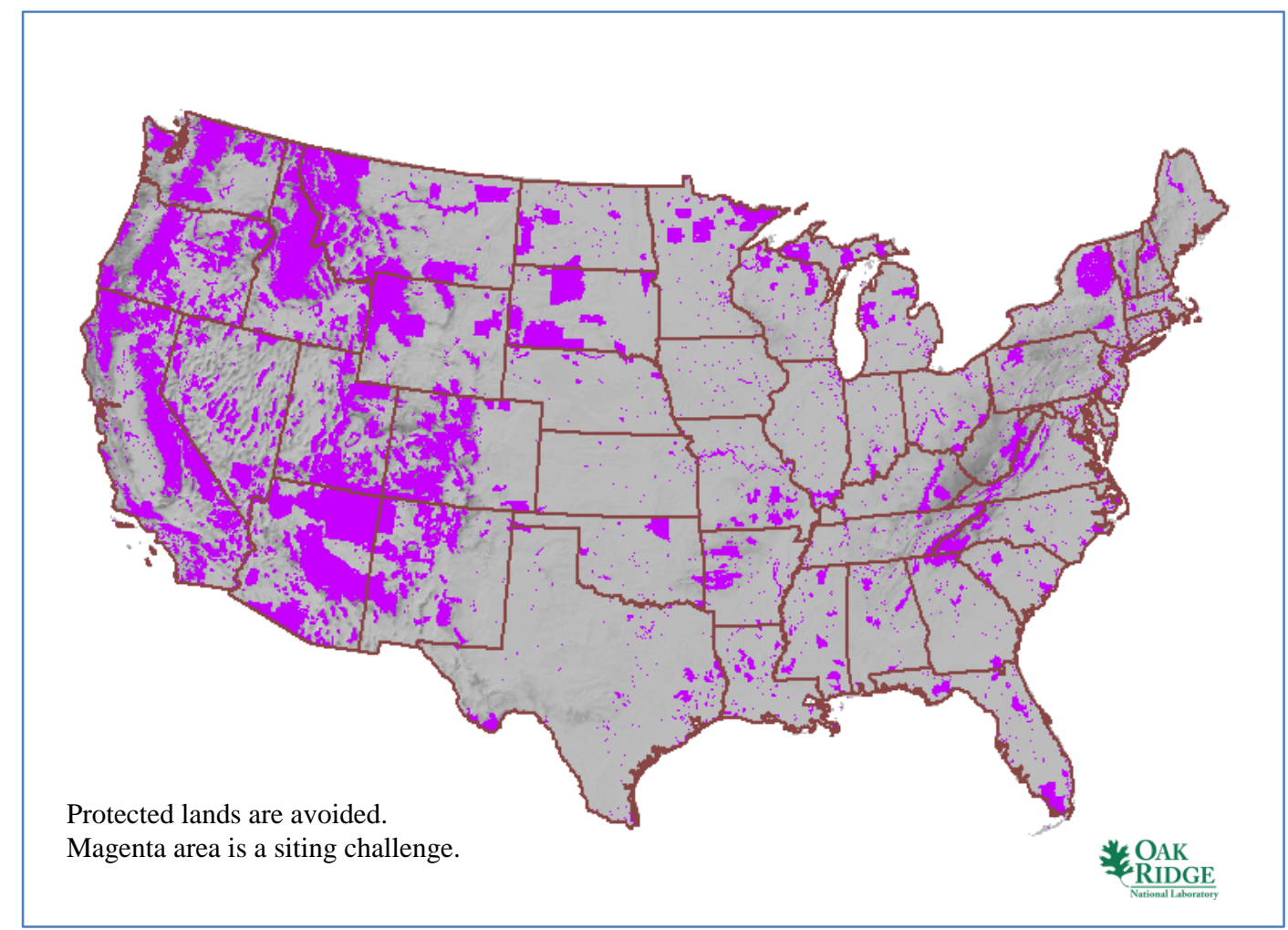

Fig. 9. Nominal, bounding SMR protected-lands SSEC layer.

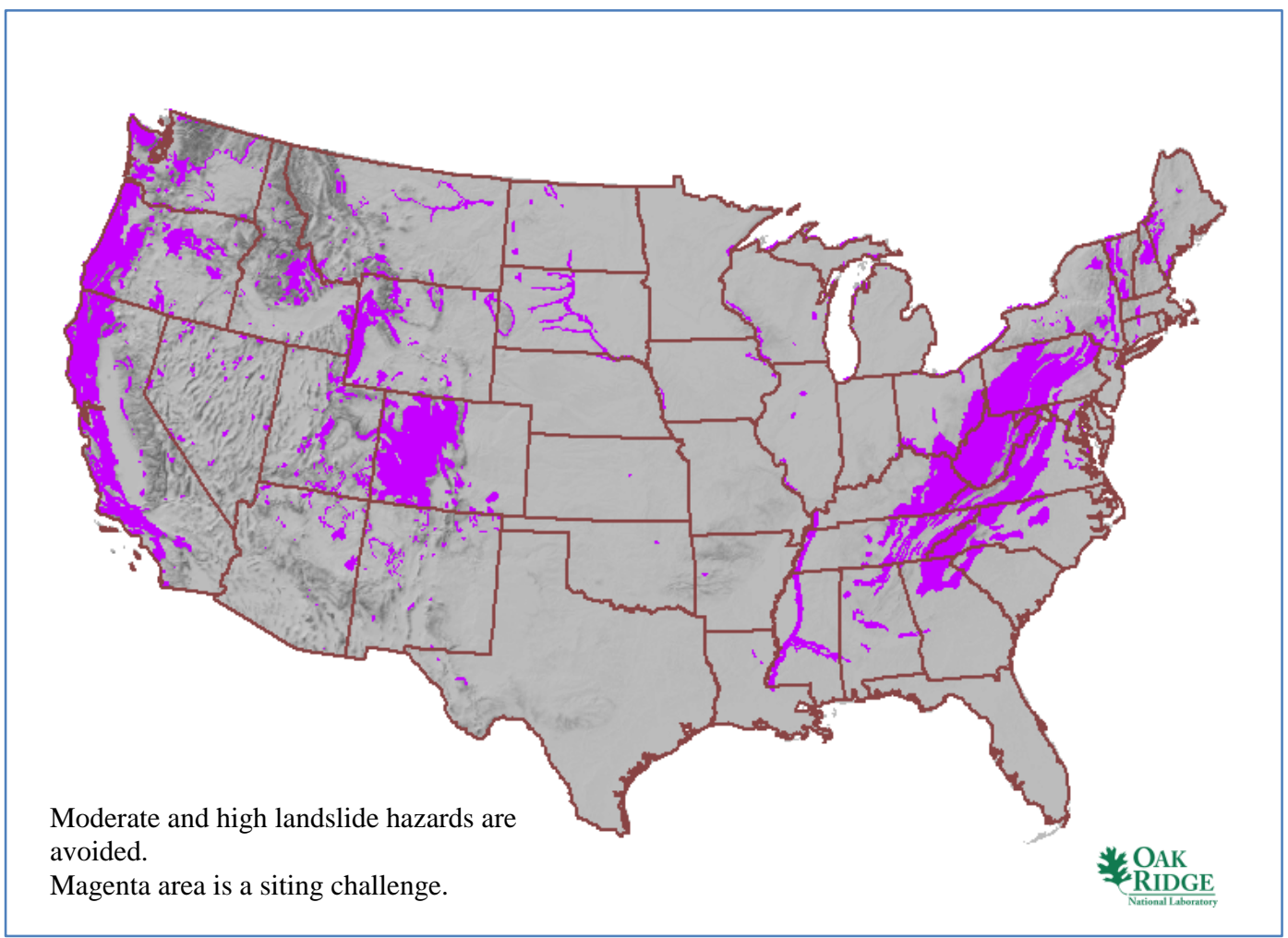

Fig. 10. Nominal, bounding SMR landslide-hazards SSEC layer. 


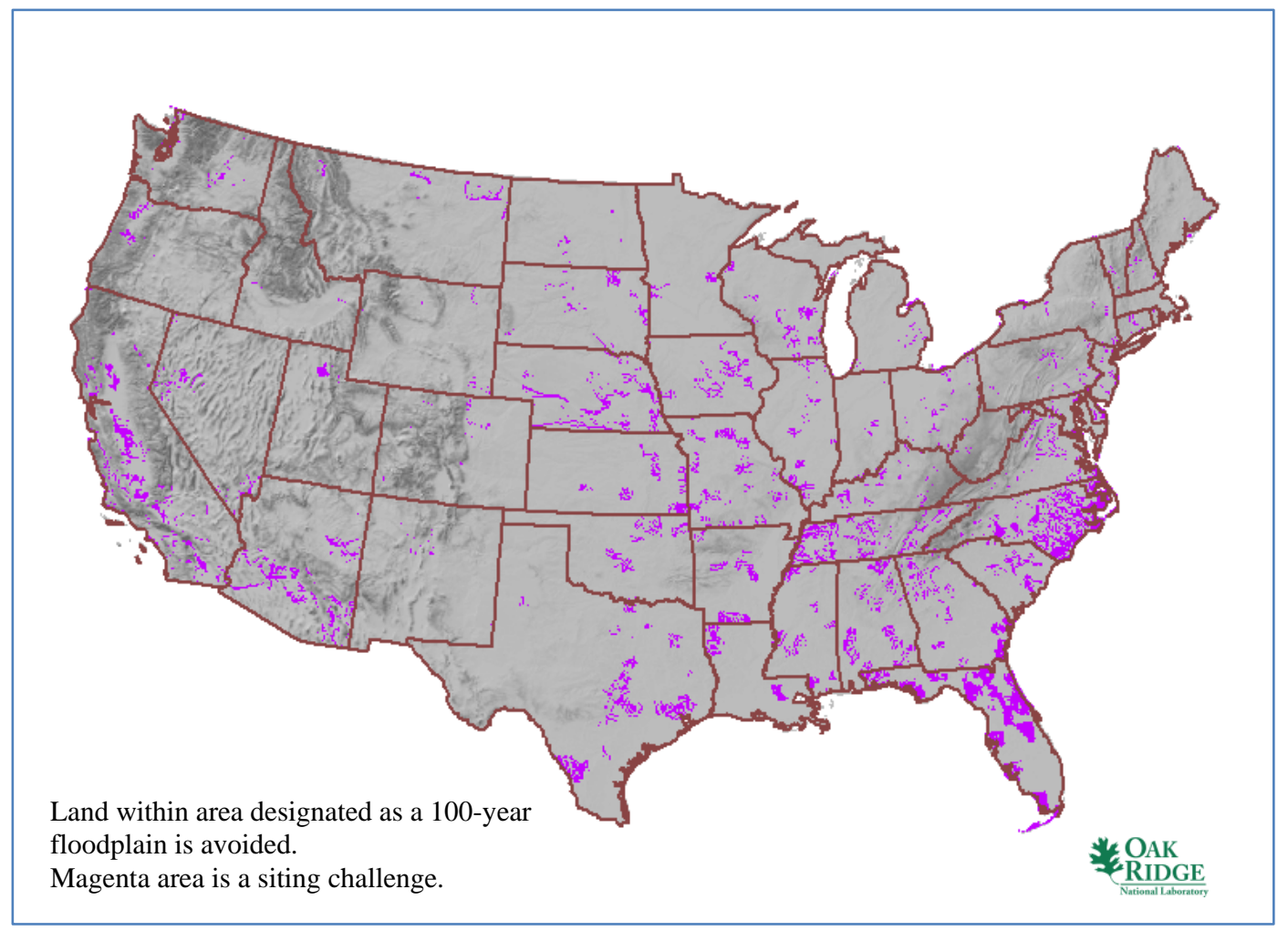

Fig. 11. Nominal, bounding SMR 100-year floodplain SSEC layer.

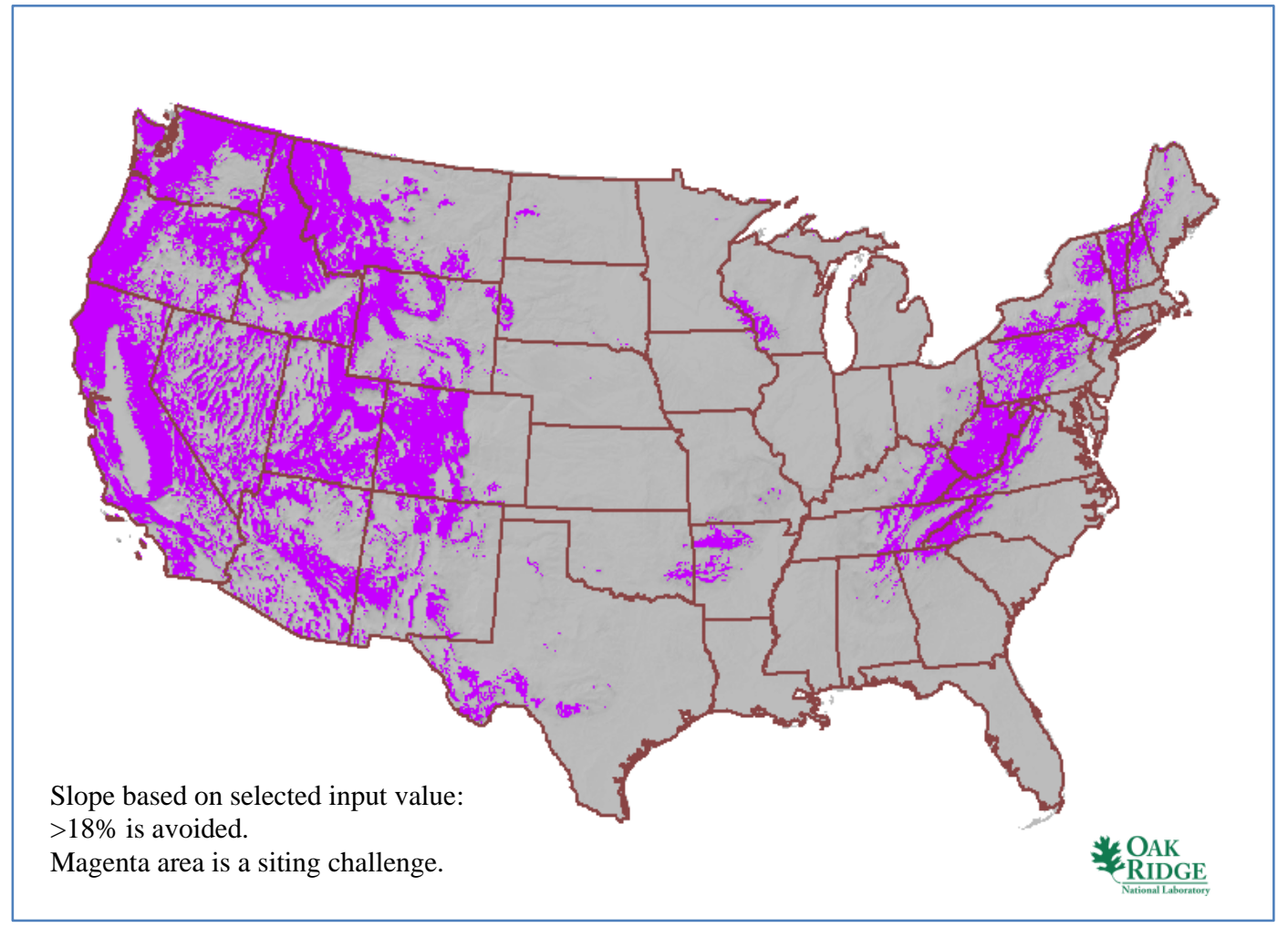

Fig. 12. Nominal, bounding SMR high-slope SSEC layer. 


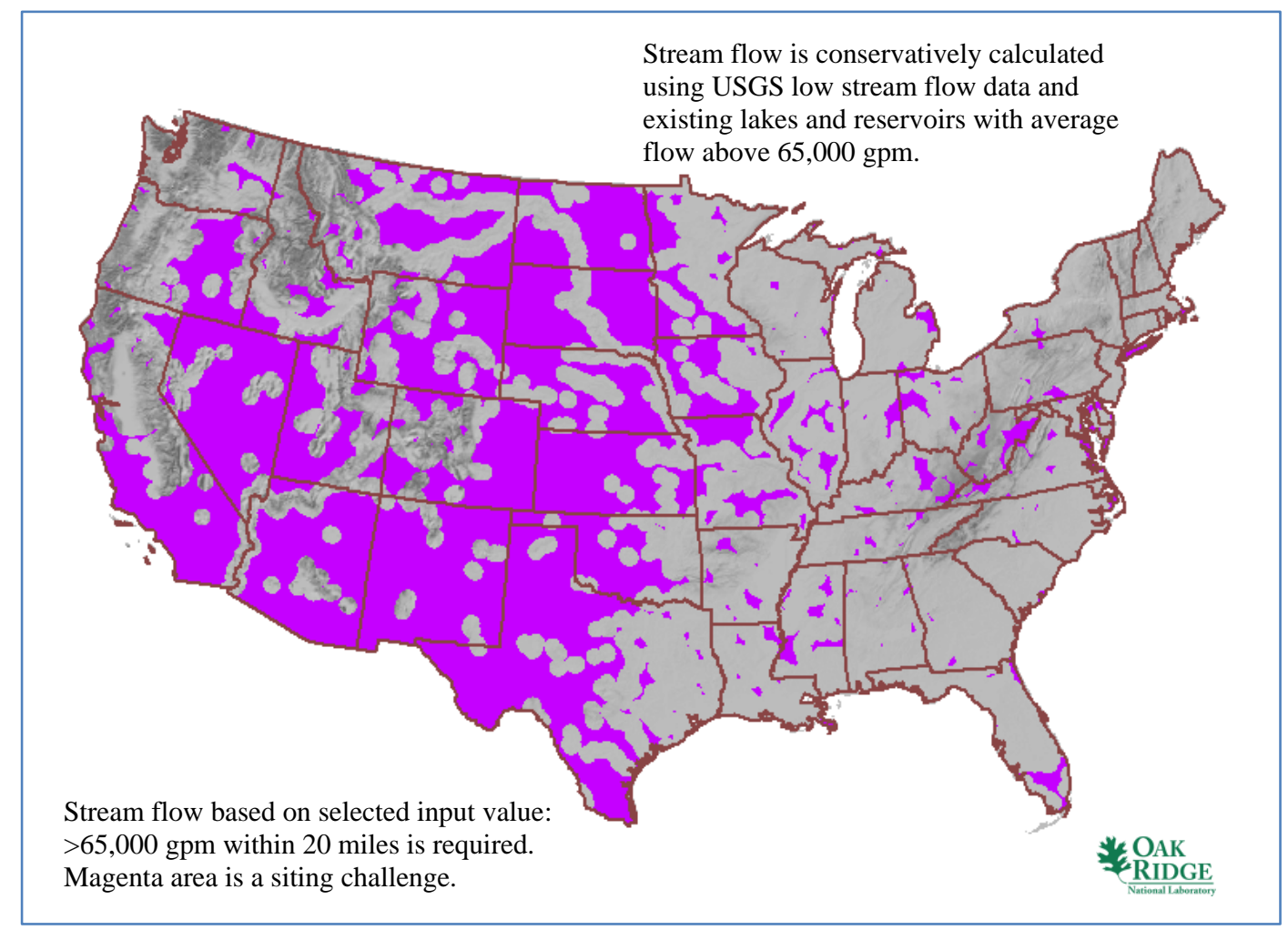

Fig. 13. Nominal, bounding SMR minimum low-stream-flow SSEC layer.

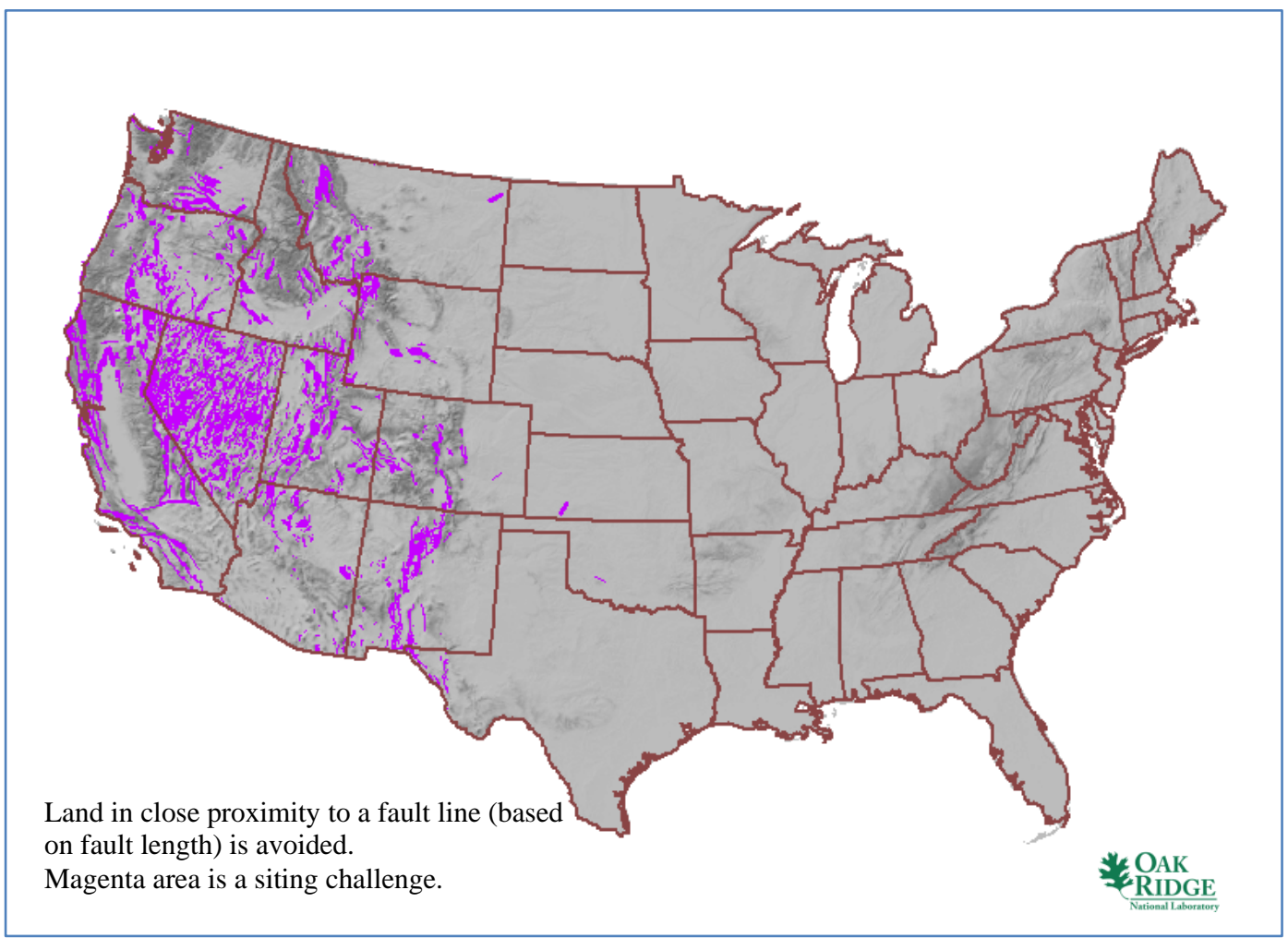

Fig. 14. Nominal, bounding SMR proximity-to-fault-lines SSEC layer. 


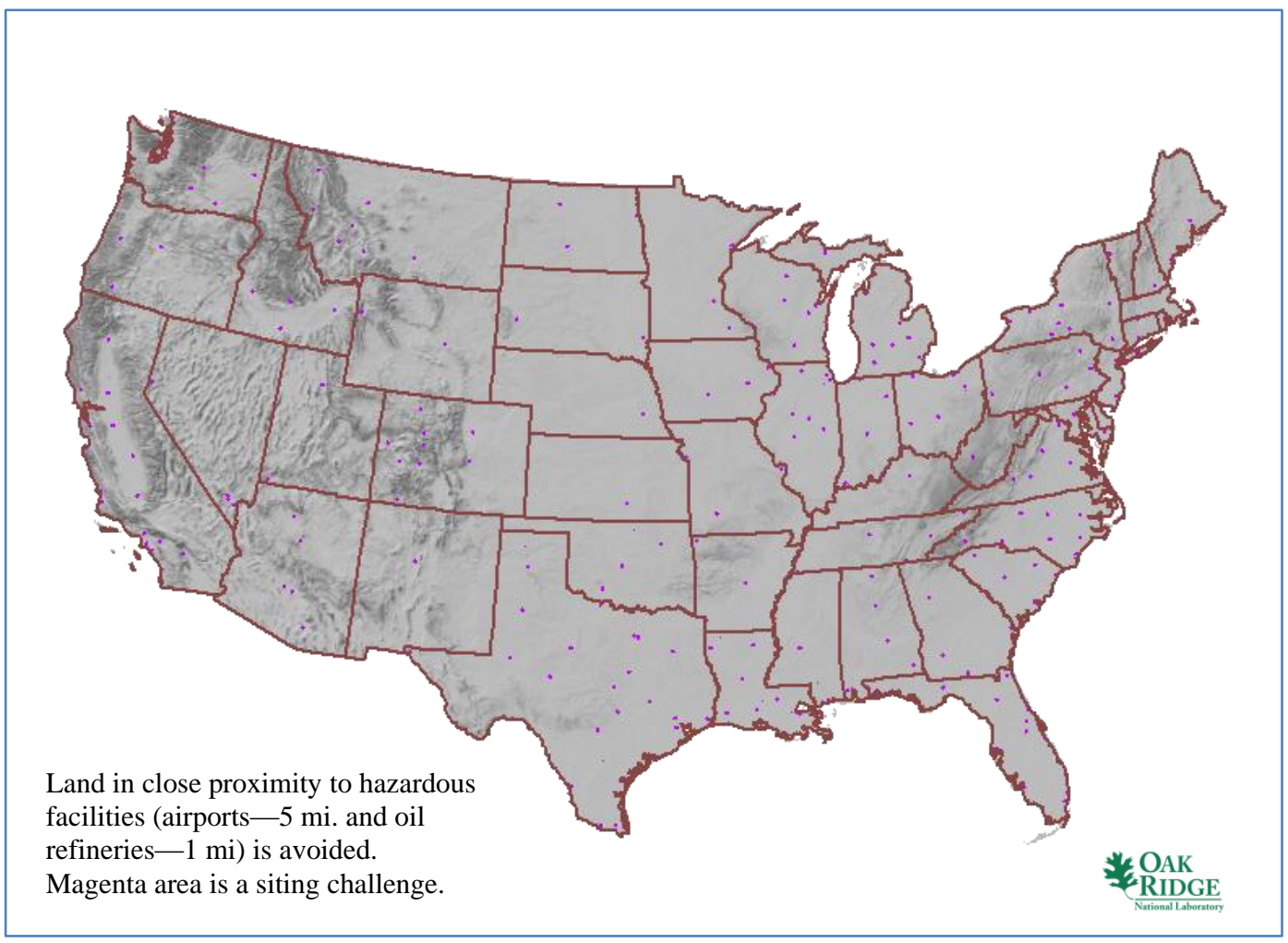

Fig. 15. Nominal, bounding SMR proximity-to-hazards SSEC layer.

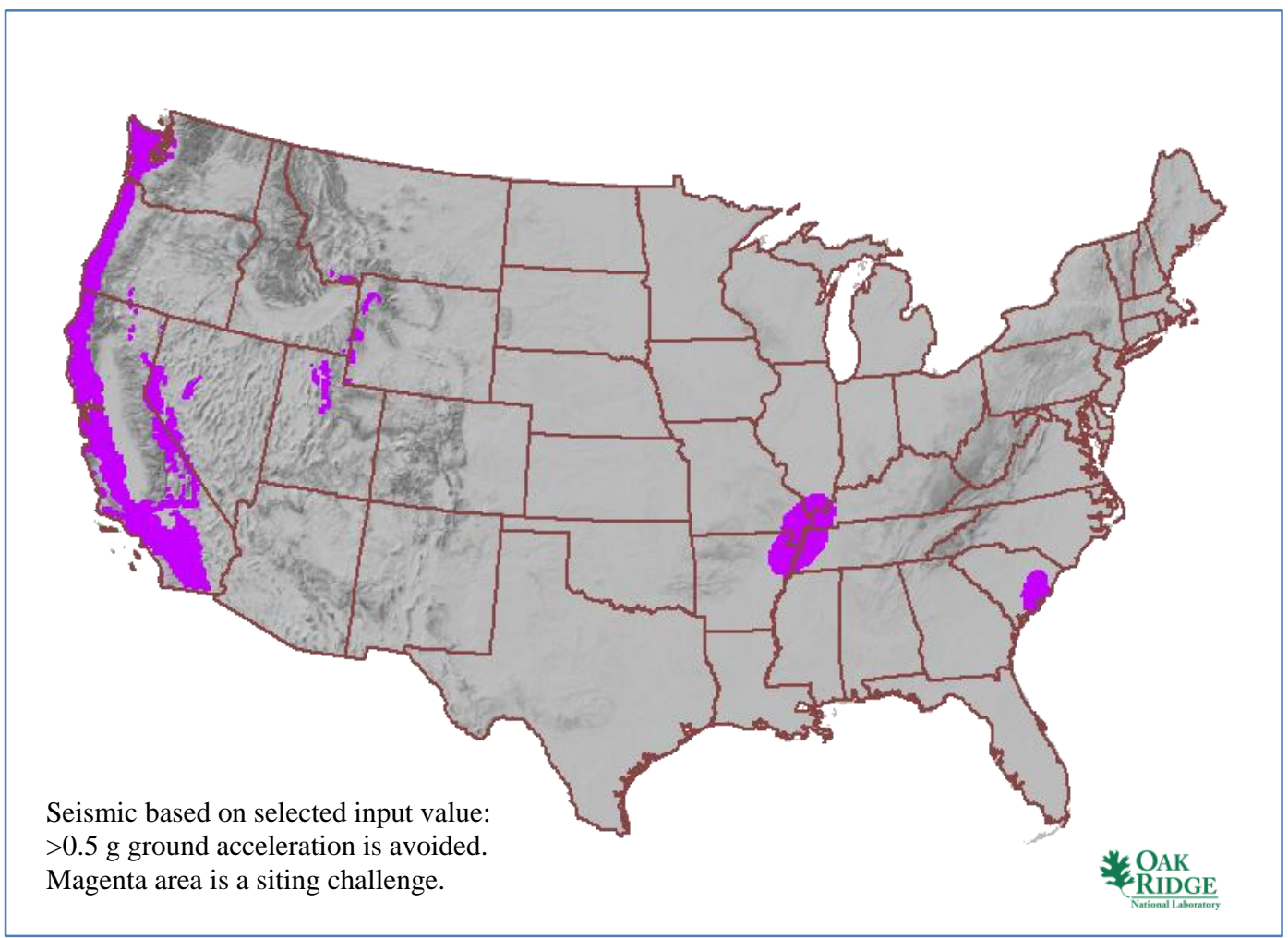

Fig. 16. Nominal, bounding SMR safe-shutdown earthquake SSEC layer. 
A review of the individual SSEC layers and the histogram below provides the following insights:

- Population is a significant limiting factor in the northeast and in many coastal areas.

- Protected lands, seismic considerations, and slope are significant limiting factors in the west.

- Landslide hazards are limiting along the eastern continental divide.

- Cooling water makeup is a significant restrictive factor in the west and in the central portion of the United States.

- Relaxing the SMR slope requirement to $18 \%$ from $12 \%$ used in previous studies did not increase the available land extensively because landslide hazards are similar to the previous $12 \%$ slope exclusion layer.

The successive application of each SMR SSEC layer to the overall available land in the contiguous United States can be captured as a step-down histogram as shown in Fig. 17. Since the SSEC layers are independent, the shape of the cumulative histogram is strictly determined by the order in which the SSEC layers (steps) are applied. However, the end result at step 10 is the same no matter the SSEC layer application order. One-third of the contiguous United States is initially amenable to siting SMR iPWR designs that requires cooling water based on the selection of a nominal plant. Therefore, two thirds of the contiguous United States has at least one concern based on the selected criteria that makes siting an SMR a challenge.

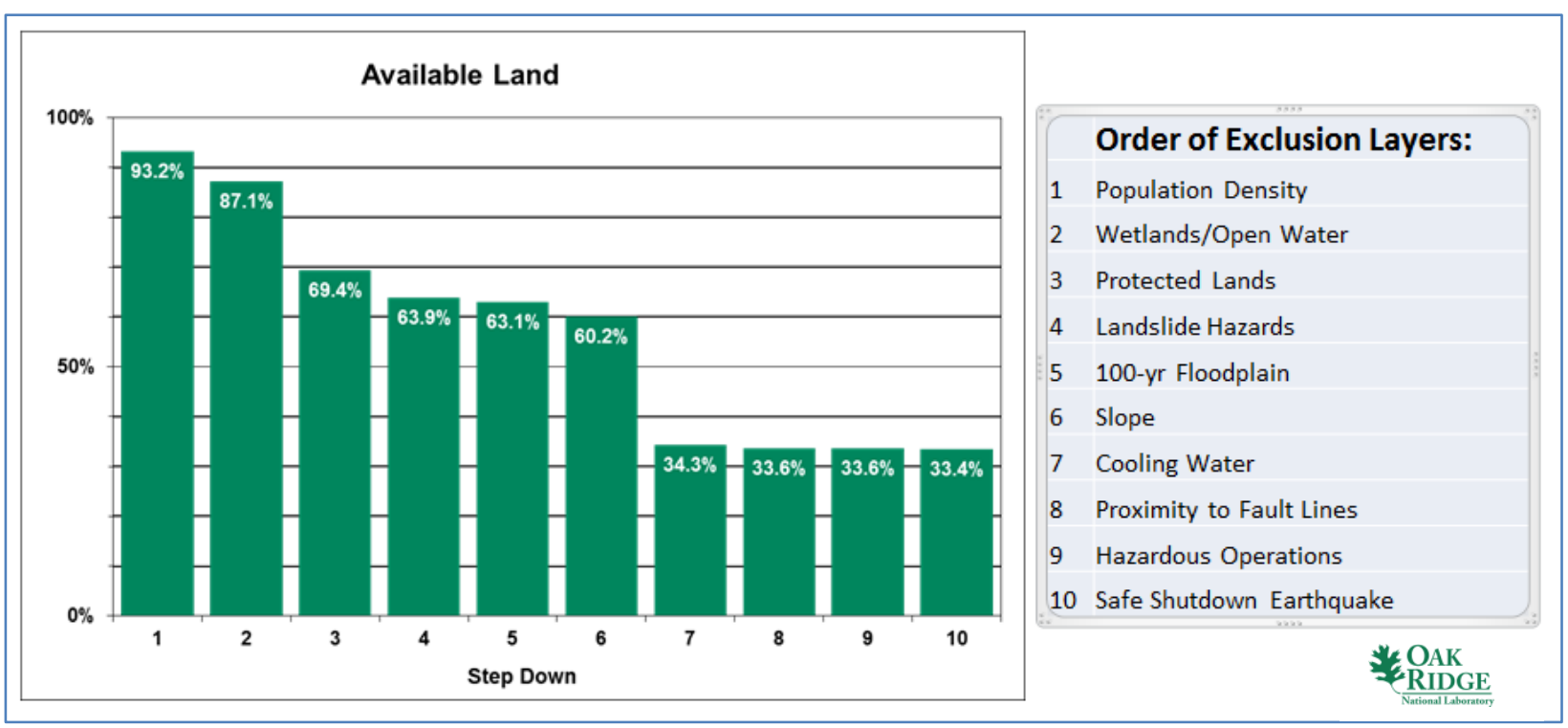

Fig. 17. SMR step-down histogram.

The OR-SAGE tool tracks the parameters for each 100- by 100-m cell. As a result, not only can the cells that are clear of all the SSEC layer exclusions be displayed visually, but also cells that are tripped by one, two, or three or more exclusions can be tracked and displayed. This is known as the "SMR composite map," shown in Fig. 18. This is a powerful aspect to the OR-SAGE tool, because it allows areas with a limited number of siting challenges to also be identified. Engineering solutions to areas with limited siting challenges may be available. The areas in green in Fig. 18 have no siting challenges based on the selected values for the SMR SSEC layers and make up 33.4\% of the contiguous United States as identified in the step-down histogram in Fig. 17. However, the areas in yellow in Fig. 18 make up $41.3 \%$ of the contiguous United Sates and have just a single siting challenge. Further evaluation of the single-issue area in Fig. 18 is discussed in Chap. 6 of the report. Nevertheless, an examination of the individual layers indicates that inadequate stream flow as shown in Fig. 13 is the most common siting challenge in the mid-section of the contiguous United States. This leads directly to the consideration of alternative methods of providing 
cooling water makeup other than stream flow. Other stream flow values are considered in Sect. 2.2 to evaluate the range of SMR iPWR designs and the impact on candidate areas for siting. Other cooling water makeup alternatives besides stream flow are explored in Chapter 3 of the report.

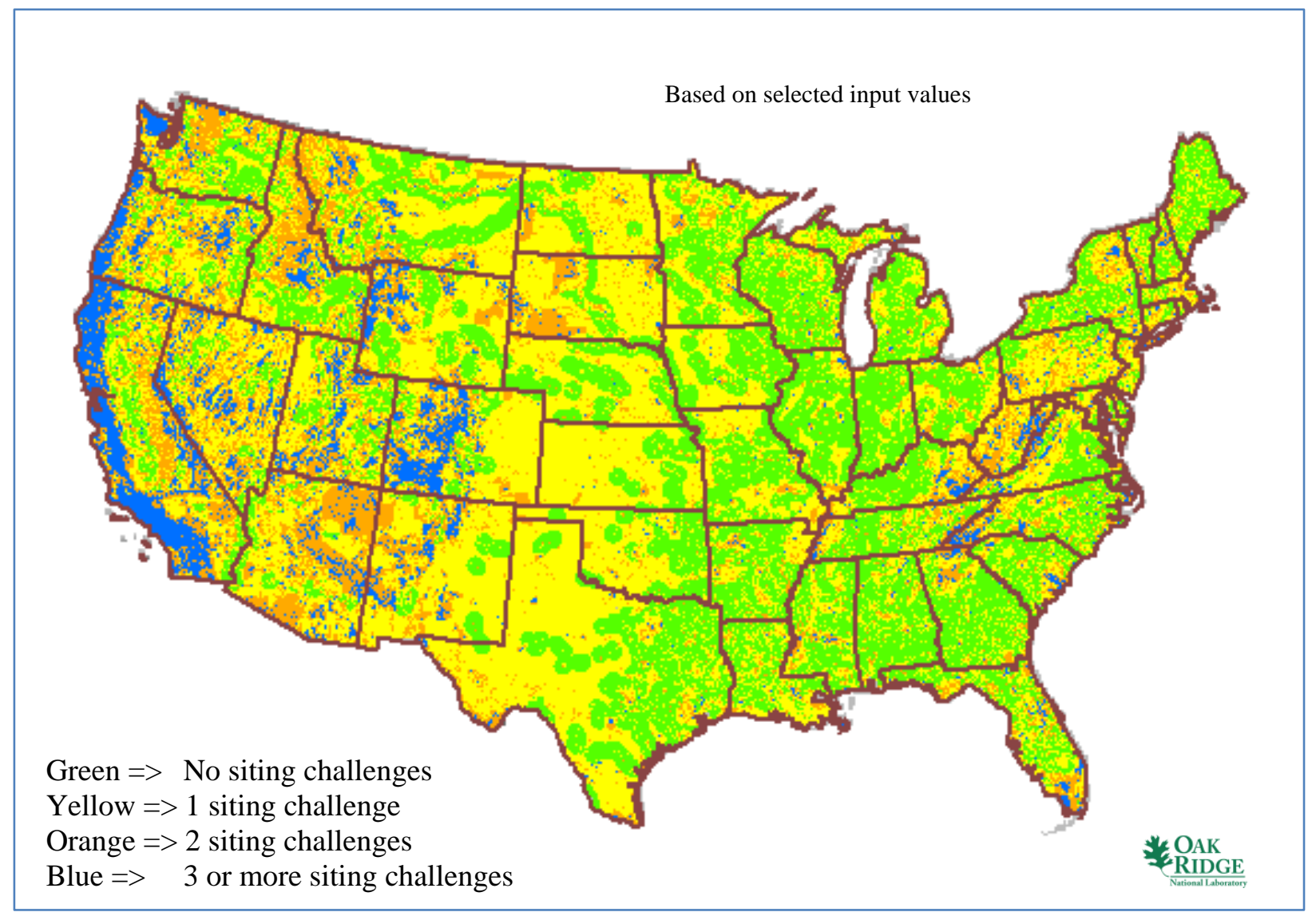

Fig. 18. Nominal, bounding SMR composite map detailing siting challenges.

\subsubsection{Base Map}

The "Approach and Methodology" section (Sect. 1.3) describes the process of developing a base map. A base map is created to reflect one set of values based on the stated assumptions and on nuclear plant SSEC. The base map shows where all SSEC criteria are met. The areas depicted in green from the SMR composite map shown in Fig. 18 are used to develop an SMR base map for a given set of selected conditions.

The SMR base map, depicting only the areas that have no siting challenges based on the entire set of SMR SSEC, is shown in Fig. 19. As discussed above, the area in green represents $33.4 \%$ of the contiguous United States or 572 million acres, but these candidate areas have not been aggregated for 50-acre SMR sites. In other words, this is a collection of 2.5-acre cells, some of which may support SMR siting when grouped together. As shown in Fig. 19, the green cells follow rivers in the Northwest and Great Plains states, while the Southeast, Great Lakes, and New England states have sufficient cooling water to have more widespread potential siting areas. The central valley of California is amenable to SMR siting as well. The Appalachian and Rocky Mountain ranges, as well as the arid desert regions, generate obvious exclusions. 


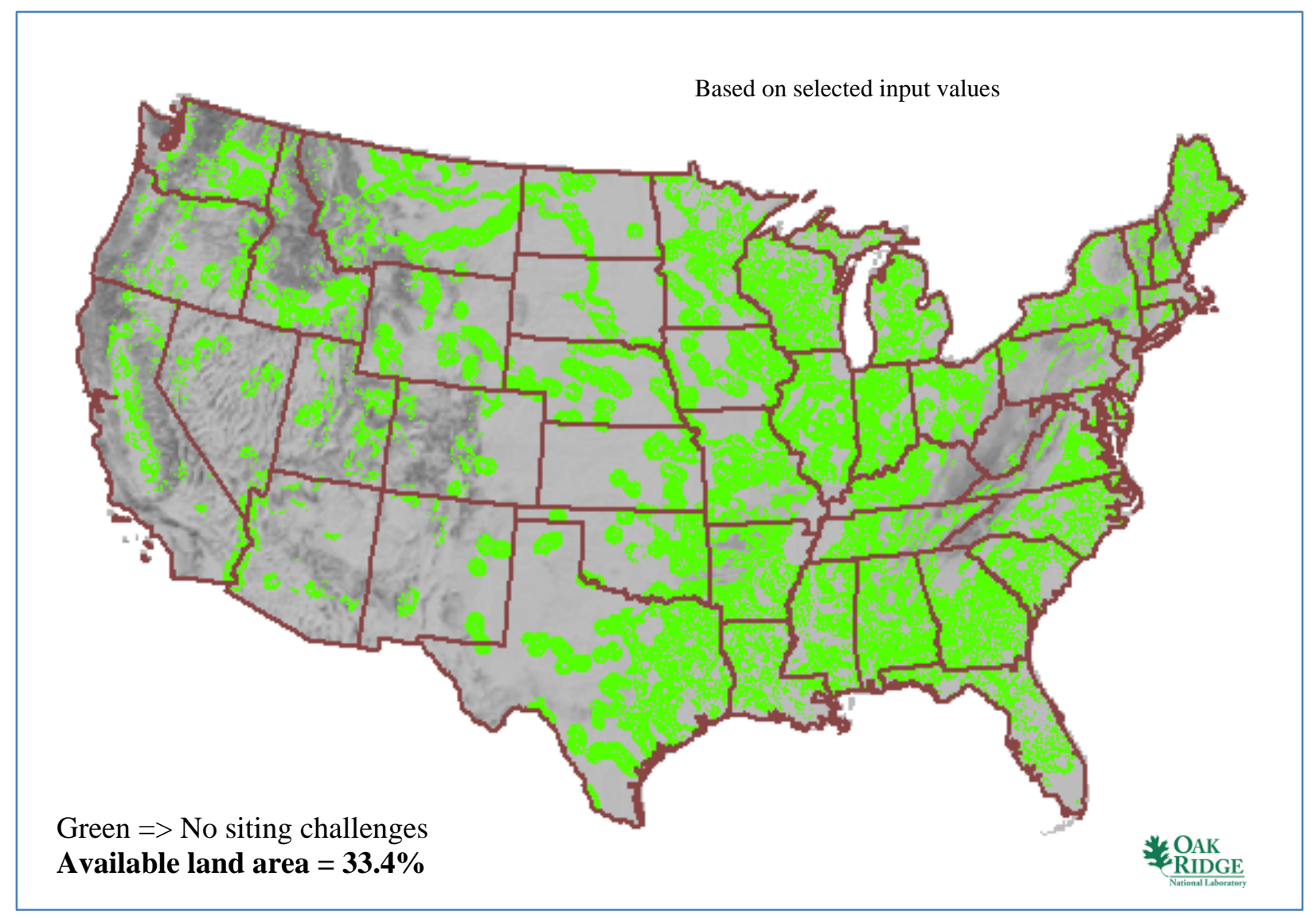

Fig. 19. Nominal, bounding SMR base map.

\subsubsection{Aggregate Map}

The map in Fig. 19 shows the cumulative land suitable for siting, based on selected input parameters, in 100 - by 100 -m cells. Each of these cells is about 2.5 acres and cannot individually support an SMR installation. The SMR base map results are aggregated in Fig. 20 to show the effect of gathering the available land from the SMR base map into 50-acre tracts at a $90 \%$ aggregation rate $(90 \%$ of the individual cells in the group must pass the SSEC criteria). The available land with no siting challenges for SMR facilities is reduced from $33.4 \%$ (Fig. 19) to $26.9 \%$ (460 million acres) of the contiguous United States when the cells are aggregated, based on the stated assumptions and selected values for the SMR SSEC. This is based on the upper bound of 65,000 gpm of makeup water. Using a smaller value of makeup water will increase the available land as discussed in Sects. 2.3.1 and 2.3.2.

The power plant siting study performed for EPRI identified approximately $13 \%$ of the contiguous United States aggregated to 500 -acre sites as candidate areas for a large-scale [1.6 GW(e)] nuclear power plant. ${ }^{5}$ Therefore, there is more than twice as much land available to site the bounding SMR iPWR design as there is to site the bounding large reactor plant design. The report prepared for EPRI also reviewed candidate areas for a generic small reactor with parameters similar to those for a large reactor. This yielded approximately $24 \%$ of the contiguous United States aggregated to 50 -acre sites as candidate areas for a nominal small nuclear power plant. ${ }^{5}$ Focusing more on the attributes of the SMR iPWR designs yields a slight increase in available land as shown in Table 1. The cumulative increase in available land area for SMRs compared to the larger current reactor designs is discussed in Chapter 4. 


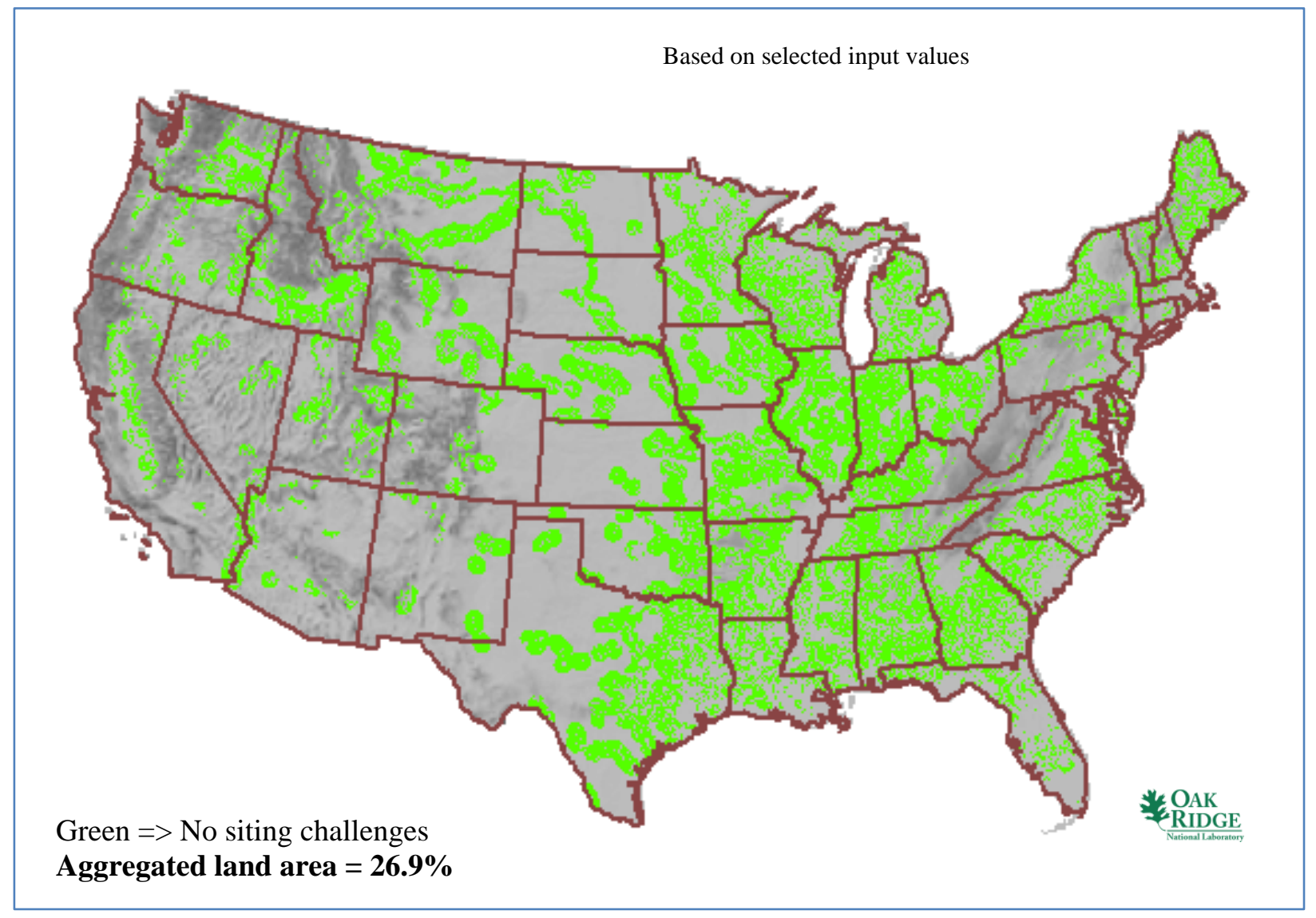

Fig. 20. Nominal, bounding SMR base map aggregated for 50-acre sites.

Table 1. Comparison of large and small reactor candidate areas (percentage of contiguous United States)

\begin{tabular}{|l|c|c|c|}
\hline \multirow{2}{*}{ Map type } & \multicolumn{2}{|c|}{ EPRI Project $^{\mathbf{5}}$} & DOE-NE Project \\
\cline { 2 - 4 } & $\begin{array}{c}\text { Small reactor } \\
{[\mathbf{3 5 0} \mathbf{M W}(\mathbf{e})]}\end{array}$ & $\begin{array}{c}\text { Large reactor }_{[\mathbf{1 , 6 0 0} \mathbf{M W}(\mathbf{e})]} \\
\text { Advanced SMR }\end{array}$ & $\begin{array}{c}\text { Adva } \\
{[\mathbf{1 6 0} \text { MW(e) to 540 MW(e)] }}\end{array}$ \\
\hline Base map & $31 \%$ & $22 \%$ & $33 \%$ \\
\hline Aggregate map $(90 \%)$ & $24 \%$ & $13 \%$ & $27 \%$ \\
\hline
\end{tabular}

\subsection{Additional Data Layers for Analysis}

\subsubsection{Rail Transportation}

One advantage of SMRs that is cited frequently is the ability to factory-build the entire reactor vessel or in some cases the containment and the reactor vessel. This subsequently requires access to shipping such as available rail lines to get the completed reactor vessel to the site. The available rail lines are shown in Fig. 21. 


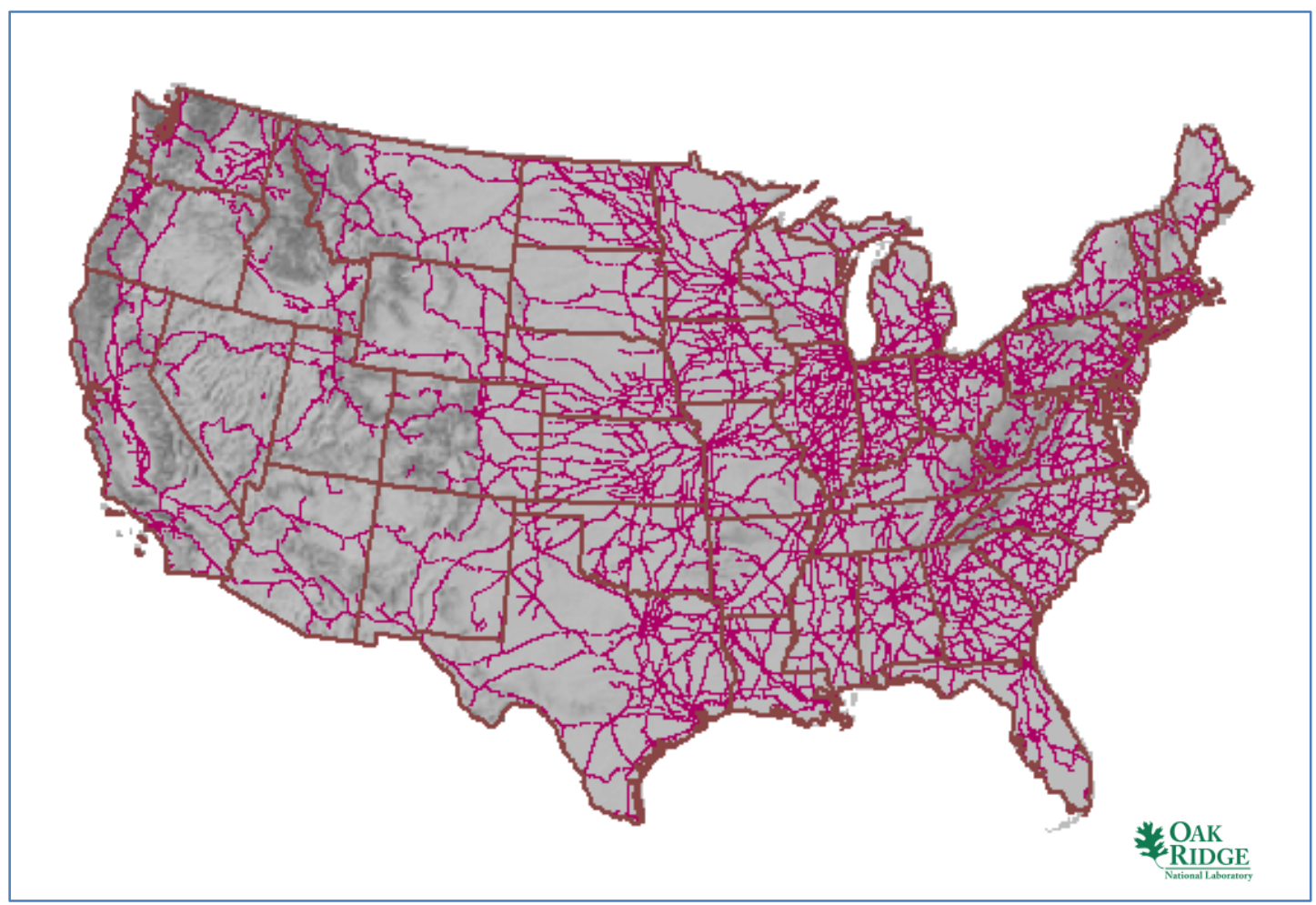

Fig. 21. Rail line GIS layer.

The rail lines can be overlaid onto the SMR aggregate map to further evaluate the SMR candidate areas for ease of module transportation to an eventual SMR site. This type of overlay is shown in Fig. 22.

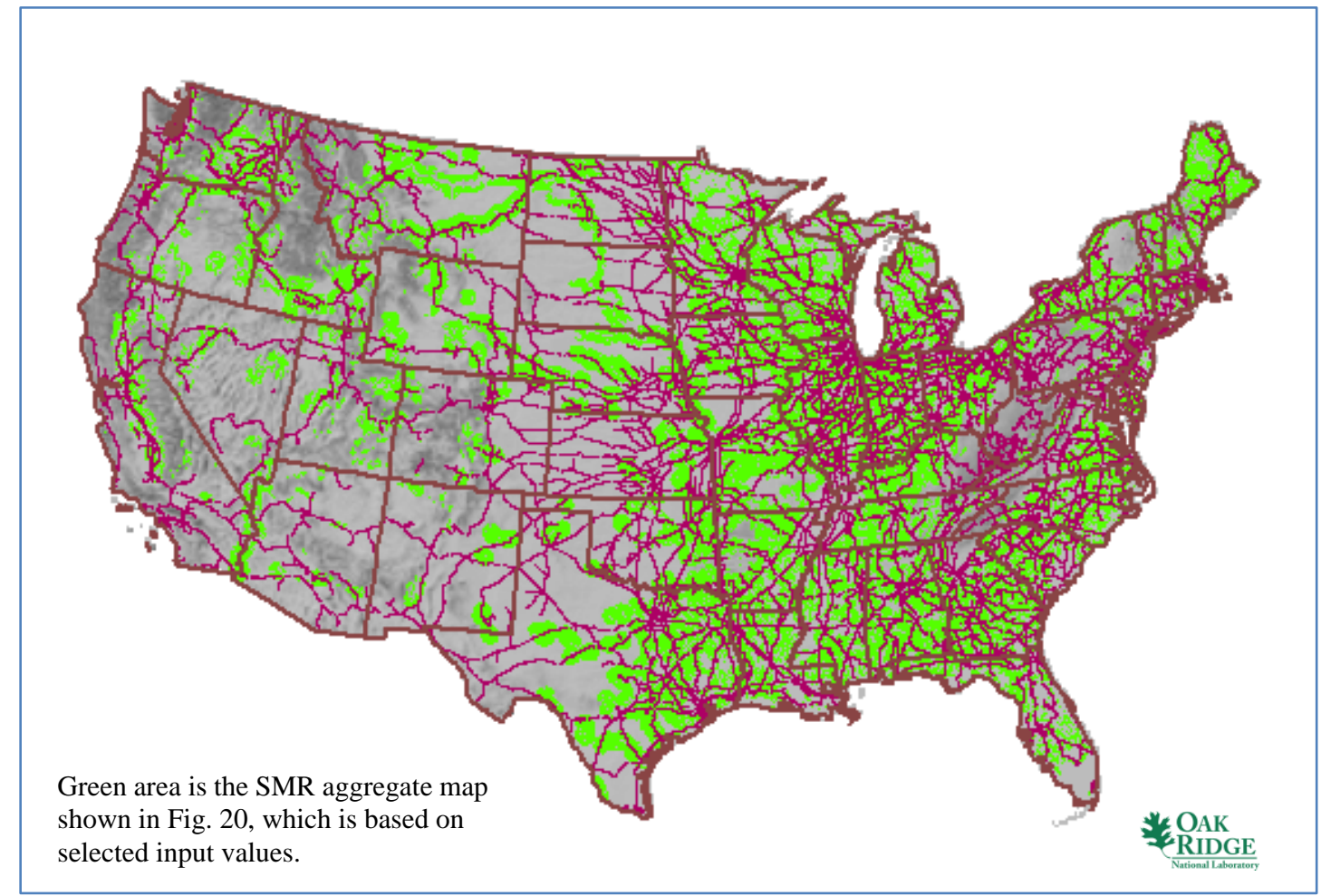

Fig. 22. Rail line overlay on the SMR aggregate map. 
Based on the selected SSEC criteria, 88\% of the SMR aggregated land is within 20 miles of an available rail line, but just $73 \%$ of the SMR aggregated land is within 10 miles of an available rail line. A rail spur or truck transportation could easily bridge these offsets. One way to visualize this result is to include a 10-mile buffer on the rail lines as shown by the orange trails in Fig. 23. Subsequently, the buffered rail lines can be overlaid onto the SMR aggregate map as shown in Fig. 24.

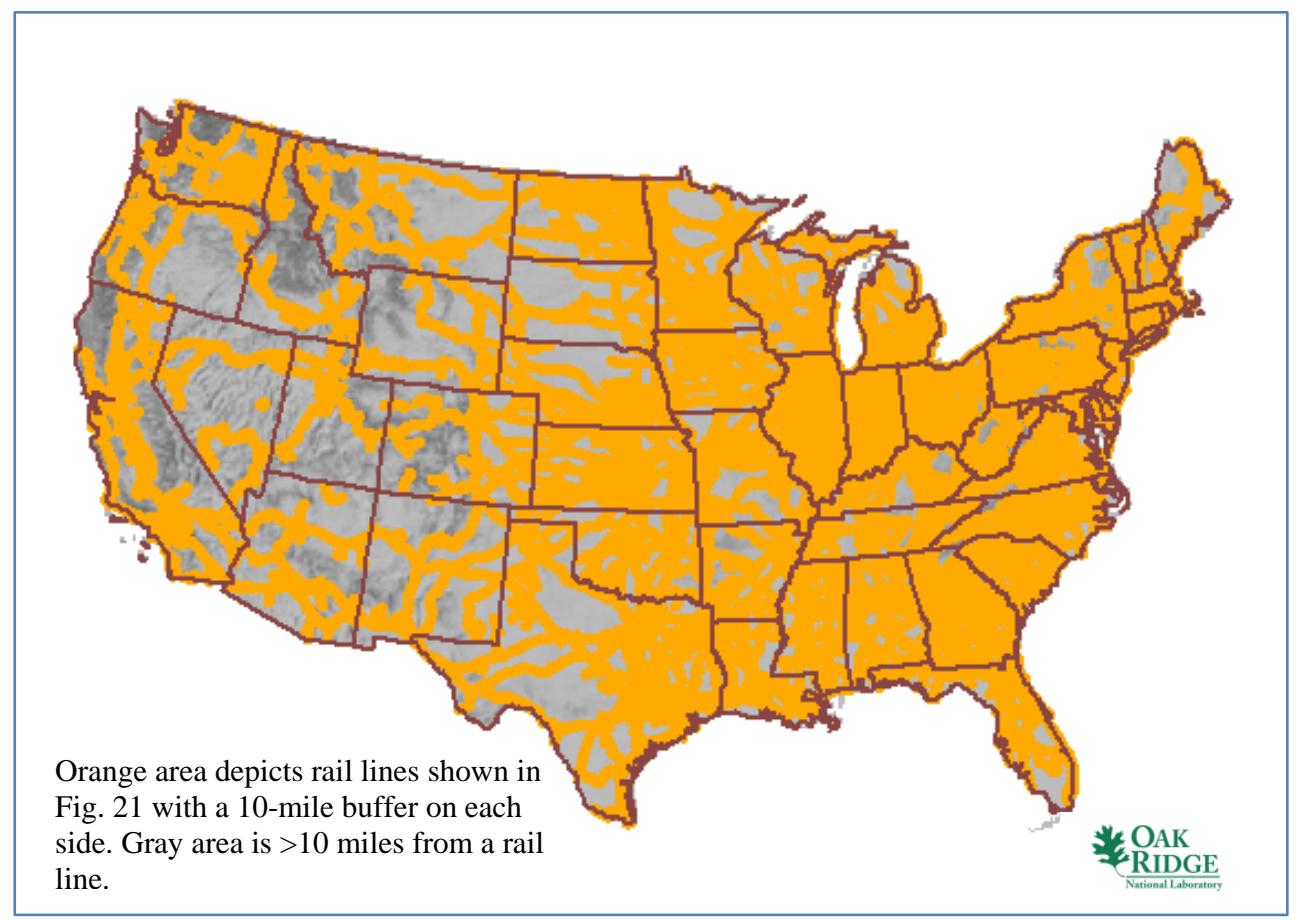

Fig. 23. Rail lines with 10-mile buffer on each side of the track.

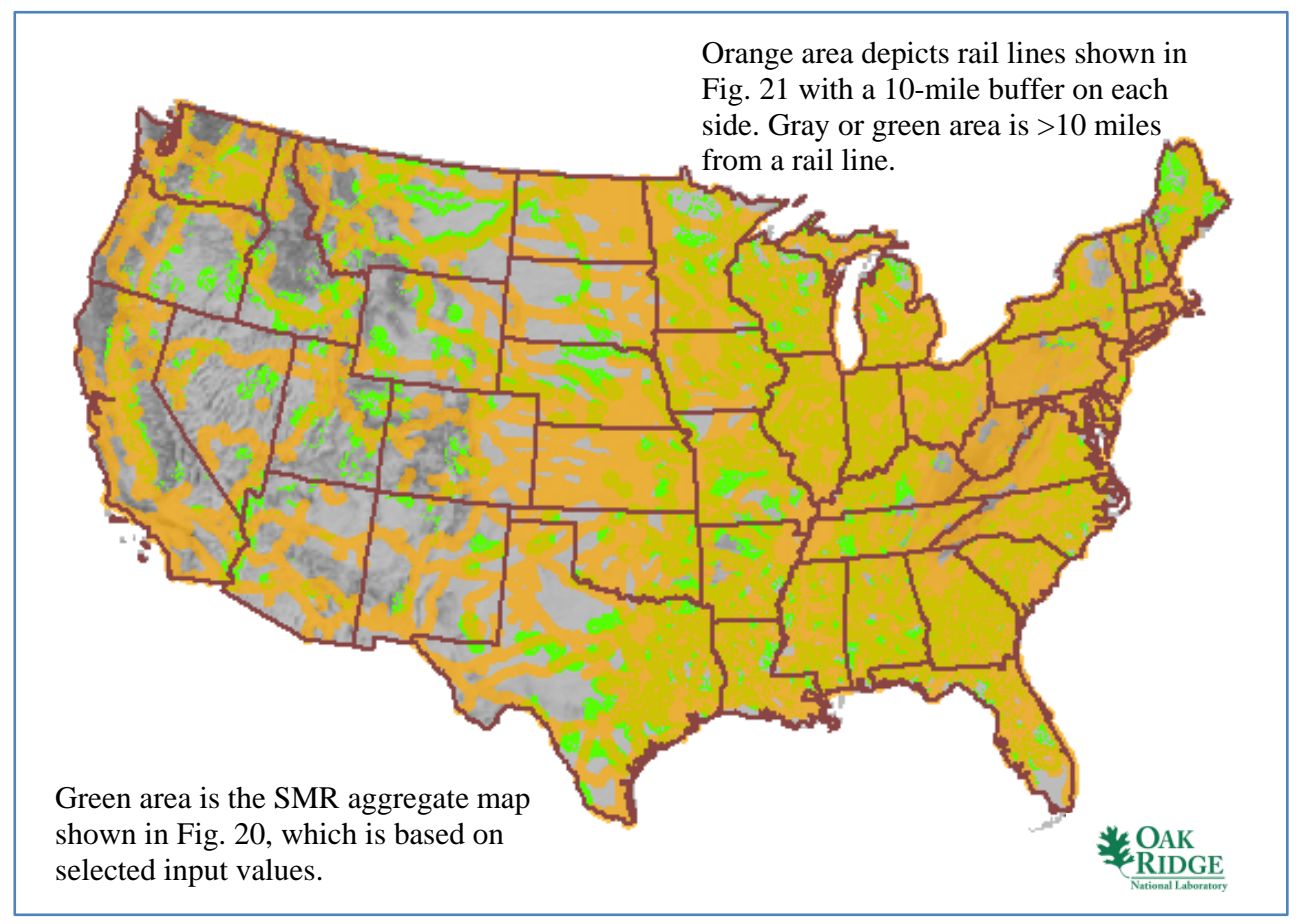

Fig. 24. Rail lines with 10-mile buffer overlaid on SMR aggregate map. 
The areas in gray and green in Fig. 24 are beyond the 10 mile buffer of the available rail lines. Based on the selected SMR SSEC parameters, the visible green area in Fig. 24, 27\% of the SMR aggregate map, could be assigned a lower weight than green areas that are covered by the orange buffered rail lines. Obviously, the analyzed distance from existing rail lines can be subjective, but this type of analysis can be factored into an overall analysis (or scoring/weighting) of the SMR candidate area results as appropriate. Similar analyses on heavy haul roads or barge-accessible waterways could be could be performed as well.

\subsubsection{Transmission Lines}

A similar analysis can be made for existing transmission lines. This is a critical aspect of overall project cost when siting a new power plant. American Electric Power noted that an extra high voltage $345 \mathrm{kV}$ single circuit line would cost 1.1 to 2.0 million dollars per mile in 2008 dollars, ${ }^{12}$ so, proximity to available transmission lines would carry a significant weight in selecting a power plant site. A map of $110-230 \mathrm{kV}$ transmission lines is overlaid onto the SMR aggregate map in Fig. 25. Based on the selected SSEC criteria, 93\% of the SMR aggregated land is within 20 miles of an available transmission line up to $230 \mathrm{kV}$ while $78 \%$ of the aggregated land is within 10 miles of an available transmission line.

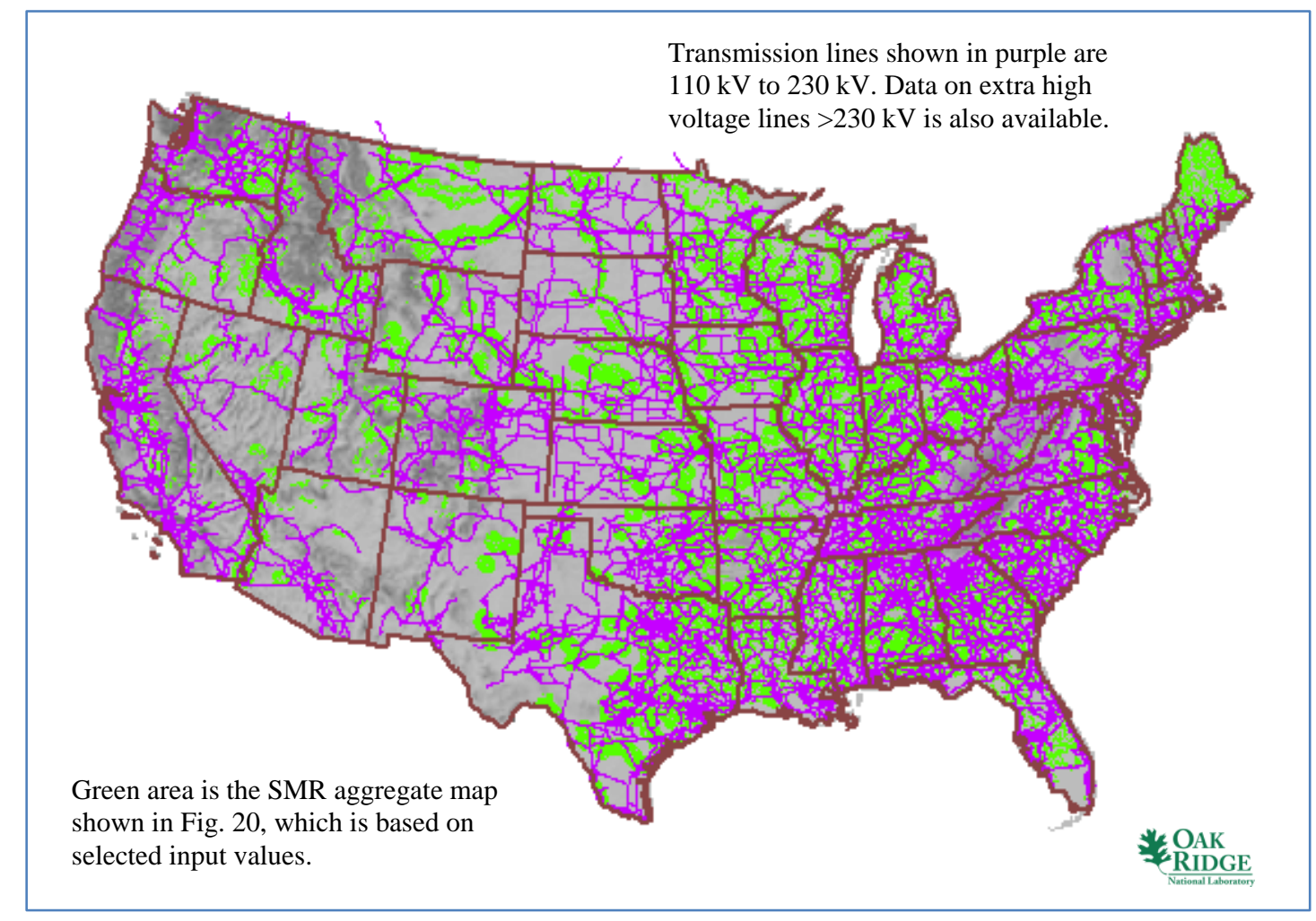

Fig. 25. Transmission line overlaid on the SMR aggregate map.

Extra high-voltage transmission lines above $230 \mathrm{kV}$ are less available than lower-voltage transmission lines. Based on the selected SMR SSEC criteria, 72\% of the SMR aggregated land is within 20 miles of an available extra high-voltage transmission line, but just 50\% of the aggregated land is within 10 miles of an available extra high-voltage transmission line. These extra high-voltage transmission lines would allow SMRs to be sited further from the load centers.

\footnotetext{
${ }^{12}$ American Electric Power Transmission Facts, www.aep.com/about/transmission/docs/transmission-facts.pdf.
} 
An existing transmission line does not necessarily have additional capacity to transport electricity from a new power plant. Alternate analyses could be performed to explore existing transmission lines with spare capacity. These types of snapshot analyses, which are dependent on factors such as season and time of day, could also provide some weighting of SMR candidate siting areas. One such snapshot of all transmission lines with excess capacity is shown in Fig. 26.

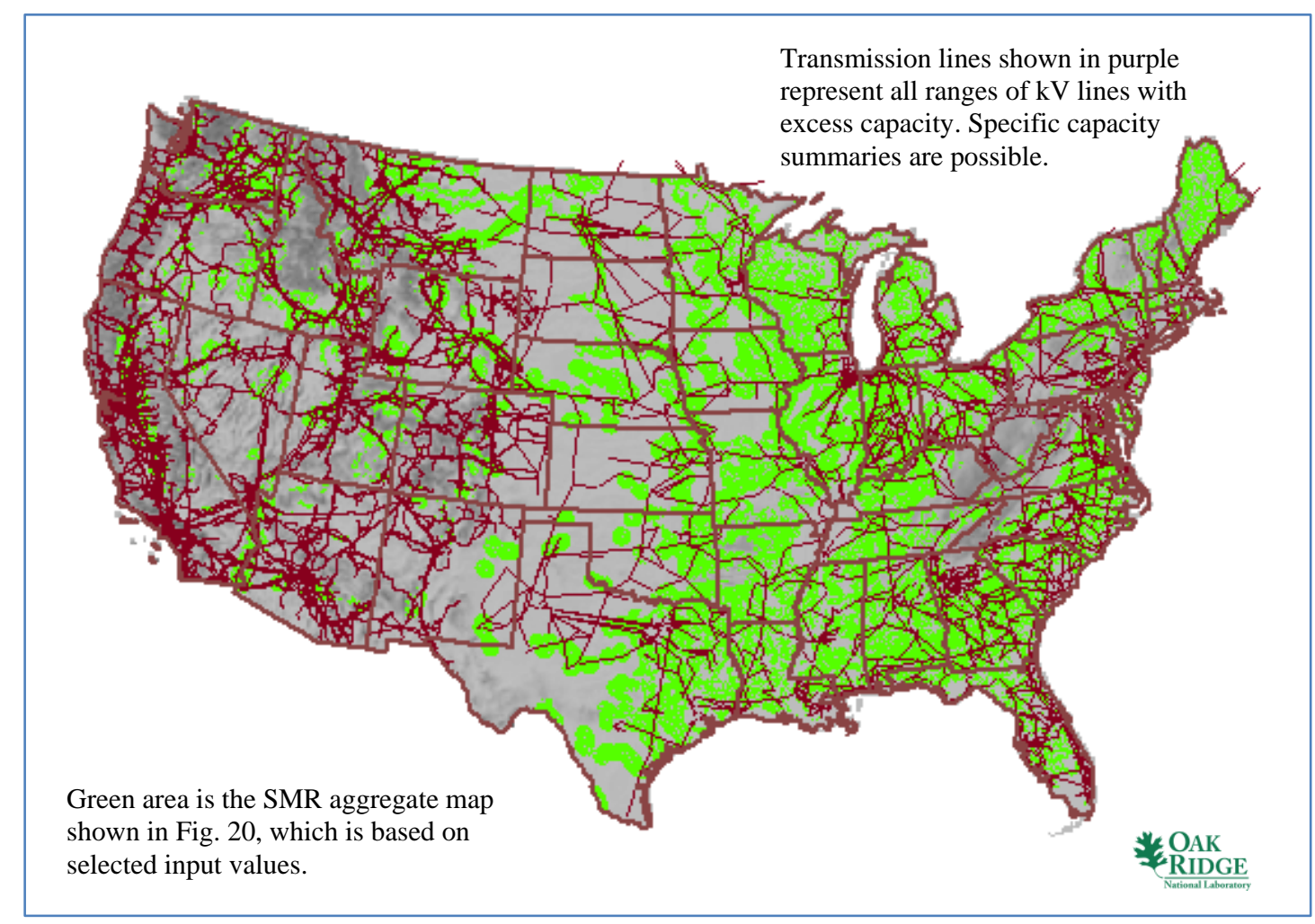

Fig. 26. Transmission lines with excess capacity overlaid on the SMR aggregate map.

\subsection{Additional Stream Flow Layer SSEC Values}

\subsubsection{Stream Flow Requirements for an SMR with an Electrical Capacity of 250 MW(e)}

One of the SMR iPWR designs under consideration is rated at less than half the electrical capacity [250 MW(e)] of the nominal, bounding SMR design [540 MW(e)]. This impacts the cooling water makeup SSEC, which is calculated based on electric capacity. At $250 \mathrm{MW}(\mathrm{e})$, only 30,000 gpm stream flow is required for cooling water makeup in a closed-cycle cooling system. ${ }^{10}$ A revised 30,000 gpm stream flow SSEC layer is shown in Fig. 27. Areas in magenta are excluded. Figure 27can be compared to Fig. 13, which depicts the nominal, bounding SMR cooling water makeup stream flow at 65,000 gpm. 


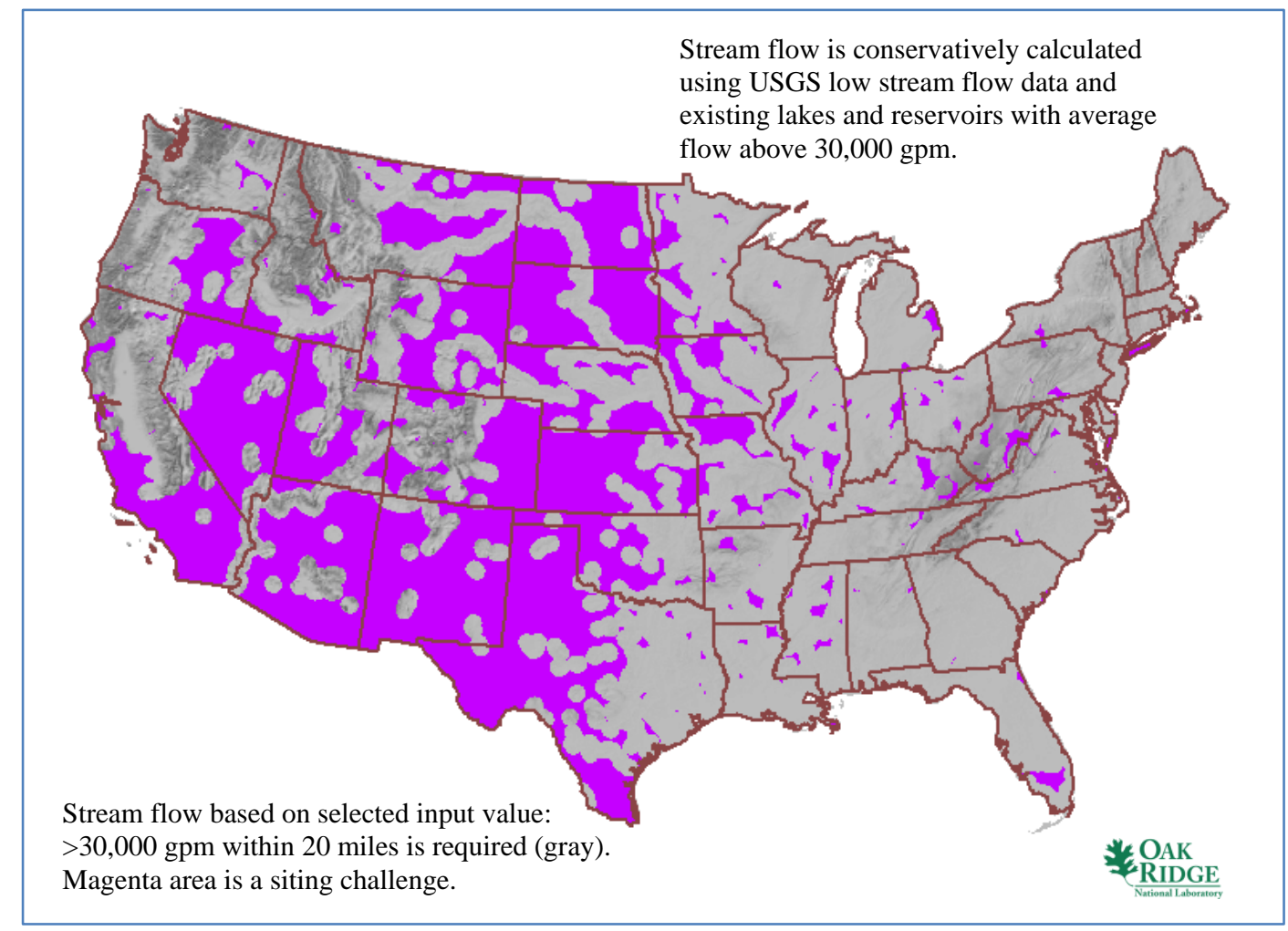

Fig. 27. SMR minimum low stream flow SSEC layer for 30,000 gpm.

The resulting SMR base map using the 30,000 gpm stream flow cooling water makeup layer instead of the $65,000 \mathrm{gpm}$ stream flow cooling water makeup layer produces a $2 \%$ increase in available land from 33.4 to $35.4 \%$. This represents an increase in the available SMR candidate area siting of 34 million acres (equivalent to the approximate land area of Georgia). Aggregated at a $90 \%$ threshold, a $2.6 \%$ increase in amassed 50 acre sites is generated from 26.9 to $29.5 \%$. Three of the four SMR iPWR designs are bounded between 30,000 gpm stream flow and 65,000 gpm stream flow to provide makeup water for the closedcycle cooling system.

\subsubsection{Stream Flow Requirements for Minimal Station Water Requirements}

A number of studies estimate that plant water demands could be reduced by at least $90 \%$ through the use of dry cooling. To be conservative, a value of $85 \%$ water reduction was used for a stream flow sensitivity study. For nuclear power plants, this equates to 115 gallons of makeup water per megawatt hour. ${ }^{10}$ Using the SSEC parameters for the nominal SMR plant at $540 \mathrm{MW}(\mathrm{e})$, this equates to a required stream flow of 10,000 gpm while still assuming no more than $10 \%$ of the available fresh-water stream flow would be diverted to the cooling water makeup needs of a new SMR. It should be noted that plant efficiencies are typically reduced with dry cooling, which could reduce the actual electrical capacity in this case to less than $540 \mathrm{MW}(\mathrm{e})$. A revised stream flow SSEC layer is shown in Fig. 28. Areas in magenta are excluded. Figure 28 can be compared to Fig. 13, which depicts the nominal, bounding SMR cooling water makeup flow at $65,000 \mathrm{gpm}$. 


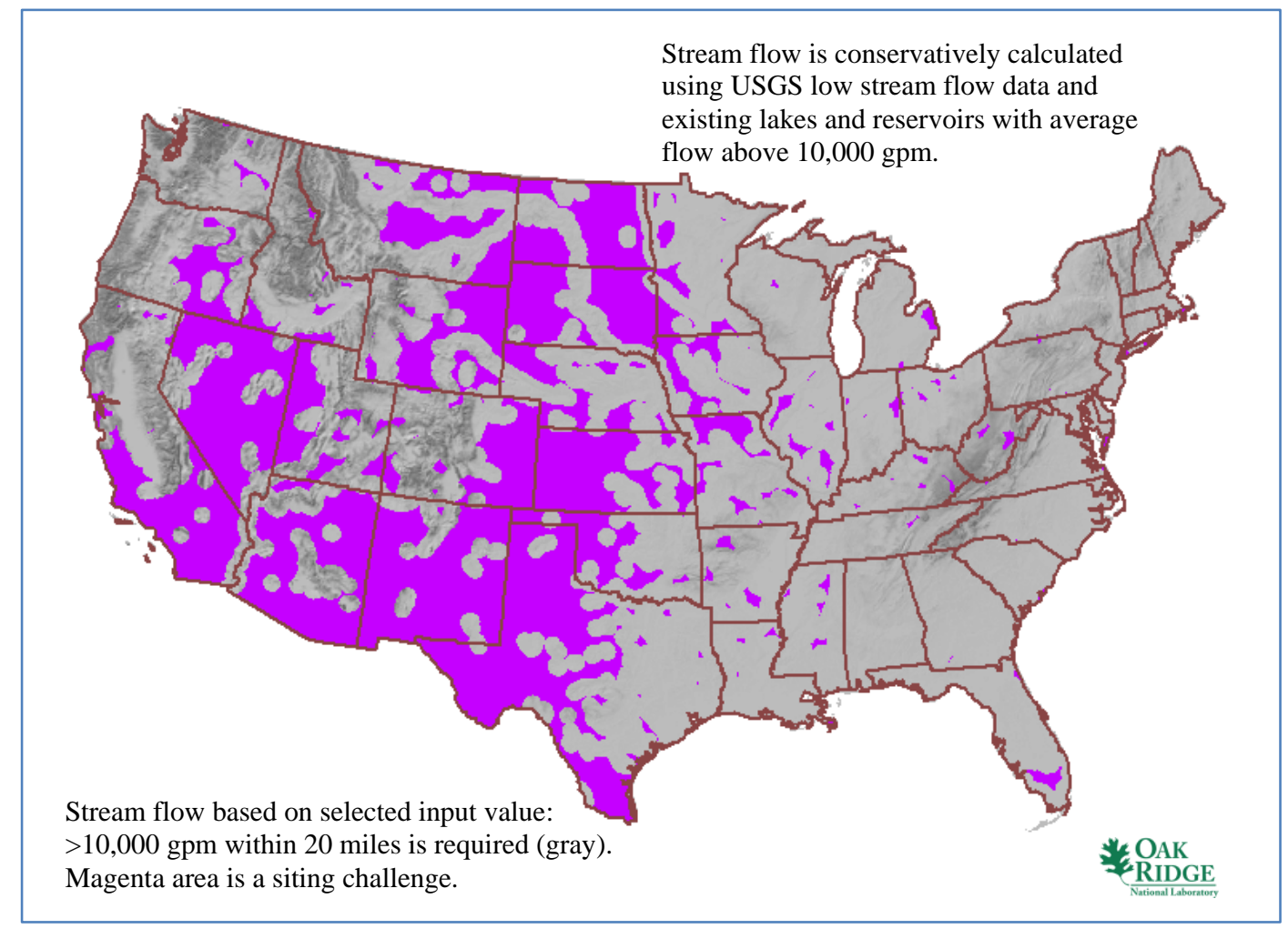

Fig. 28. SMR minimum low stream flow SSEC layer for 10,000 gpm.

The resulting SMR base map using the 10,000 gpm stream flow cooling water makeup layer instead of the 30,000 gpm stream flow cooling water makeup layer produces an additional $2.1 \%$ increase in available land from 35.4 to $37.4 \%$. This represents another increase in the available SMR candidate area siting of 36 million acres. Aggregated at a $90 \%$ threshold, a $1.9 \%$ increase in amassed 50-acre sites is generated from 29.5 to $31.4 \%$.

Although this sensitivity is intended to initiate a look at dry cooling, it also bounds the remaining SMR iPWR design rated at $160 \mathrm{MW}(\mathrm{e})$, which requires about 19,000 gpm of stream flow for makeup water. A further analysis is conducted in the following section assuming no stream flow water requirement as an absolute dry-cooling alternative. A summary of the sensitivity study results on varying SMR stream flow requirements is shown in Table 2.

Table 2. Stream flow sensitivity study results

\begin{tabular}{|l|c|c|c|}
\hline \multirow{2}{*}{} & \multicolumn{3}{|c|}{ SMR stream flow (percentage of contiguous United States) } \\
\cline { 2 - 4 } & $\mathbf{6 5 , 0 0 0} \mathbf{~ g p m}$ & $\mathbf{3 0 , 0 0 0} \mathbf{g p m}$ & $\mathbf{1 0 , 0 0 0} \mathbf{~ g p m}$ \\
\hline \multirow{2}{*}{ Base map } & $33.4 \%$ & $35.4 \%$ & $37.5 \%$ \\
& 572 million acres & 606 million acres & 642 million acres \\
\hline \multirow{2}{*}{ Aggregate map (90\%) } & $26.9 \%$ & $29.5 \%$ & $31.4 \%$ \\
& 461 million acres & 505 million acres & 538 million acres \\
\hline
\end{tabular}

The differences in the SMR stream flow layers for these sensitivity analyses is difficult to detect visually by comparing individual maps. However, the combined aggregate map shown in Fig. 29 indicates that the additional land added to the SMR candidate area siting mix by incrementally decreasing the stream flow requirements is primarily in the central United States. 


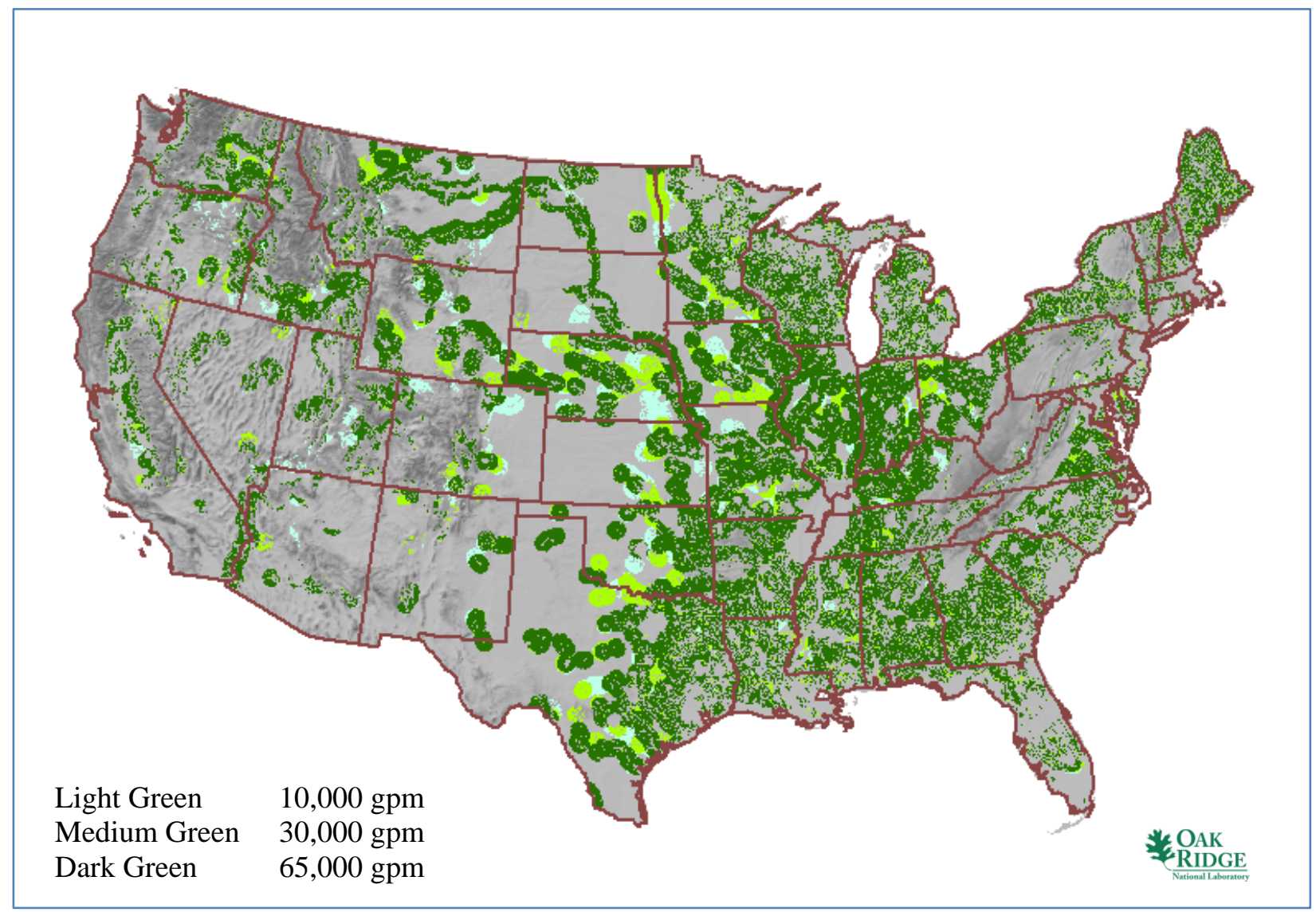

Fig. 29. SMR aggregate map variants with multiple stream flow values. 


\section{ALTERNATIVE SOURCES OF COOLING WATER MAKEUP}

Over half of the areas that fail due to a single-issue in the nominal, bounding SMR case are due to inadequate makeup water for closed-cycle cooling. This calls for an expanded look at makeup water alternatives for SMRs. The nominal SMR screening case identifies stream flow, which includes inland lakes and reservoirs, for makeup water to a closed-cycle cooling system. Underground water in aquifers is another potential source of makeup water for SMRs. Waste-water from population centers is also a potential source of makeup water. Finally, cooling water makeup from large bodies of water such as the ocean or the Great Lakes is a possibility, although ocean salt water cooling sources are typically used for once-through cooling.

\subsection{Aquifer Makeup Alternative}

One potential alternative source of SMR cooling water makeup is aquifers. Known aquifers are mapped as shown in Fig. 30 (areas in magenta do not contain aquifers). No attempt to quantify the depth or volume of any aquifer was made. Since many SMR designs are currently intended to be built below grade, shallow aquifers could prove to be detrimental to SMR siting. There was also no attempt to quantify competing uses of water in aquifers, such as irrigation water or drinking water.

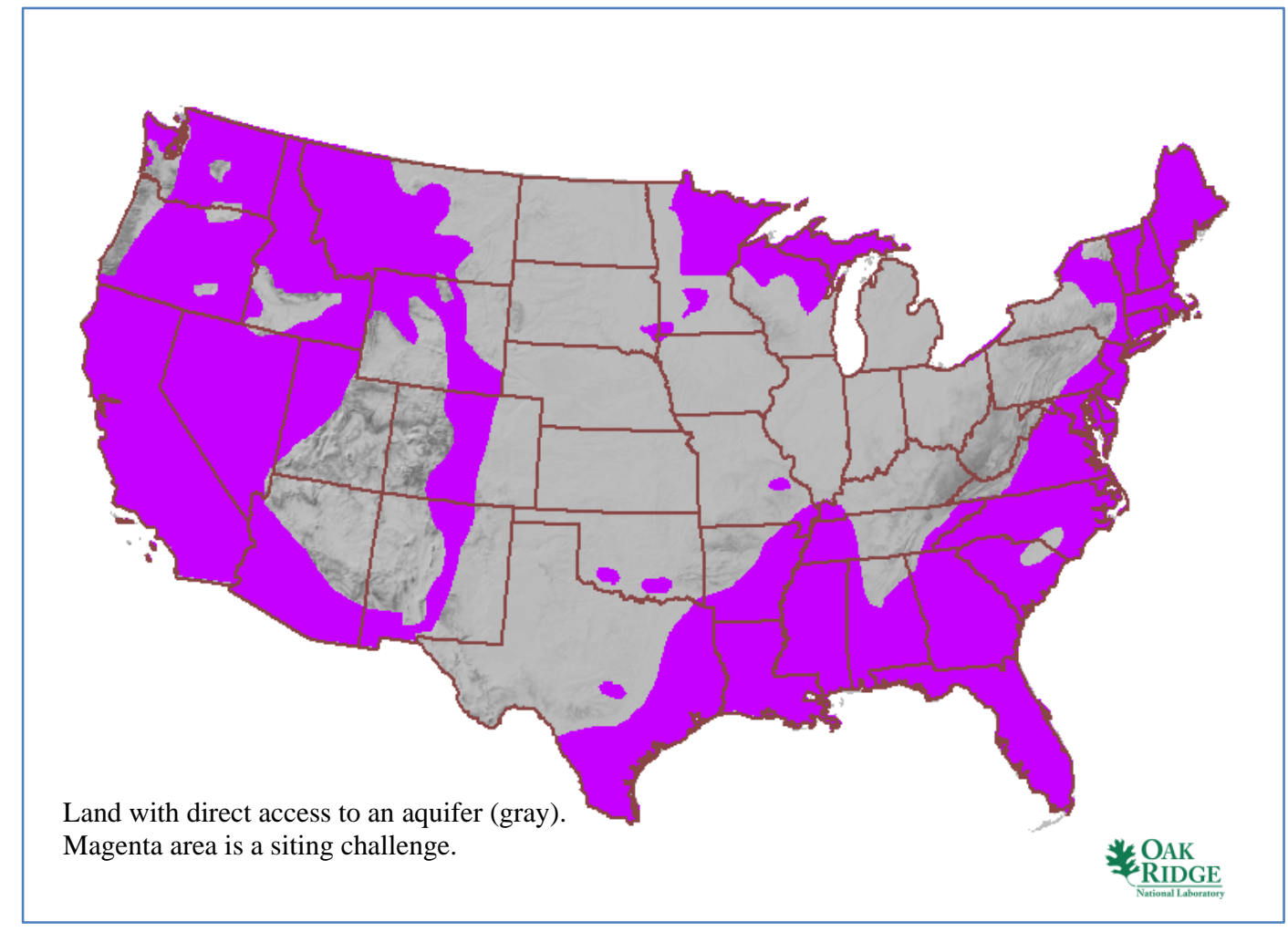

Fig. 30. SMR aquifer cooling water makeup SSEC layer.

In a report ${ }^{11}$ on potential SSEC that include subsurface factors, LANL is compiling water table data, some of which has been published. The data compiled so far on the depth to the water table for Alabama, Georgia, and Florida is shown in Fig. 31. This type of data could allow Fig. 30 to be redrawn and the opportunity for using aquifers for thermoelectric power plant cooling water makeup to be evaluated in a more quantitative process. 


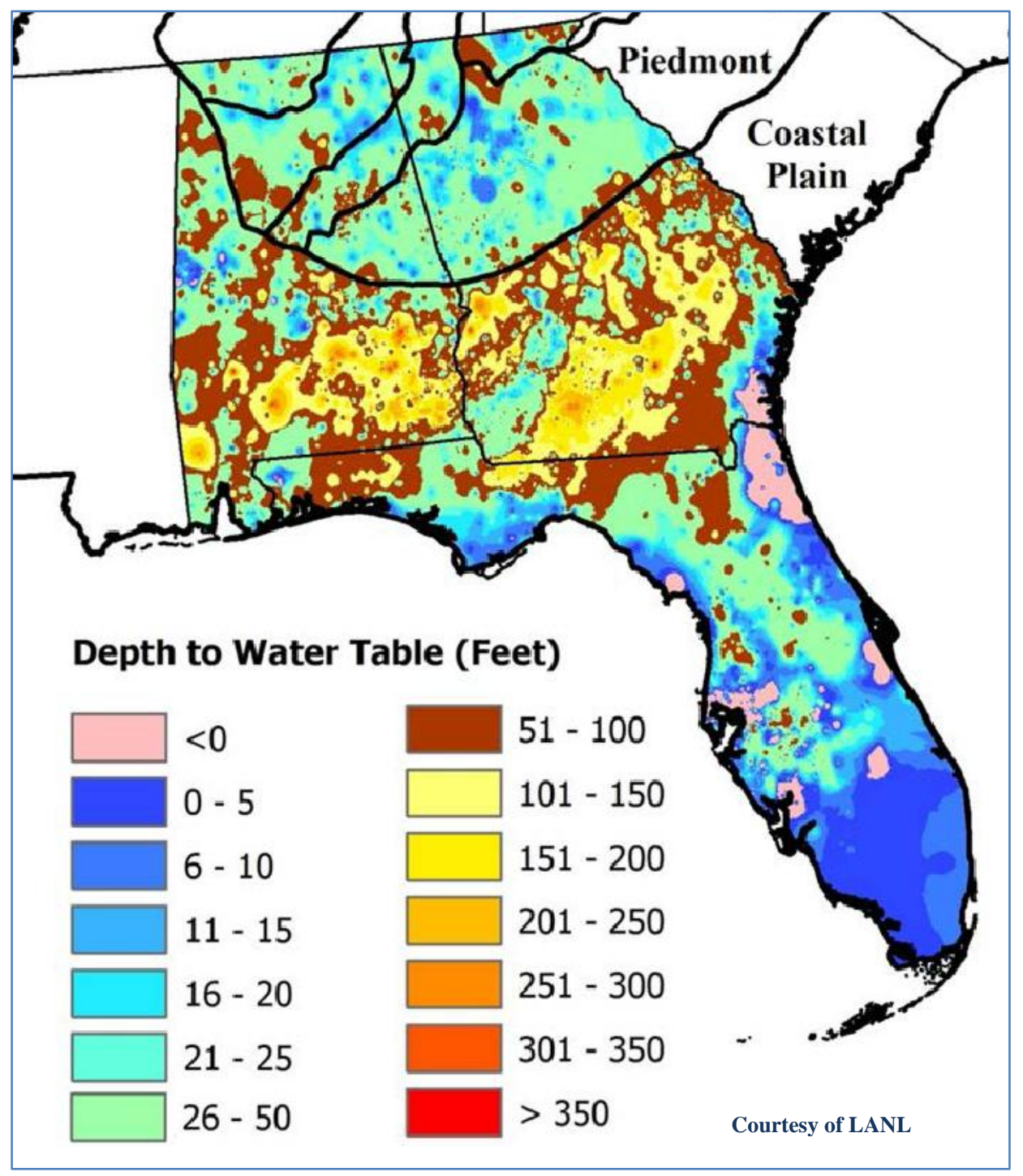

Fig. 31. Depth to water table for select Southeastern states. ${ }^{11}$

The aquifer cooling SMR SSEC layer shown in Fig. 30 can be substituted for the 65,000 gpm stream flow cooling SMR SSEC layer to regenerate the candidate area siting results. The aquifer SMR composite map is shown in Fig. 32. This composite map can be compared to the nominal bounding SMR composite map shown in Fig. 18. Note the shift in land with no siting challenges from the eastern half of the country with stream flow makeup to the central United States with aquifer makeup. Using aquifers for closed-cycle cooling makeup water, $35.6 \%$ of the country has no siting challenges (shown in green) based on the selected values for the SMR SSEC layers, while an additional $33 \%$ of the country has just a single siting challenge (shown in yellow). This is a combined $68.6 \%$ of the country with no more than one siting challenge based only on using aquifers for makeup water. This compares to a combined $74.7 \%$ of the country with no more than one siting challenge based on stream flow for makeup water to a closed-cycle cooling system. 


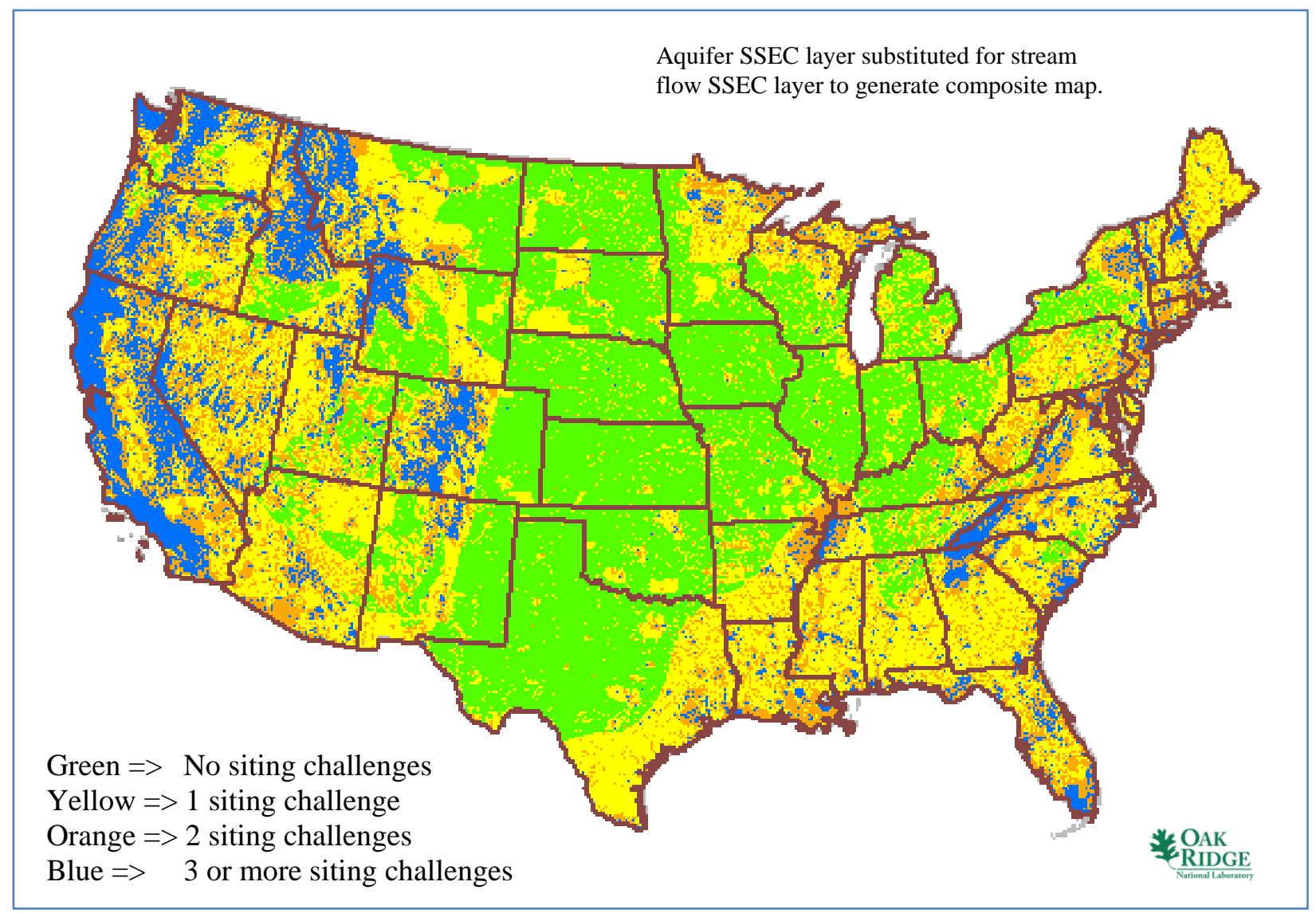

Fig. 32. SMR composite map utilizing aquifer SSEC layer.

Combining the stream flow and the aquifer cooling SMR SSEC layers into a single composite cooling layer has a dramatic effect on the makeup water layer. Instead of individual layers that exclude a large portion of the United States, the combined makeup water layer now includes most of the United States, as shown in Fig. 33. Only areas in the far west remain excluded based on the makeup water layer. Because the area with no siting challenges is dramatically different between the individual makeup water layers in this comparison, the resulting composite map, which factors in all the SMR SSEC, has a remarkable 51\% of the country with no siting challenges (shown in green). This represents a gain of approximately 301 million acres (about twice the size of Texas) available for SMR candidate siting areas for a total of 873 million acres. Much of the country east of the Rocky Mountains is included. An additional 28.2\% of the country has just one siting challenge (shown in yellow). This is a combined $79.2 \%$ of the country with no more than one siting challenge based on stream flow and aquifer cooling water makeup. 


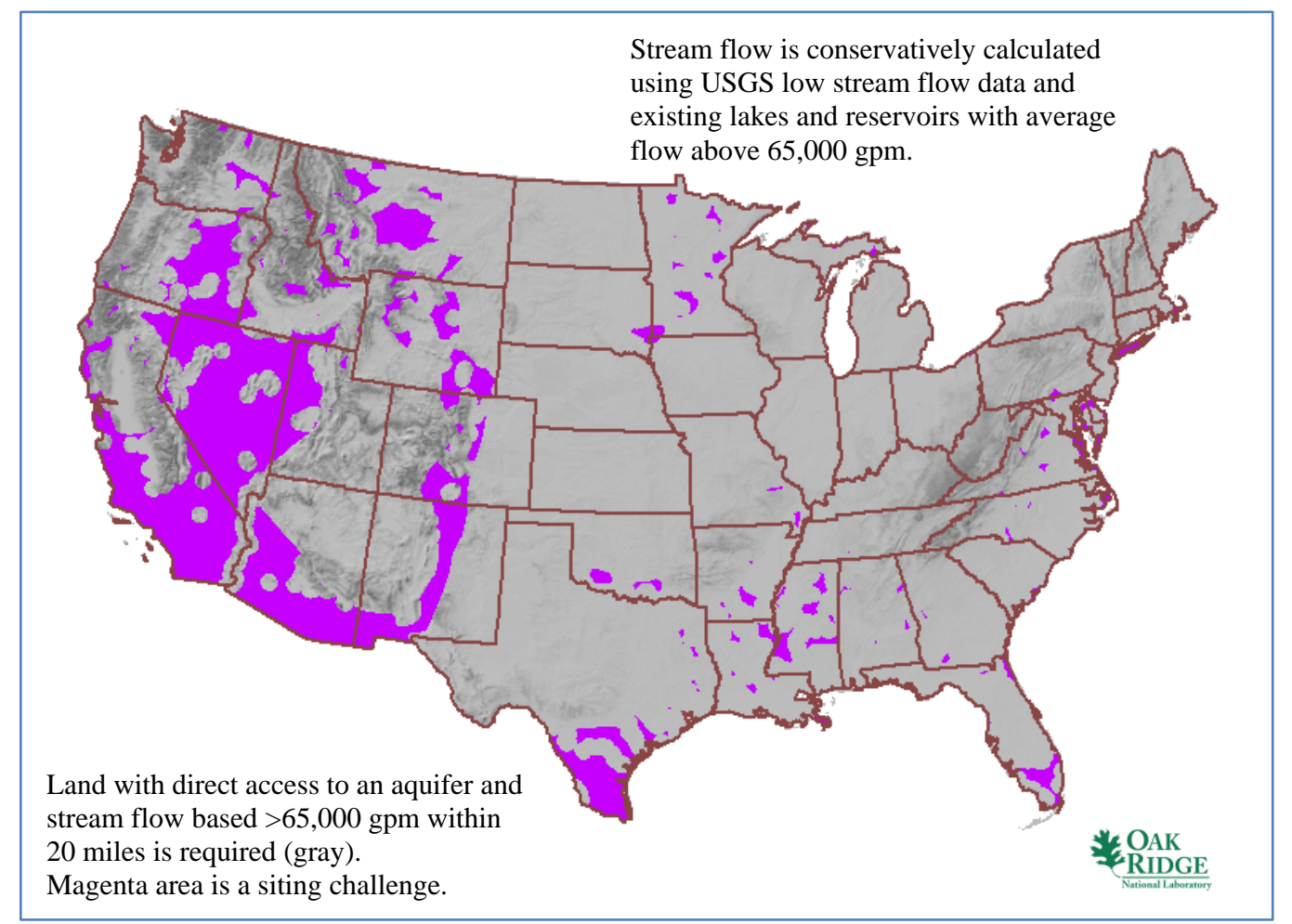

Fig. 33. Combined stream flow and aquifer cooling water makeup layer.

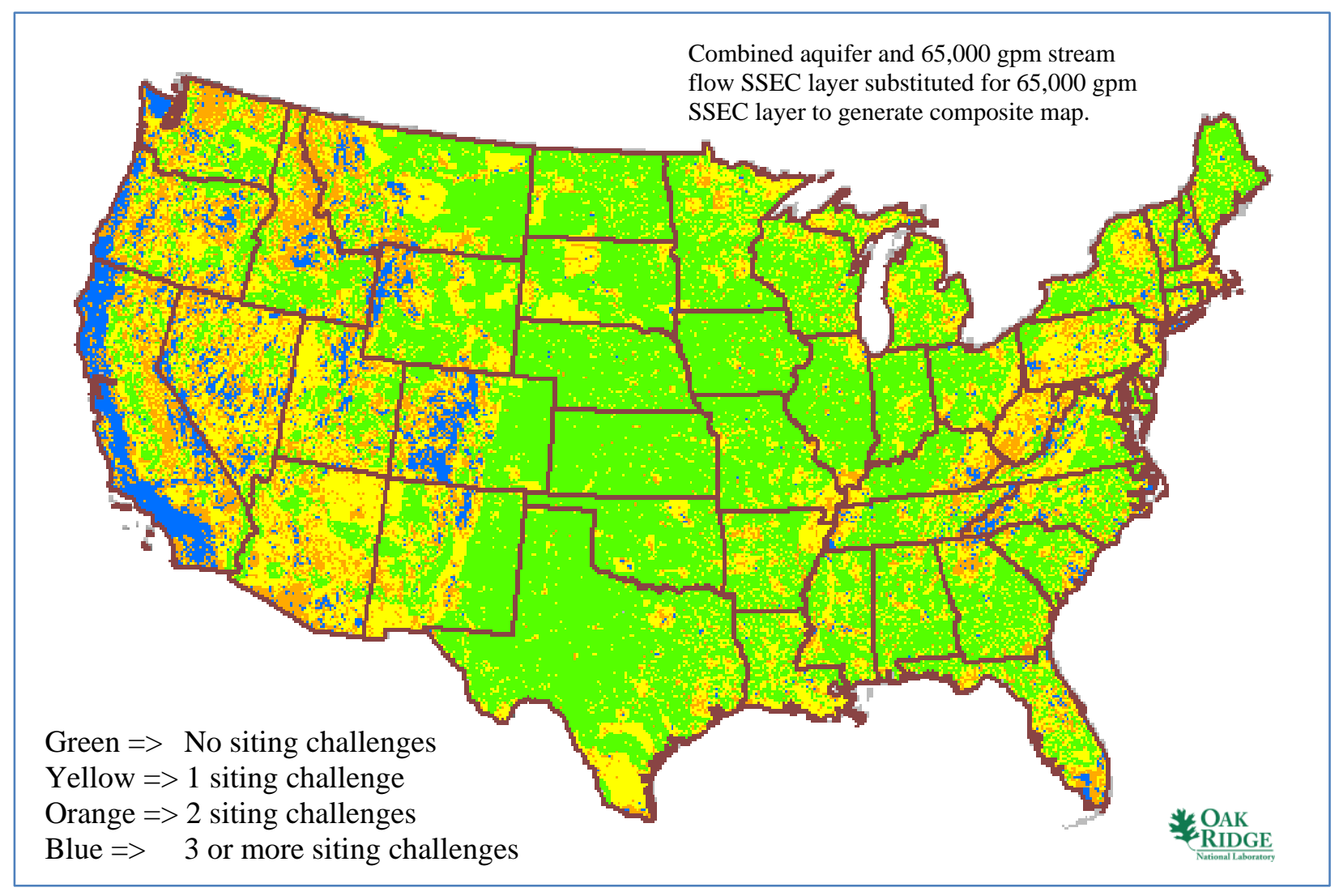

Fig. 34. SMR composite map utilizing combined stream flow and aquifer SSEC layer. 


\subsection{Gray Water Makeup Alternative}

Another potential alternative source of SMR cooling water makeup is the treated waste water from municipalities. This is typically known as gray water, which has many applications including irrigation, ground-water recharge, and industrial uses. The Palo Verde nuclear power plant uses gray water from Phoenix as its source of cooling water. To analyze the gray water potential, all database cells with a population in excess of 500 people per square mile were collected into polygon shapes. It was assumed that such population areas would include waste-water treatment facilities. A buffer of 20 miles was added to allow for pumping waste-water to an industrial site such as an SMR. The results are interesting in that most of the eastern half of the country is within reach of a population polygon with a 20-mile buffer as shown in Fig. 35. Of course the population areas themselves would be filtered out in the individual SMR population SSEC layer. No analysis was performed regarding the volume of gray water that might be available surrounding any given population area or any currently obligated uses for the gray water.

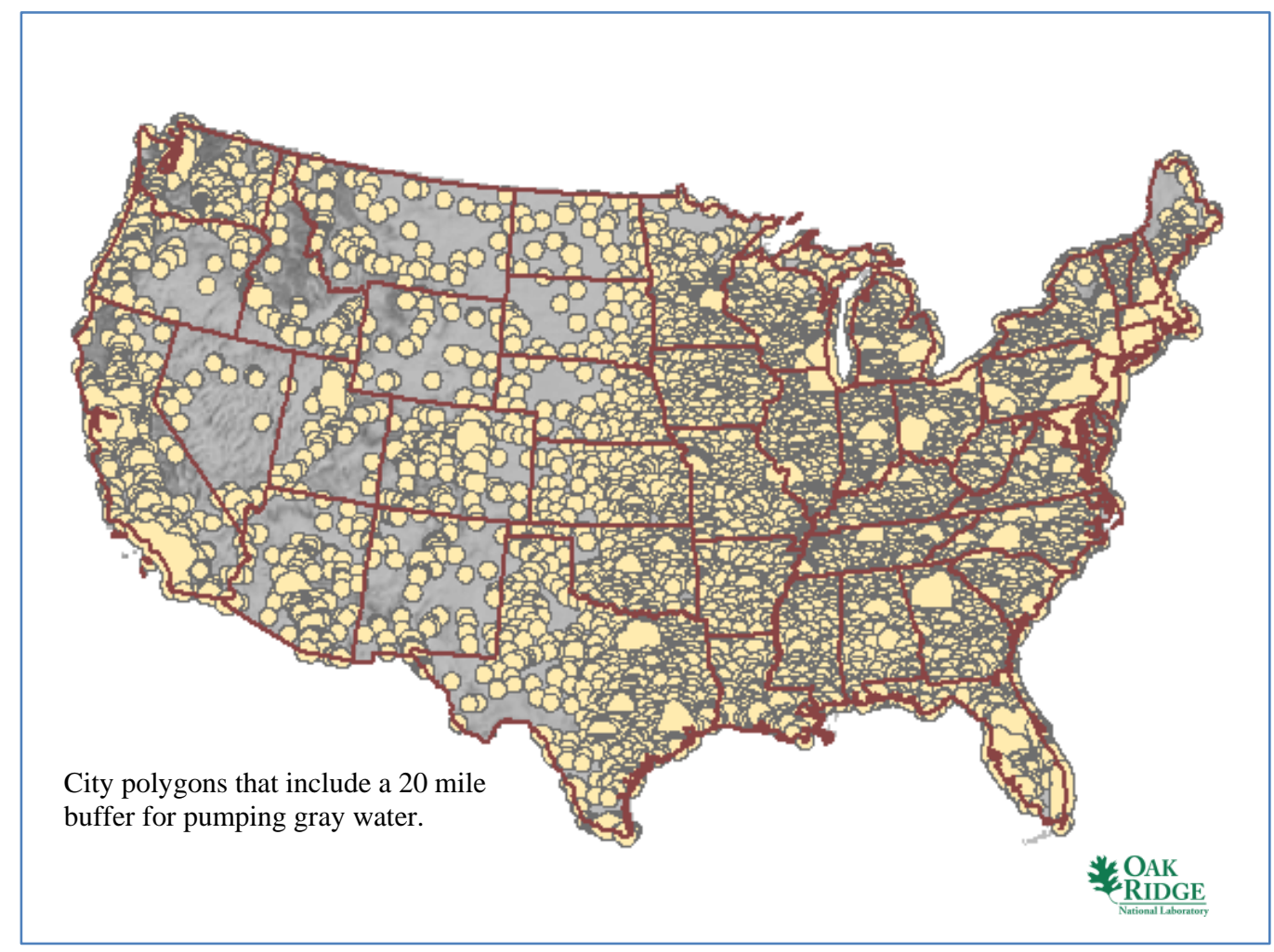

Fig. 35. Population center polygons with 20 mile buffer.

This results in an SMR gray water makeup SSEC layer that excludes much of the western half of the country as shown in Fig. 36. Except for the west coast, population densities in the western half of the country do not support the use of gray water as a makeup water alternative. This reflects the arid nature of the west, since population centers also depend on a reliable water source. 


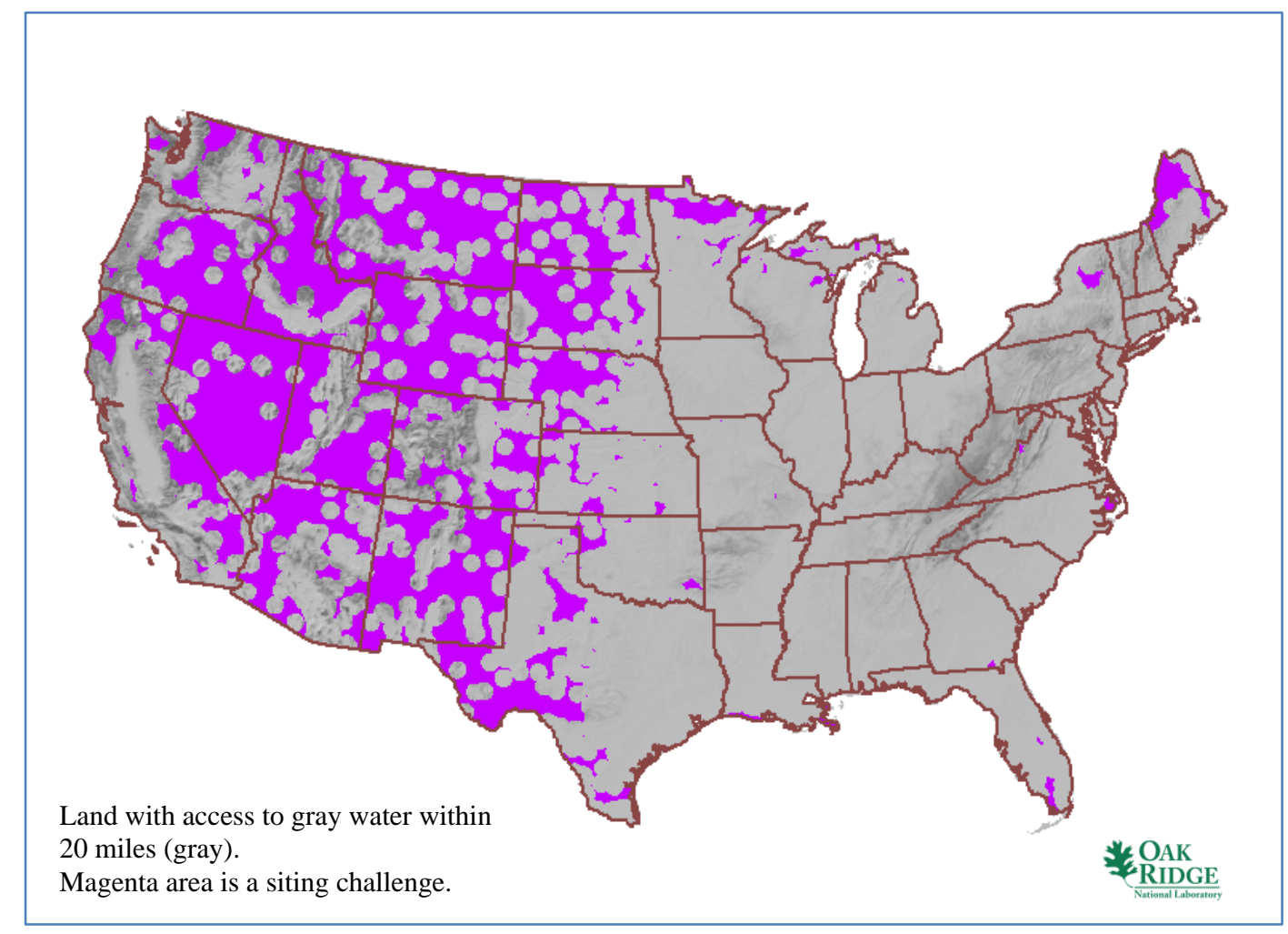

Fig. 36. SMR gray water cooling water makeup SSEC layer.

The SMR gray water makeup SSEC layer can be substituted for the 65,000 gpm stream flow cooling water makeup SMR SSEC layer to regenerate the candidate area siting results. The gray water makeup SMR composite map, incorporating all the SMR SSEC, is shown in Fig. 37. This composite map can be compared to the nominal bounding SMR composite map using stream flow as the makeup water source (Fig. 18). As expected, based on the revised cooling water makeup layer substituted into the analysis stack, the eastern half of the country shows up predominantly with no siting challenges based on the selected input criteria. Using gray water makeup, $44.2 \%$ of the country has no siting challenges (shown in green), while an additional $32.5 \%$ of the country has just a single siting challenge (shown in yellow). This is a combined $76.7 \%$ of the country with no more than one siting challenge based on gray water makeup. This is very similar to the combined $74.7 \%$ of the country with no more than one siting challenge based on stream flow cooling water makeup. 


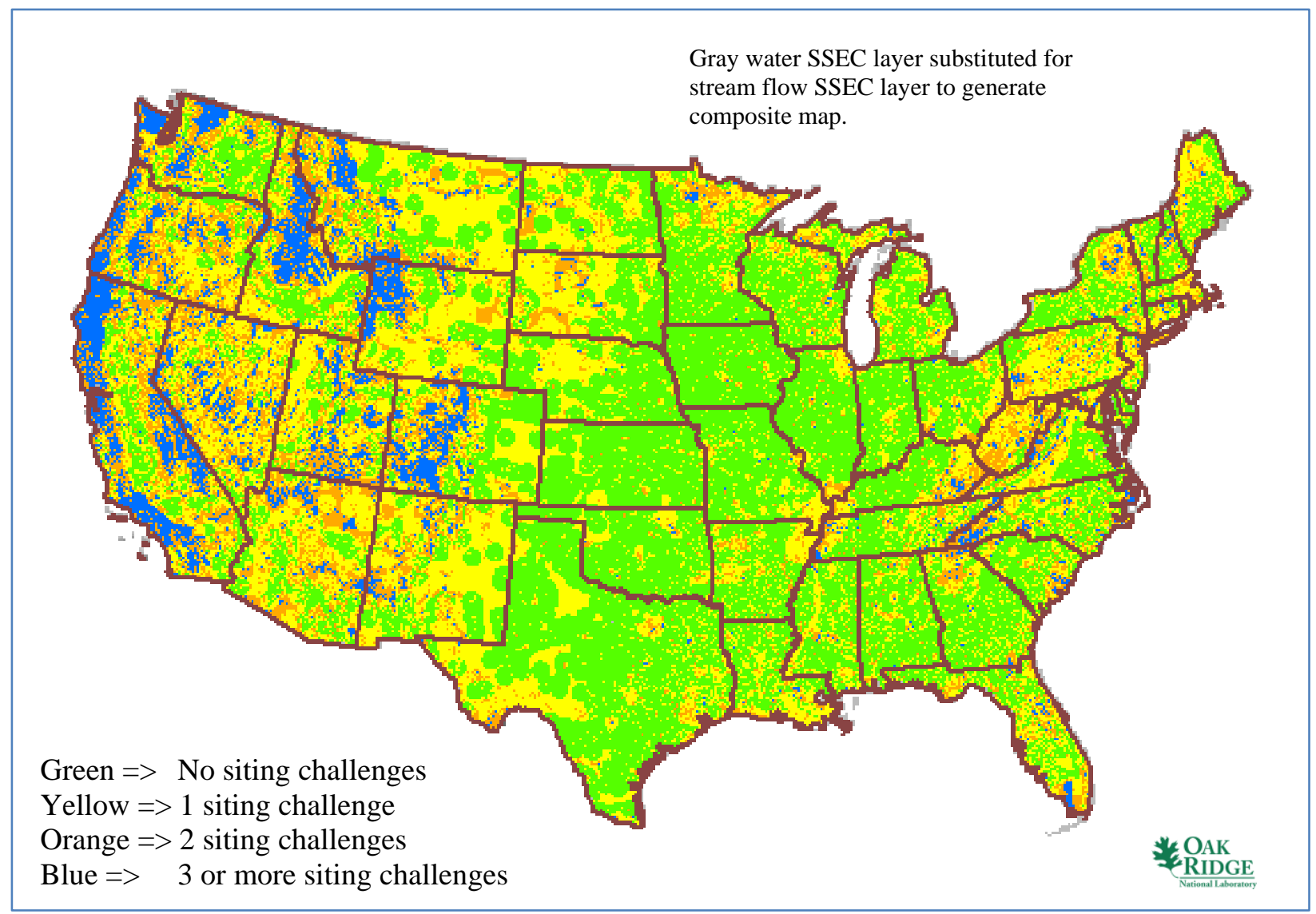

Fig. 37. SMR composite map utilizing gray water SSEC layer.

This layer produced by combining the stream flow and gray water cooling water makeup SMR SSEC layers into a single composite cooling water makeup layer is very similar to the individual gray water SSEC layer. Where the SMR stream flow cooling water makeup layer excluded significant portions of the central United States, rings around the population centers located in that region are picked up by the gray water cooling layer as shown in Fig. 38. As a result, the composite map shown in Fig. 39 shows an increase of just $3.4 \%$ of the country from 44.2 to $47.6 \%$ with no siting challenges (shown in green). This represents a gain of 58.2 million acres (about the size of Colorado) for a total of 815 million acres. Again, much of the country east of the Rocky Mountains is included. An additional 31.5\% of the country has just one siting challenge (shown in yellow). This is a combined $79.1 \%$ of the country with no more than one siting challenge based on stream flow and gray water cooling water makeup, which is similar in scope and value to the combination of stream flow and aquifer cooling. 


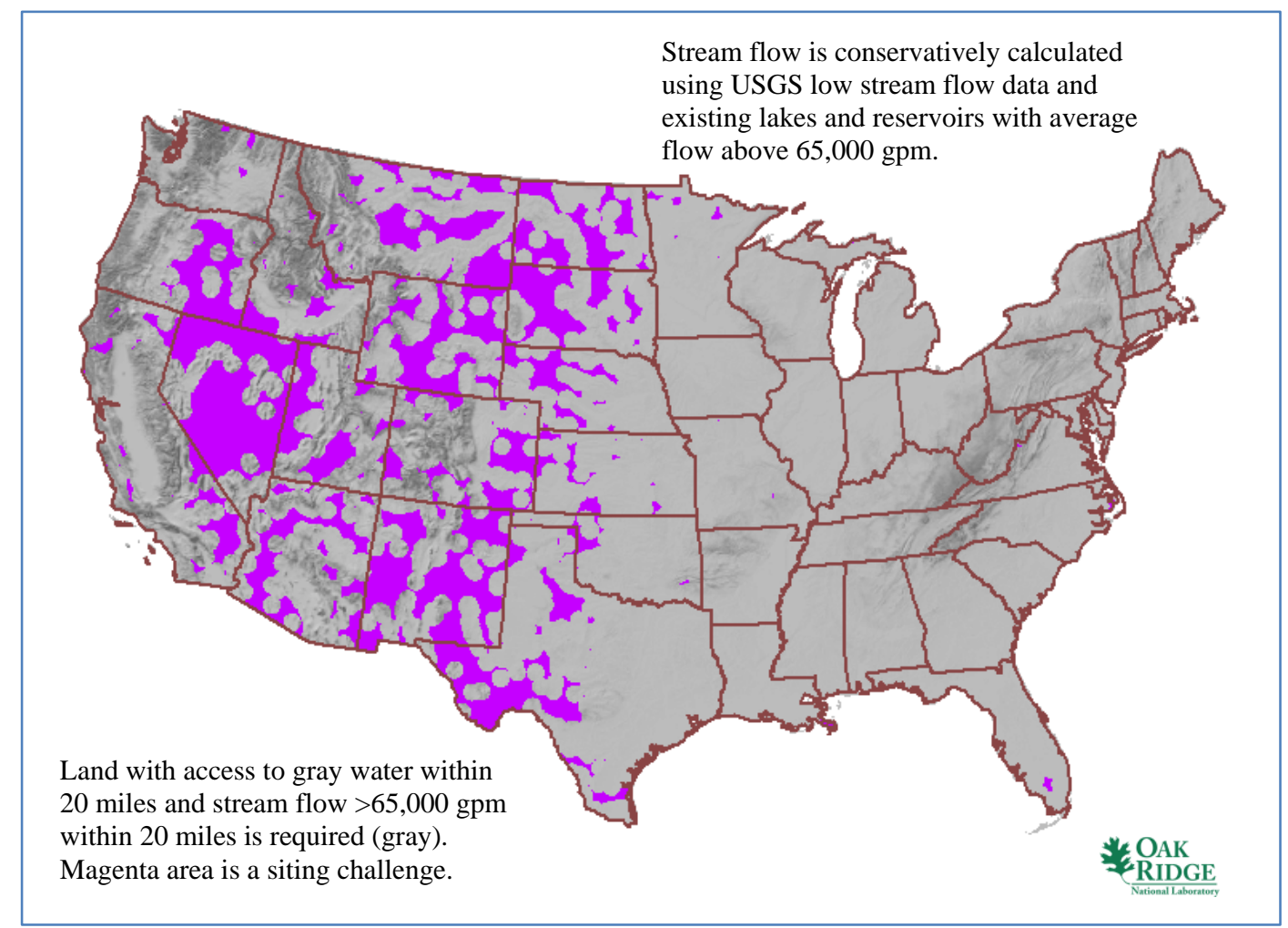

Fig. 38. Combined stream flow and gray water cooling water makeup layer.

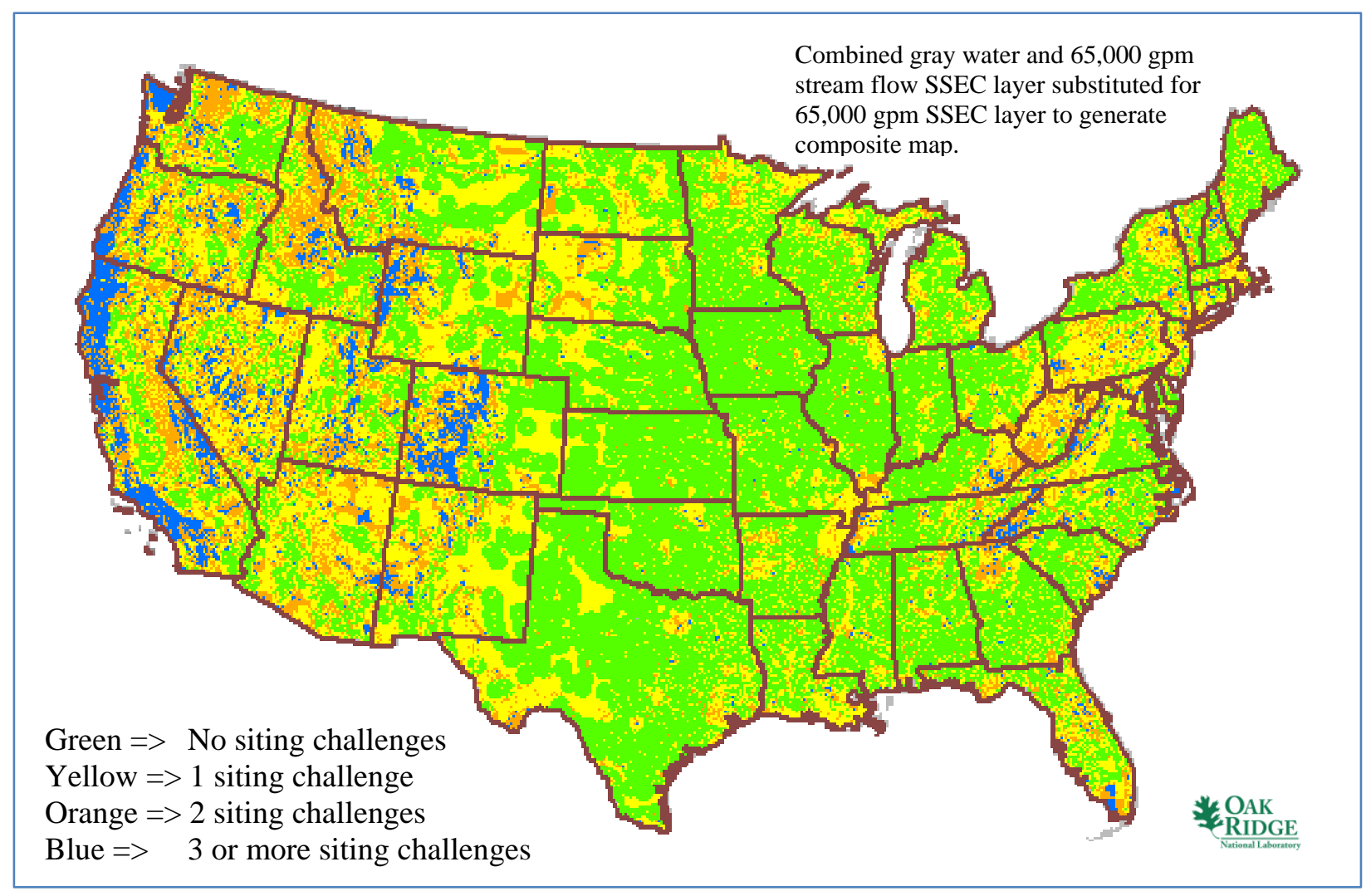

Fig. 39. SMR composite map utilizing combined stream flow and gray water SSEC layer. 


\subsection{Ocean and Great Lakes Cooling Alternative}

While stream flow cooling water makeup does consider inland lakes as a cooling source, ocean cooling and cooling water from the Great Lakes is not considered. Assuming that unlimited cooling water can also be pumped up to 20 miles from these large cooling source alternatives, as it is for stream flow cooling, additional SMR candidate siting areas can be made available. Unfortunately, when this alternate cooling layer is factored into the combination of siting SSEC layers, most of the west coast area is largely precluded because of other factors, such as population density, landslide hazards, high slopes, and seismic activity. However, as shown in the base map in Fig. 40, a limited amount of land along the Gulf coast, the Atlantic coast, and the Great Lakes becomes available for SMR siting consideration.

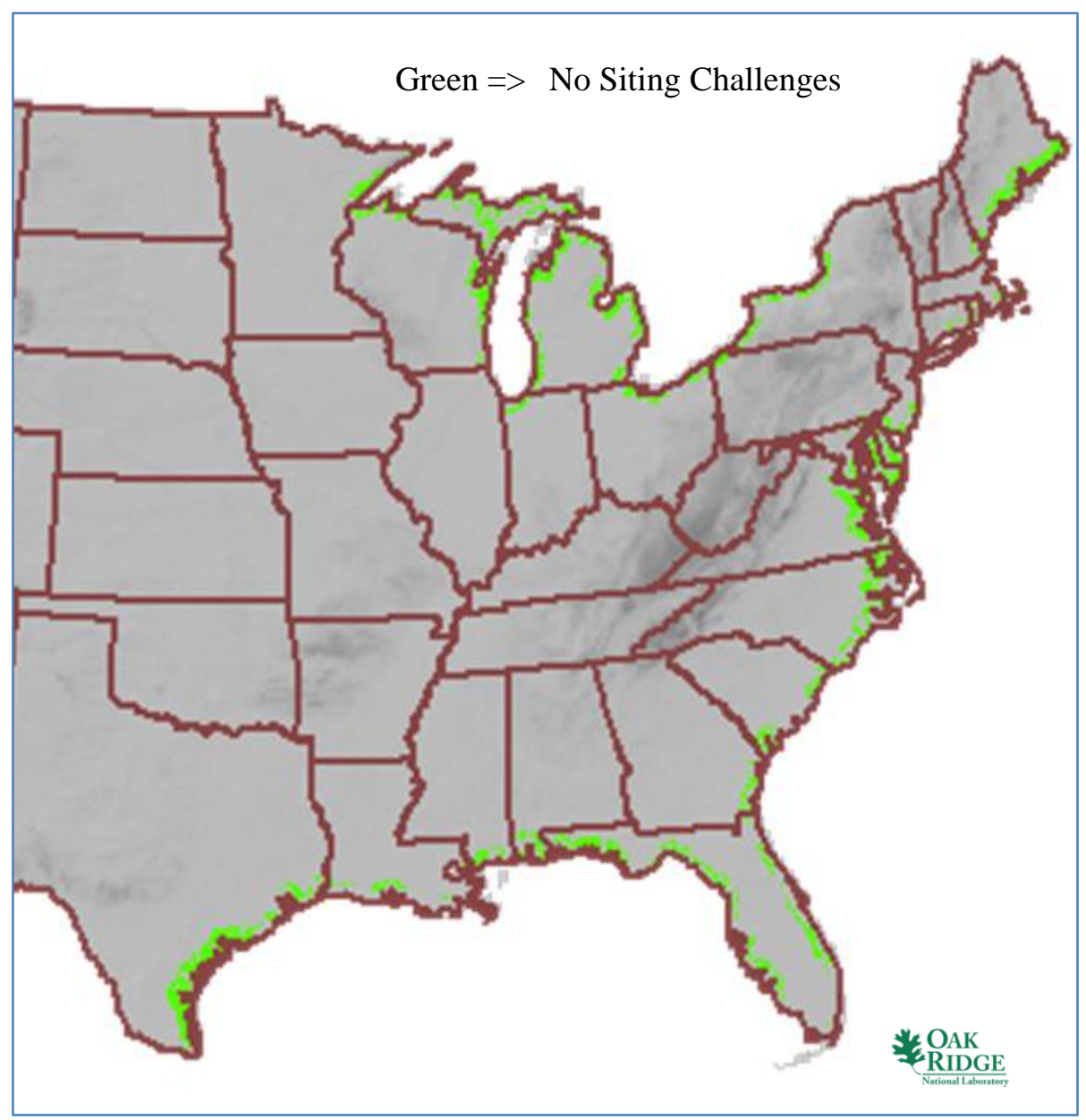

Fig. 40. SMR base map with alternate ocean and Great Lakes cooling.

When this result is combined with the nominal 65,000 gpm SMR stream flow cooling water makeup result, a composite map shows an increase of just $1 \%$ of the country from 33.4 to $34.4 \%$ with no siting challenges. A $1 \%$ increase represents an additional 17 million acres available for SMR candidate area siting. 


\subsection{Combined Cooling Source Results}

Combining all these alternative cooling water makeup sources together with the nominal stream flow cooling water makeup case provides an indication of just how much additional land could be made available for SMR candidate siting. The case of aquifer makeup combined with the nominal 65,000 gpm SMR stream flow cooling water makeup is shown in Fig. 34. With aquifer and 65,000 gpm stream flow cooling water makeup combined, $51 \%$ of the country had no siting challenges. An additional $28.2 \%$ of the country has just one siting challenge for a combined $79.2 \%$ of the country with no more than one siting challenge based on stream flow and aquifer cooling water makeup.

Combining the stream flow, aquifer, and gray water cooling water makeup SMR SSEC layers into a single composite cooling water makeup layer increases the land supported by cooling water in the southwest as shown in Fig. 41 (compare with Fig. 33 for combined stream flow and aquifer cooling). At this point, only Nevada retains substantial land without a significant cooling water makeup source. As a result, the composite map using these makeup water sources in Fig. 42 shows an increase of an additional $3 \%$ of the country from 51 to $54 \%$ with no siting challenges (shown in green). This represents an additional 51 million acres for a total of 925 million acres. For comparison, Kansas, in the center of the United States, has approximately 46.5 million acres. Much of the country east of the Rocky Mountains is included, but more area in the arid southwest is also picked up with no siting challenges. An additional $27 \%$ of the country has just one siting challenge (shown in yellow). This is a combined $81 \%$ of the country with no more than one siting challenge based on stream flow, aquifer, and gray water cooling water makeup, which is an increase to the combination of stream flow and aquifer cooling water makeup. As a result, the areas with multiple siting challenges are beginning to fade significantly as the area with no siting challenges continues to increase with the addition of alternate makeup water sources.

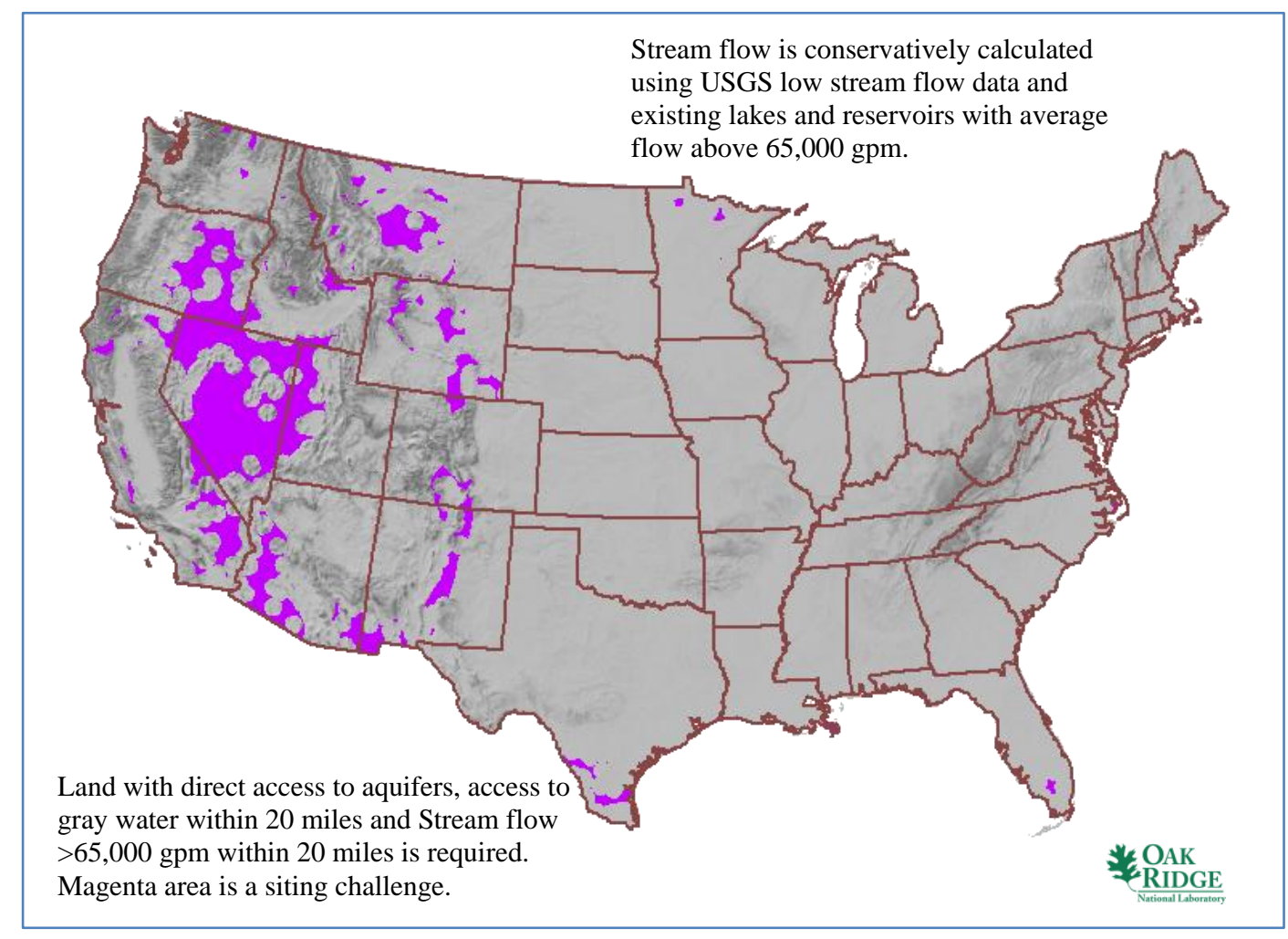

Fig. 41. Combined stream flow, aquifer, and gray water cooling water makeup layer. 


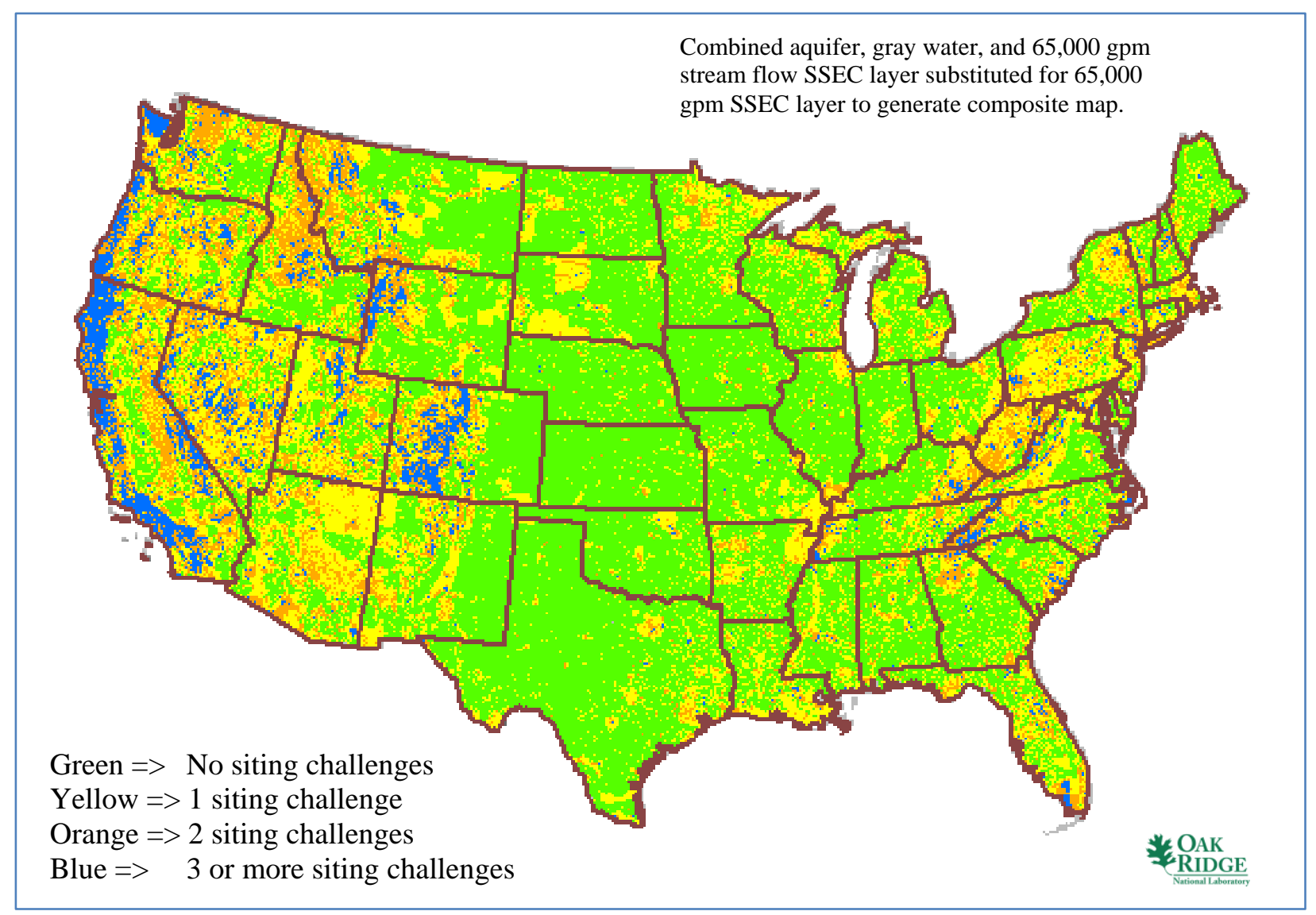

Fig. 42. SMR composite map utilizing combined stream flow, aquifer, and gray water SSEC layer.

Adding ocean cooling and Great Lakes cooling to the combination provides an alternate cooling source to the mix, but provides no significant increase in available land for SMR candidate siting areas. The results of the various combinations of cooling water sources are tabulated in Table 3. Again, this is based on the nominal case with 65,000 gpm stream flow included. A smaller-capacity SMR would require less stream flow producing a slight increase in the cooling water makeup combination values. 
Table 3. Cooling source combinations

(percentage of contiguous United States)

\begin{tabular}{|l|c|c|c|c|c|c|c|c|}
\hline $\begin{array}{l}\text { Number of } \\
\text { challenges }\end{array}$ & $\begin{array}{c}\mathbf{6 5 , 0 0 0} \\
\text { gpm } \\
\text { stream } \\
\text { flow }\end{array}$ & Aquifers & $\begin{array}{c}\text { Gray } \\
\text { water }\end{array}$ & Ocean & $\begin{array}{c}\text { Stream } \\
\text { flow + } \\
\text { aquifer }\end{array}$ & $\begin{array}{c}\text { Stream } \\
\text { flow + } \\
\text { gray } \\
\text { water }\end{array}$ & $\begin{array}{c}\text { Stream } \\
\text { flow + } \\
\text { ocean }\end{array}$ & $\begin{array}{c}\text { Stream flow + } \\
\text { aquifer+ gray } \\
\text { water* }\end{array}$ \\
\hline None & 33.4 & 35.6 & 44.2 & 1.8 & 51.0 & 47.6 & 34.4 & 54.0 \\
\hline One & 41.3 & 33.0 & 32.5 & 57.1 & 28.2 & 31.5 & 41.4 & 27.0 \\
\hline Two & 17.0 & 18.5 & 14.7 & 25.2 & 13.8 & 14.4 & 16.5 & 13.1 \\
\hline $\begin{array}{l}\text { Three } \\
\text { or more }\end{array}$ & 8.3 & 12.9 & 8.6 & 15.9 & 7.0 & 6.5 & 7.7 & 5.9 \\
\hline
\end{tabular}

*The contribution of ocean cooling does not change the values reflected in this column.

\subsection{Dry-Cooling Results}

A limited dry-cooling sensitivity analysis was documented in Sect. 2.3.2 with 10,000 gpm stream flow cooling water makeup required or 1,000 gpm to the plant for drinking, plant make-up, and auxiliary cooling system needs. This was based on an SMR with a capacity of $540 \mathrm{MW}(\mathrm{e})$ and is somewhat subjective regarding the actual value of water required. A case that totally bounds an SMR using drycooling technology to reject heat in the thermoelectric plant Rankine cycle was evaluated by removing the cooling water makeup layer entirely. The resulting SMR dry-cooling composite map is shown in Fig. 43. 


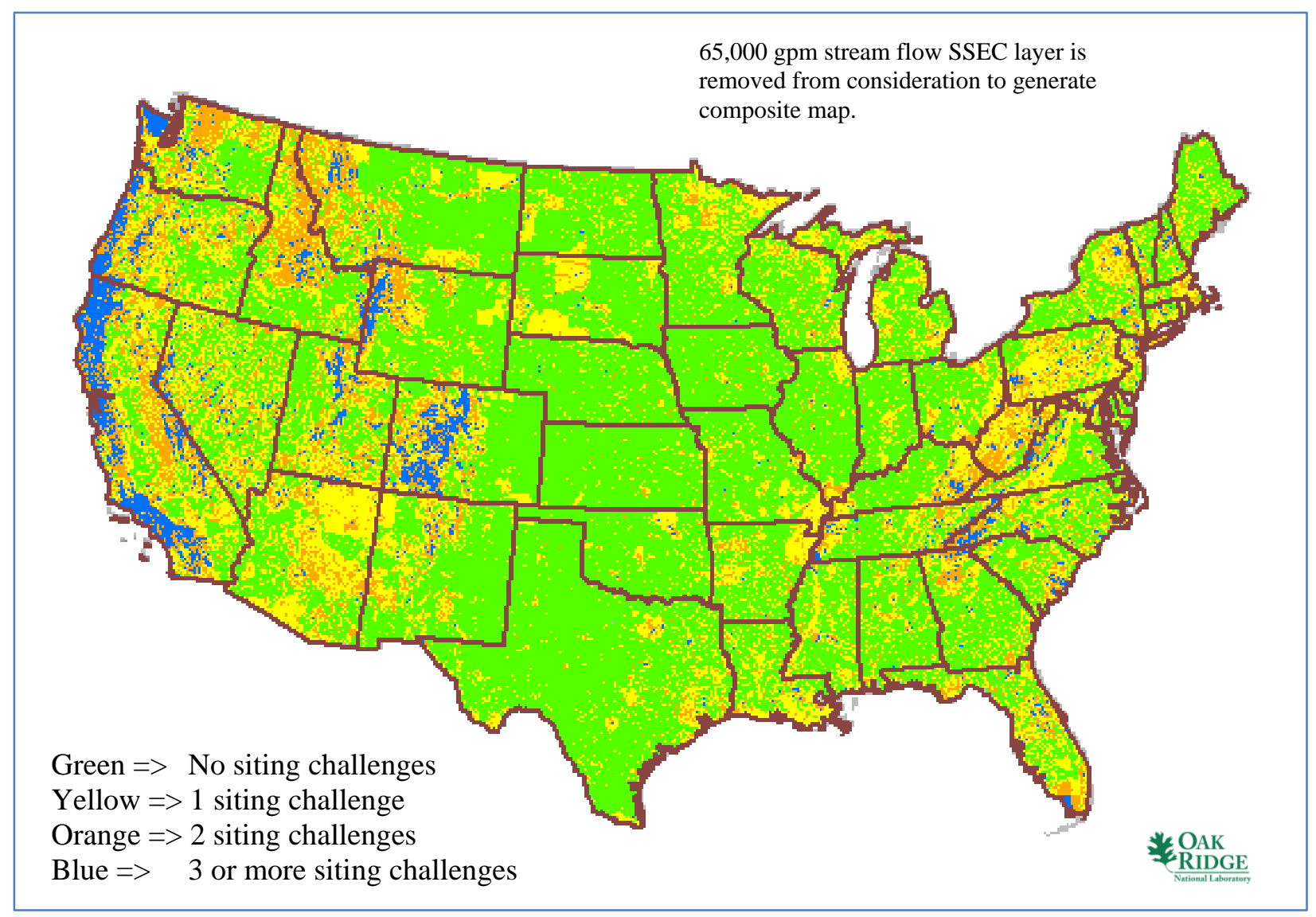

Fig. 43. SMR composite map utilizing no cooling water (dry cooling).

This composite map is not limited to any particular SMR design capacity. Compared to Fig. 42, which shows multiple alternate cooling water sources, Fig. 43 shows significant improvement in SMR candidate area availability in the western portion of the country using dry-cooling technology. In the totally dry cooling case, $57.1 \%$ of the country or 978 million acres becomes available for siting any near-term SMR design without any siting challenges based on the selected SMR SSEC values. This is comparable to, but slightly larger than the case for multiple cooling water sources at $54 \%$ of the country or 925 million acres. The difference in area between these two cases is approximately equivalent to the area of Oregon. Plant efficiencies would decrease with dry cooling, but the significant increase in available candidate land for SMR siting, especially in the dry southwest, is worth the exploration into these dry technologies. Furthermore, this increase in land is not dependent on gaining water rights now or in the future

Table 4 shows the comparison between the various makeup water stream flows that were analyzed and the case for no cooling flow.

Table 4. Comparison of stream flow cooling water makeup and dry cooling

\begin{tabular}{|c|c|c|c|c|}
\hline \multirow{2}{*}{} & \multicolumn{3}{|c|}{ SMR stream flow (percentage of contiguous United States) } \\
\cline { 2 - 5 } & $\mathbf{6 5 , 0 0 0} \mathbf{~ g p m}$ & $\mathbf{3 0 , 0 0 0} \mathbf{~ g p m}$ & $\mathbf{1 0 , 0 0 0} \mathbf{~ g p m}$ & $\begin{array}{c}\text { No cooling } \\
\text { water }\end{array}$ \\
\hline $\begin{array}{c}\text { Base map } \\
\text { (no challenges) }\end{array}$ & 33.4 & 35.4 & 37.5 & 57.1 \\
\hline
\end{tabular}





\section{CHARACTERIZATION OF AREAS WHERE SCREENING RESULTS INDICATE THAT SMRS CAN BE SITED AND LARGE LWRS CANNOT BE SITED}

As identified in Table 1, calculations suggest that SMR design characteristics generate 1.5 times the available base map siting area compared to large LWRs, based on selected SSEC values. The additional candidate siting area available only to SMRs can be evaluated separately from the candidate siting area available to both large LWRs and SMRs. This comparison may provide further insight on SMR siting.

SMRs offer a number of potential advantages over large reactors regarding their siting suitability. These include smaller site footprints, reduced cooling water requirements, potential accommodation of sites with higher slope, potentially less restrictive population buffer, a more robust design with respect to SSE, and a greater tolerance to threats from nearby hazardous facilities. These benefits could be justified by typical SMR designs characterized by very low core damage frequencies, elimination of large break loss-ofcoolant accidents, smaller source terms, and reduced early release fractions than large reactors. Collectively, these design strengths could result in the capability to satisfy siting requirements in a greater number of locations, and potentially in closer proximity to the end-user facilities, than is possible with current large LWR designs. The smaller SMR site footprints and power outputs may also help make SMRs an effective electrical generation alternative for existing sites with small, aging coal-powered plants. This section illustrates the use of OR-SAGE to explore these beneficial characteristics of SMRs. For this study, the following siting-requirement changes were considered reasonable or worthy of consideration for the SMR designs, as noted in Sect. 2.1:

1. SMR site with a population density less than or equal to 500 people per square mile, including a 10-mile buffer, compared to current guidelines recommending a 20-mile buffer;

2. SMR site slight slope of less than or equal to $18 \%$ compared to a slope of less than or equal to $12 \%$ for a large reactor site ${ }^{5}$

3. SMR design cooling water requirement of $65,000 \mathrm{gpm}$ compared 200,000 gpm for a large reactor site ${ }^{5}$

4. SMR site located within 5 miles of an airport compared to 10 miles for a large reactor site 5 plus areas used by military bases (since it may be desirable to use SMRs to remove some defense installations from the grid);

5. SMR design capable of accommodating a $0.5 \mathrm{SSE}$ compared to $0.3 \mathrm{~g}$ for a large reactor site; and

6. SMR site footprint of 50 acres compared to 500 acres used for large reactor sites. ${ }^{5}$

\subsection{Comparison to EPRI Study Large Reactor Results}

ORNL evaluated potential siting options for various electrical generating sources, as noted previously. ${ }^{5}$ Suitable land areas for large nuclear power reactors are shown in Fig. 44. As documented in Table 1, these areas comprise about $21.6 \%$ (approximately 370 million acres) of the contiguous United States prior to aggregating the land for a specific plant footprint. Clearly, the land area depicted in green in Fig. 44 would also support siting SMRs since the large reactor SSEC bound the SMR SSEC criteria. However, siting advantages offered by SMRs increase the land area suitable for small reactors to $33.4 \%$ without aggregating the land for a specific plant footprint (highlighted in yellow in Fig. 45). This is the same nominal bounding SMR base map as shown in Fig. 19, recolored to show the split between large and SMR-only candidate areas. The yellow area in Fig. 45 is pulled out separately and shown as the SMRonly base map area in Fig. 46. This represents $11.8 \%$ of the contiguous United States, which is a significant expansion of the available area for siting nuclear power plants (154\% of the initial $21.6 \%$ of the contiguous United States calculated for large reactors ${ }^{5}$ ). Analysis of this SMR-only base map candidate siting area is the subject of this report section. Specifically of interest are the increases in SMR 
candidate land area associated with the differences in SMR siting requirements listed above compared to candidate land area associated with large reactors. This comparison is done without aggregating the land for the different footprint sizes of each reactor type, since the large reactors are based on a 500-acre footprint ${ }^{5}$ and the small reactors are based on a 50-acre footprint.

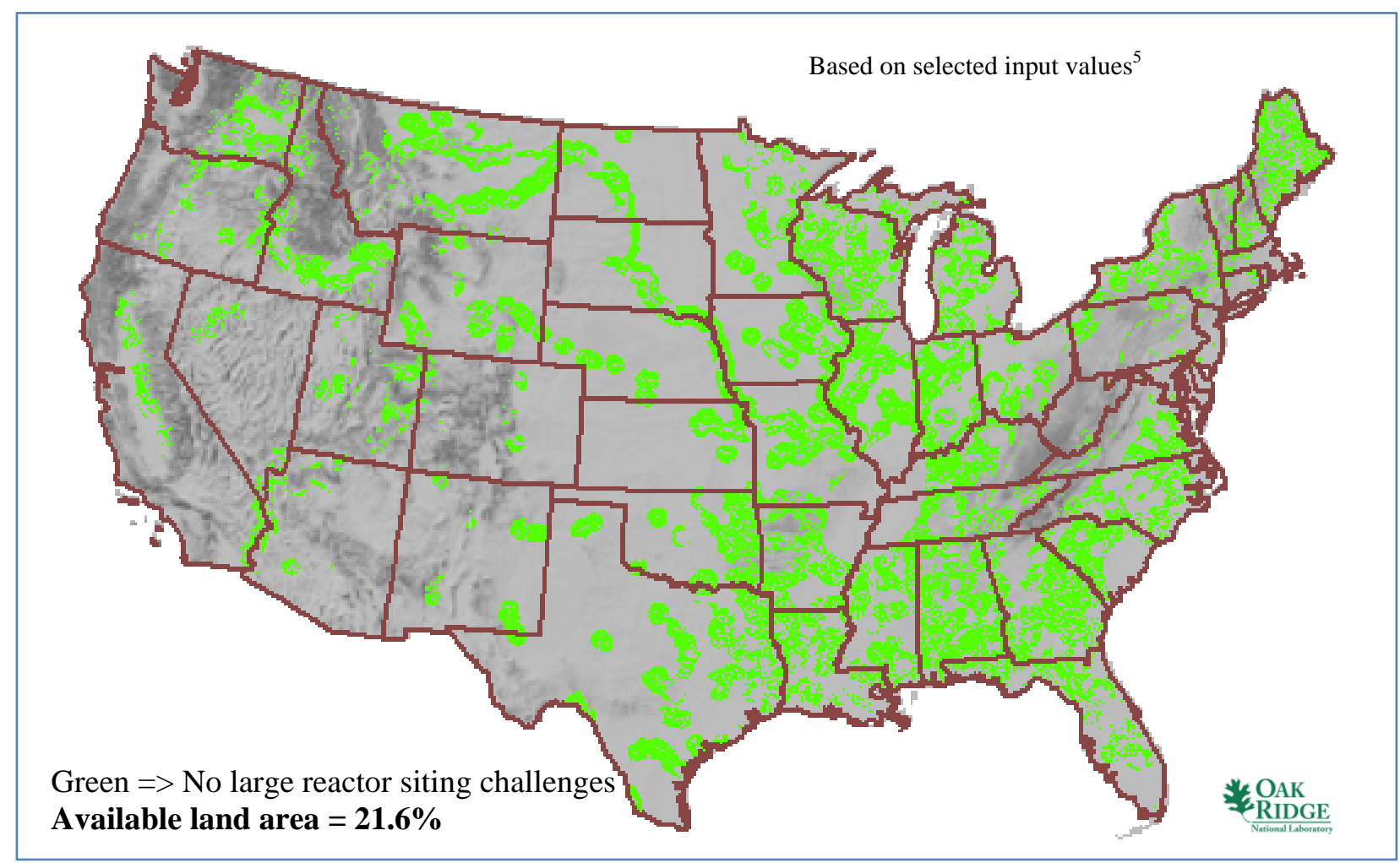

Fig. 44. Large reactor $[1600 \mathrm{MW}(\mathrm{e})]$ base map. ${ }^{5}$ 


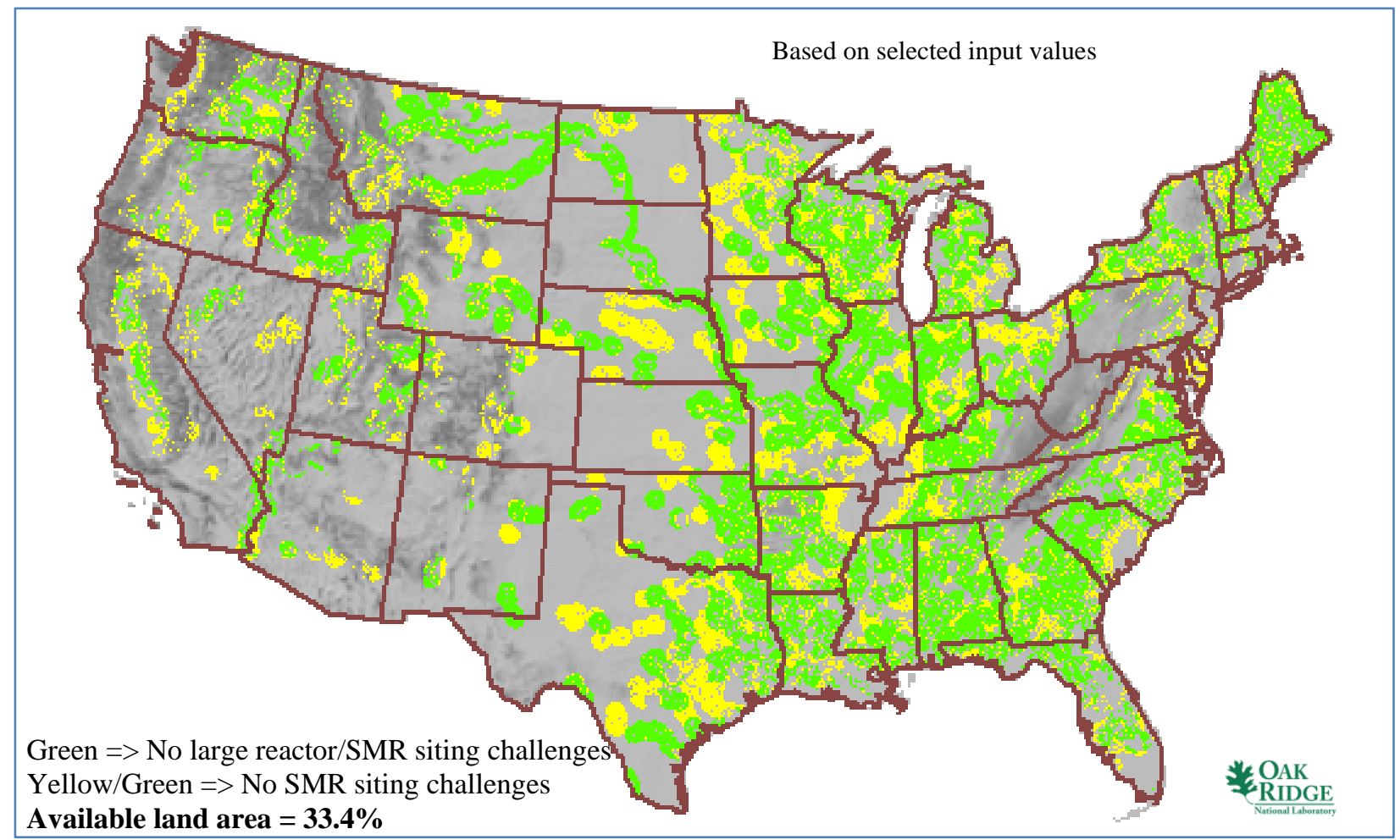

Fig. 45. SMR base map with large reactor base map overlay.

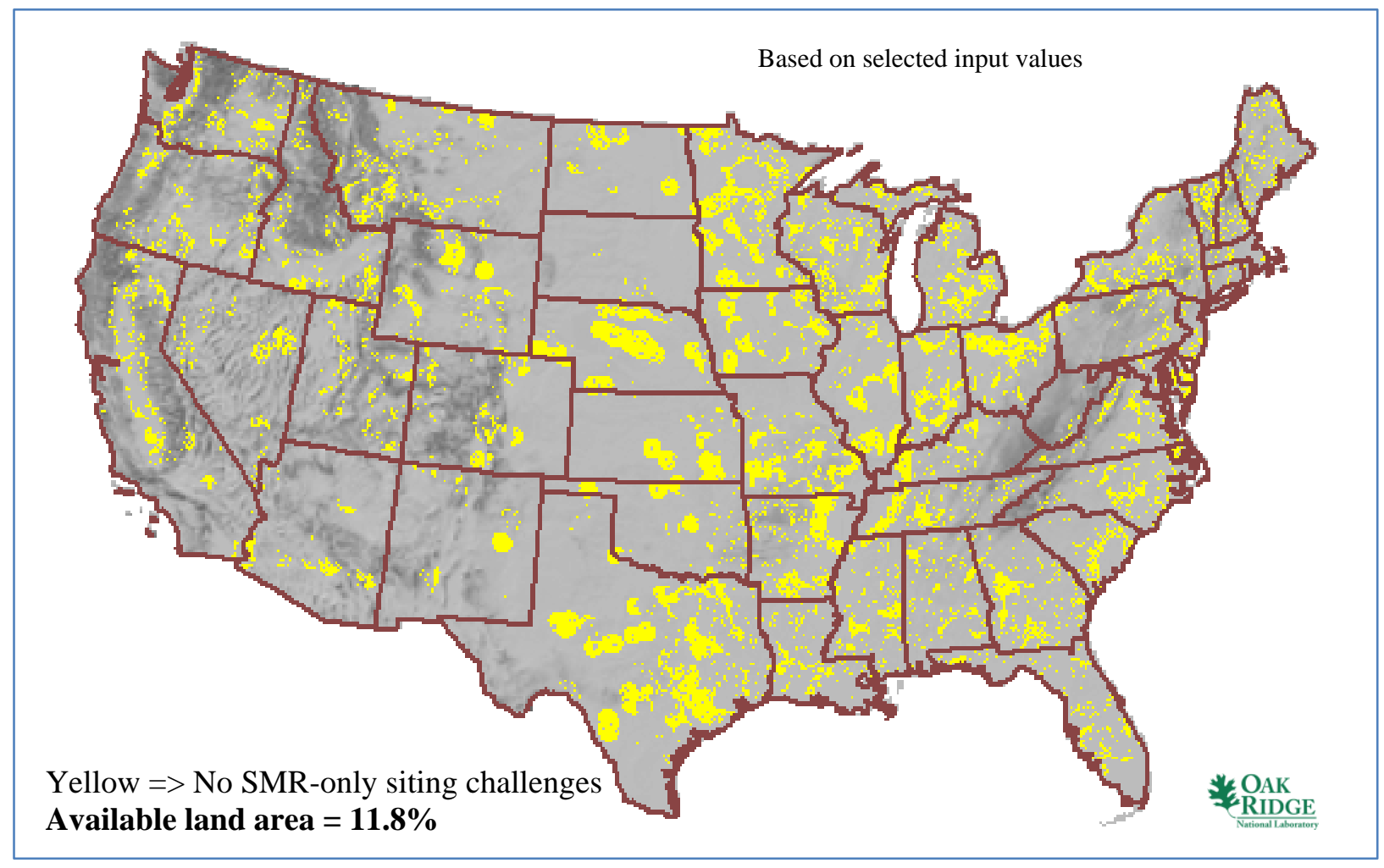

Fig. 46. Extraction of SMR base map (Fig. 45) where only SMRs (yellow) can be sited. 


\subsubsection{Effect of Reduced Population Buffer}

NRC siting guidance ${ }^{8}$ recommends calculating the population density within 20 miles of the site and excluding areas with population densities of greater than 500 people per square mile. Current SMR vendors identify the ability to replace smaller, aging coal plants with SMRs having similar capacity and a similar footprint as an advantage of SMR iPWR designs. In order to provide this function, SMRs will need to be located closer to population centers where many of these coal plants already exist and into which populations have expanded. Arguments for allowing SMRs to be closer to population centers typically include a reduced core damage frequency, elimination of large-break loss-of-coolant accident sequences, smaller source term, reduced early release fraction, reactor vessels and containment vessels that are located entirely underwater or below grade, and reactor buildings that are located partially or totally below grade. Thus, the appropriate evacuation zone for SMR iPWR designs is an issue still under discussion with the NRC staff. For the purposes of this study, a 10 mile buffer was deemed possible for SMR siting. The increase in SMR-only candidate land area associated with a 10-mile population buffer area vs a 20 -mile population buffer is $1.8 \%$ of the land area of the contiguous United States compared to the large reactor candidate land area, as shown in Fig. 47. The circular bands in Fig. 47 provide a visualization of the possibility of locating SMRs closer to the loads created by large population centers. These bands collectively represent 30 million acres of additional unaggregated land available for SMRonly siting as a result of potentially greater flexibility in population considerations. This can be compared to the base of 370 million acres ${ }^{5}$ available to consider siting large or small reactors (green space in Fig. 45). A smaller scale map of a portion of the eastern seaboard in Fig. 48 provides more detail of the SMR-only area made available by the change in the population SSEC criterion.

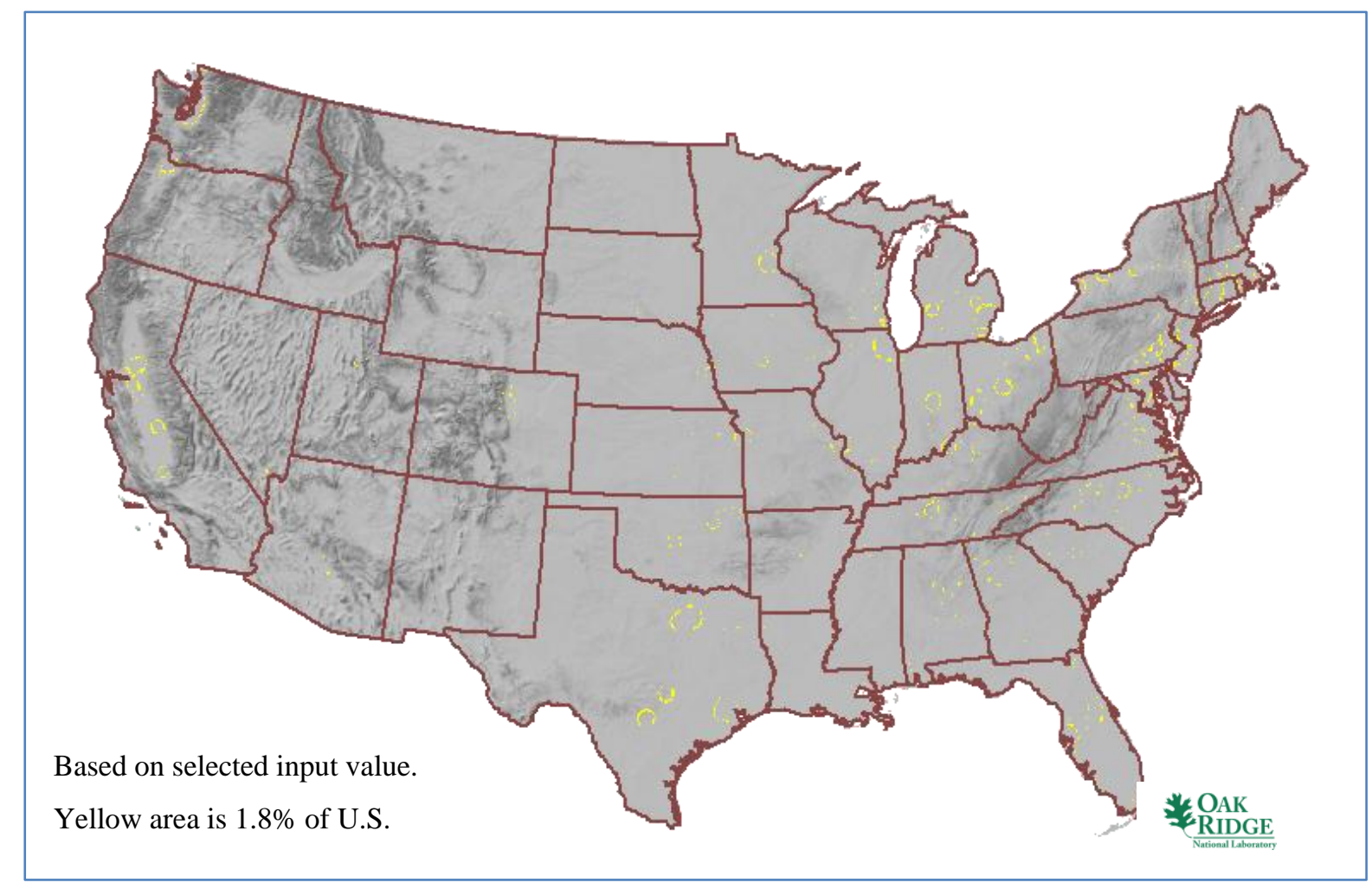

Fig. 47. SMR-only base map indicating contribution of increased land from lower population buffer. 


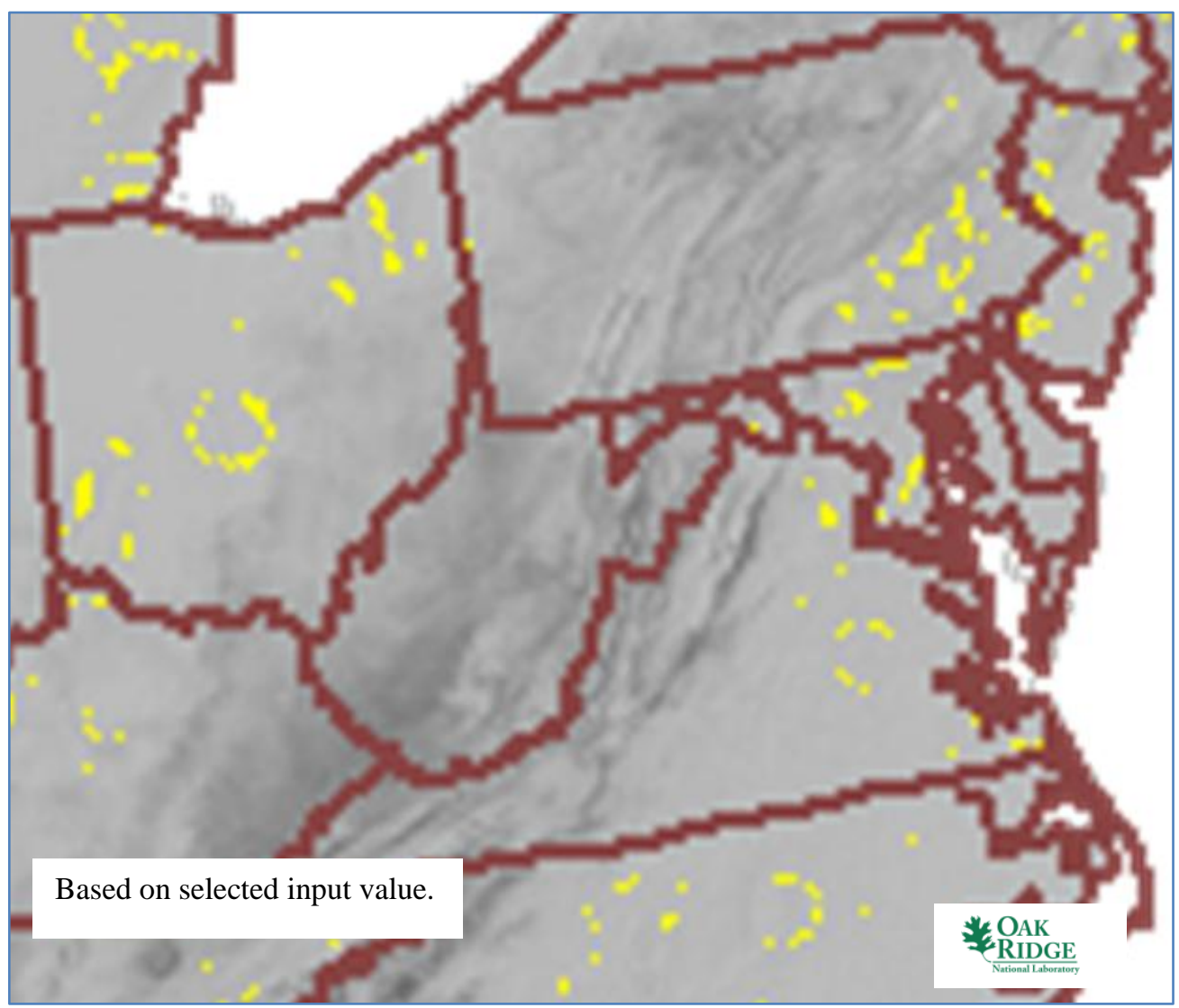

Fig. 48. Focused SMR-only base map indicating contribution of increased land from lower population buffer.

\subsubsection{Effect of Increased Slope Tolerance}

Typically, land areas with steeper slopes are avoided based on the economics of preparing sites for construction. Because the SMRs have a smaller footprint, land areas with slopes of up to $18 \%$ were permitted, compared to $12 \%$ for large reactors. The increase in SMR-only candidate land area associated with the increase in permitted slope is $1.4 \%$ of the land area in the contiguous United States compared to the large reactor candidate land area, as shown in Fig. 49. This could provide more flexibility to construct low-carbon power resources such as SMRs in areas limited by slope as shown by the accumulation of yellow dotted area around mountainous regions identified in the relief map in Fig. 49. These dotted areas collectively represent 23 million acres of additional unaggregated land available for SMR siting consideration as a result of greater flexibility in the value allowed for slope. 


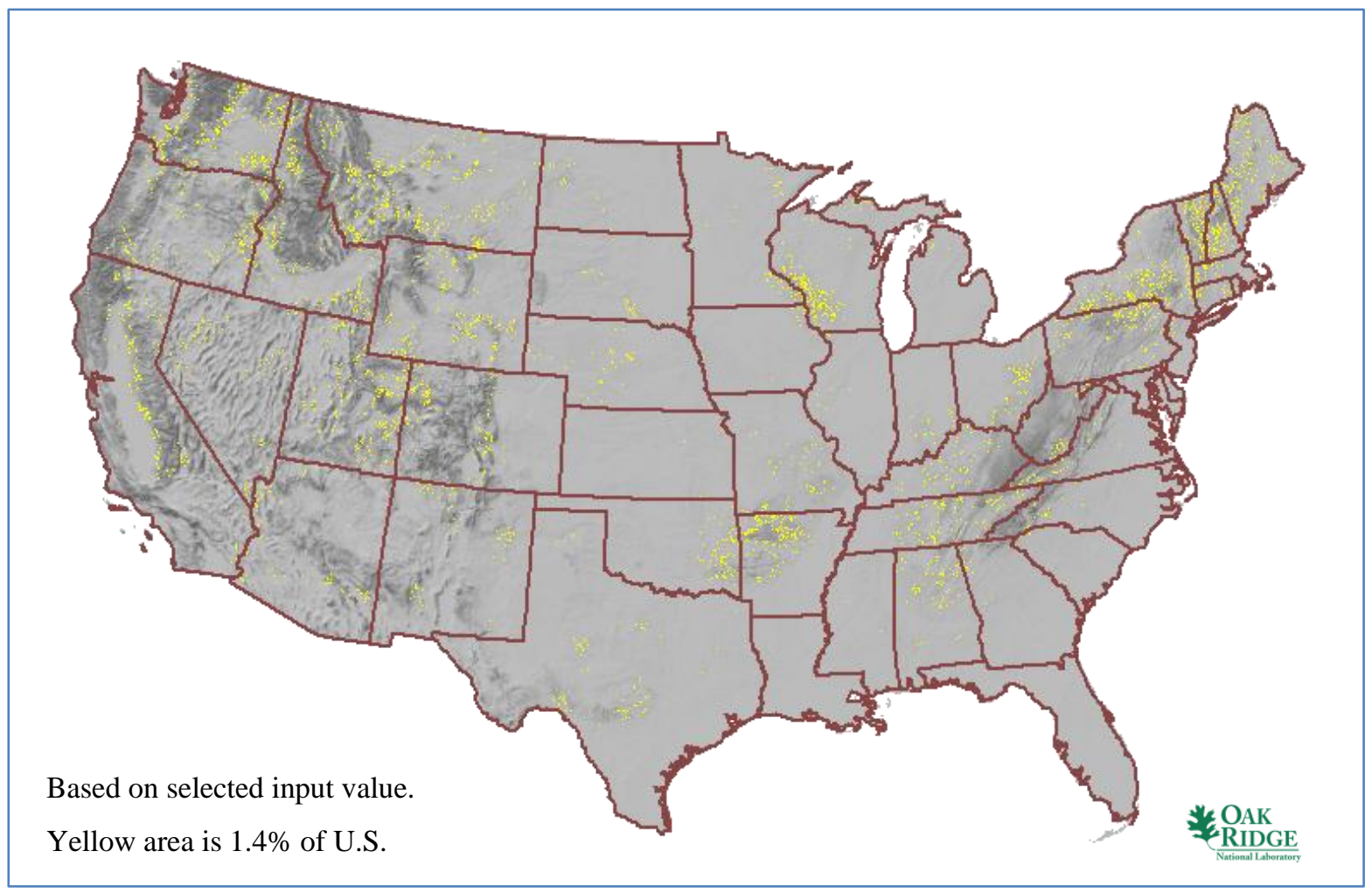

Fig. 49. SMR-only base map indicating contribution of additional land from increased slope tolerance.

\subsubsection{Effect of Reduced Cooling Water Requirement}

The model SMR used in this study has a nominal output of $540 \mathrm{MW}(\mathrm{e})$. This is representative of a 12-unit NuScale SMR plant which is the largest of the SMR designs under consideration and, therefore, bounds the current SMR designs. Cooling water makeup requirements are proportional to plant output; therefore, this representative SMR design has a cooling water makeup requirement of approximately 65,000 gpm. This is about one-third of the cooling water makeup requirement of the large reactor base case $\left(200,000 \mathrm{gpm}^{5}\right)$. A reduced cooling water makeup requirement results in expanded siting options compared to the large reactor case. The increase in SMR-only candidate land area associated with the reduced cooling water requirements is $7.7 \%$ of the contiguous U.S. land area compared to the large reactor candidate land area, as shown in Fig. 50. An expanded analysis of cooling water requirements and resources is the subject of Sect. 2.3 and Chapter. 3 of this report. Unfortunately, increased availability of cooling water does not necessarily coincide with proximity to load centers. However, the additional $7.7 \%$ of the contiguous U.S., or approximately 132 million acres, is almost 85\% of the land area of Texas. With appropriate transmission availability, this factor greatly expands the opportunity for SMR siting. 


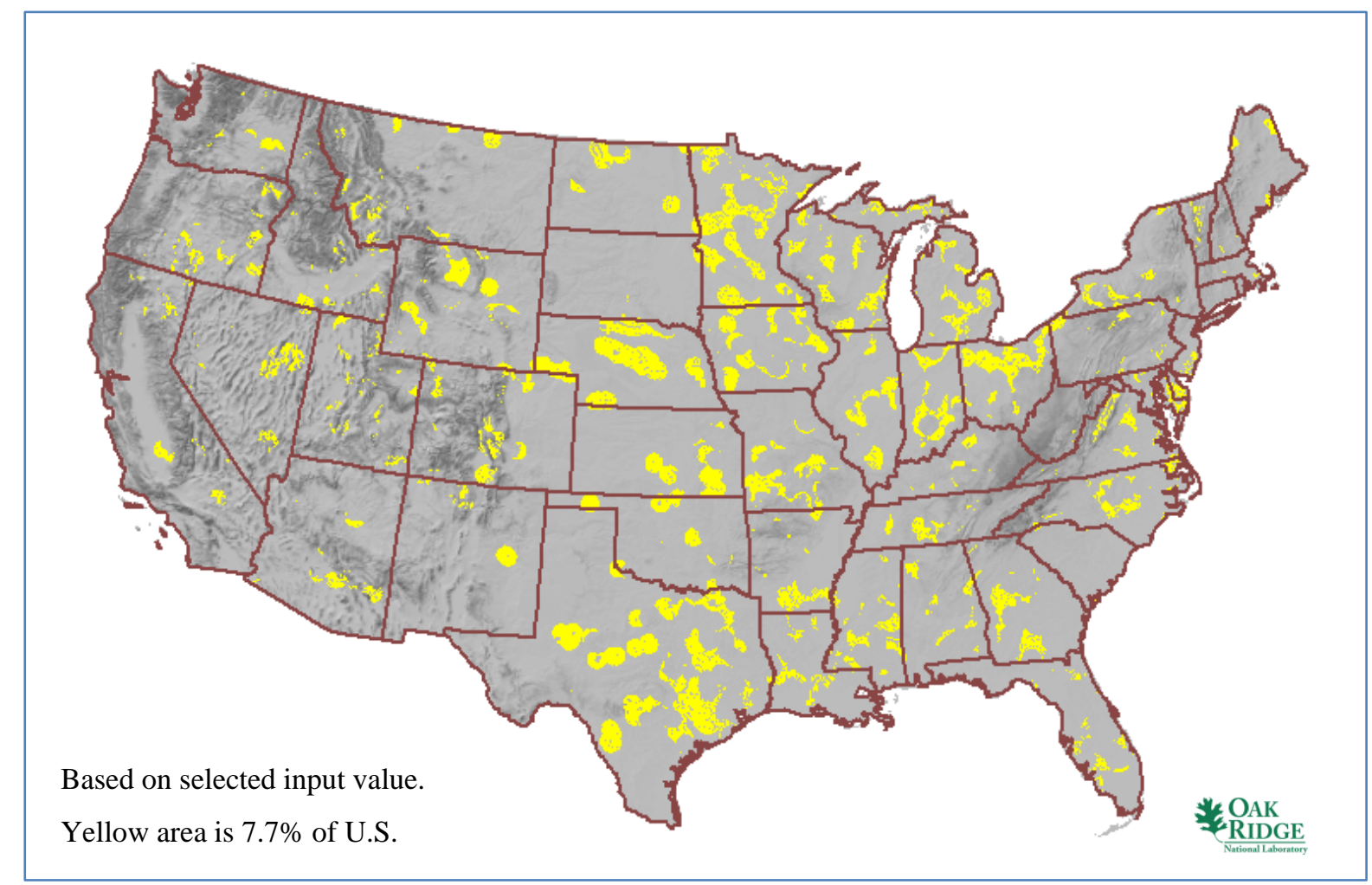

Fig. 50. SMR-only base map indicating contribution of increased land from lower makeup water requirements.

\subsubsection{Effect of Reduced Hazardous Area Exclusions}

The large reactor siting characterization study excluded areas near potentially hazardous facilities or operations, such as airports, oil refineries, and military bases. For this study, SMRs are viewed as an option for providing power to military bases, so military bases were not excluded from consideration. Also, because of their smaller footprint and more protected below-grade construction, a closer distance to airports (5 miles vs 10 miles for large reactors) was considered. The increase in SMR-only candidate land area associated with inclusion of military bases and closer proximity to airports is $0.7 \%$ of the contiguous U.S. land area as shown in Fig. 51. This collectively represents about 12 million acres of additional unaggregated land available for SMR siting consideration as a result of greater flexibility in hazardous operations. While the increased land area is smaller than other SSEC factor comparisons, it still represents a significant opportunity to provide power to significant consumers such as the military or industry near transportation hubs using SMRs. 


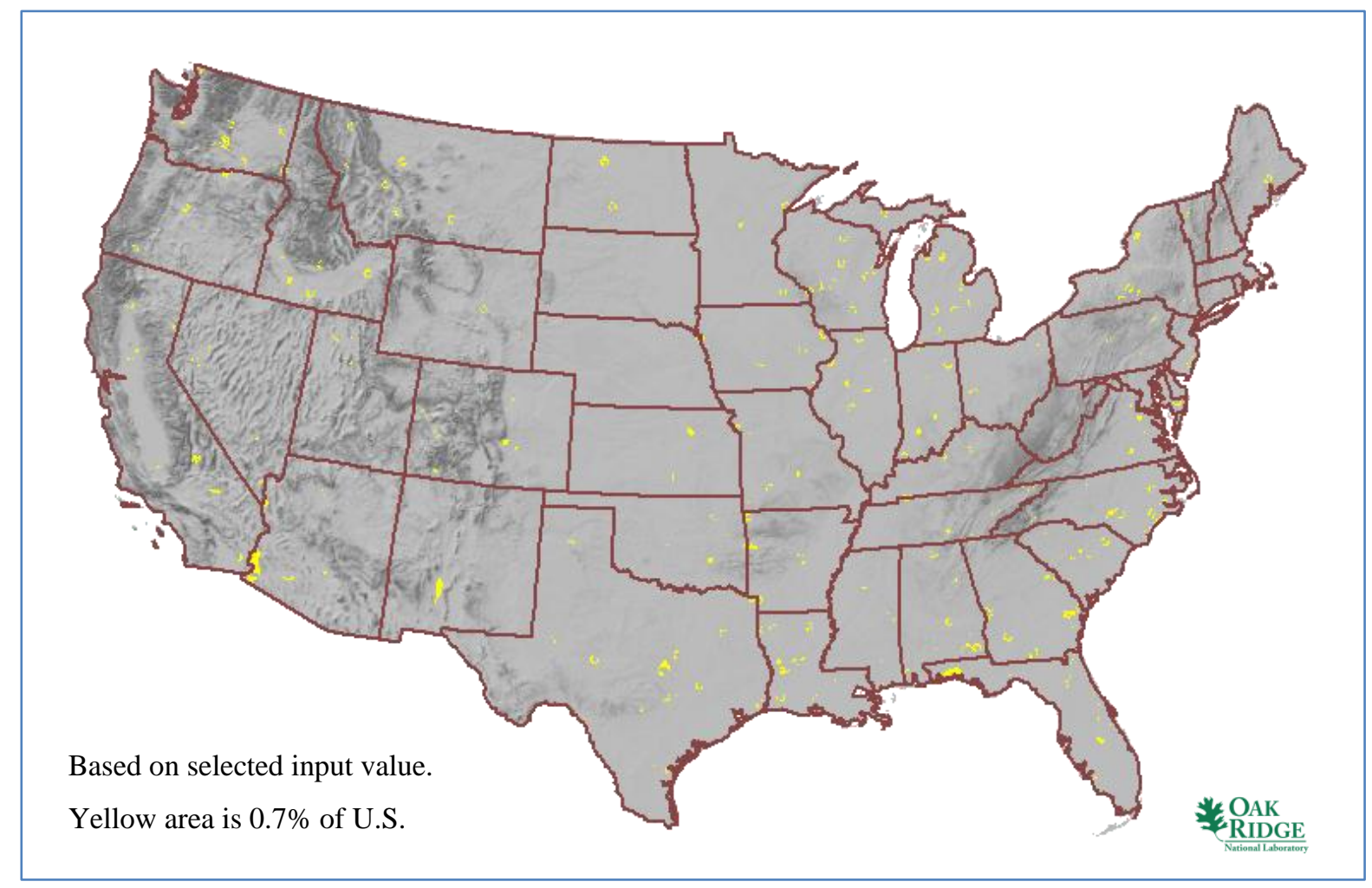

Fig. 51. SMR-only base map indicating contribution of increased land from military bases and closer proximity to airports.

\subsubsection{Effect of Greater Seismic Tolerance}

The smaller structures associated with typical SMR designs and associated below-grade construction may offer greater tolerance and capability to handle higher seismic conditions than large reactors. For this study, candidate sites with $0.5 \mathrm{~g} \mathrm{SSE}$ peak ground acceleration were considered and were compared to $0.3 \mathrm{~g}$ SSE peak ground acceleration for large reactors. ${ }^{5}$ The increase in SMR-only candidate land area associated with greater earthquake peak ground acceleration tolerance is $0.5 \%$ of the contiguous U.S. land area as shown in Fig. 52. This collectively represents approximately 8 million acres of additional unaggregated land available for SMR siting consideration as a result of greater flexibility in seismic tolerance. 


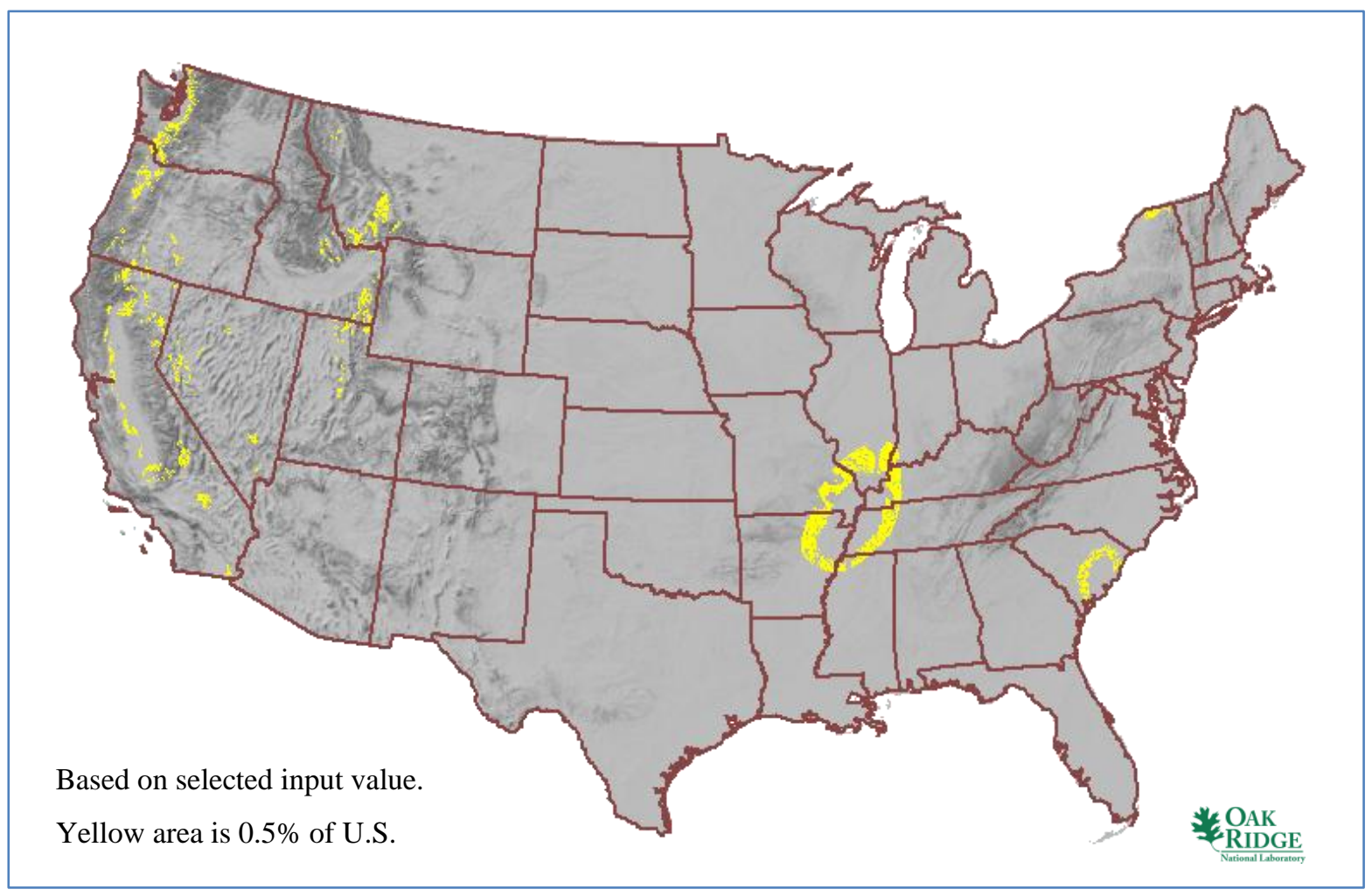

Fig. 52. SMR-only base map indicating contribution of increased land from relaxed SSE peak ground acceleration.

\subsubsection{Summary of SMR-Only Base Map Area Characterizations}

Table 5 presents a breakdown of the SMR-only land area by SSEC, as modified specifically for SMRs. Table 5 illustrates where additional land areas are available as a function of the individual SSEC. The lower stream flow requirement for the SMRs provides the greatest increase in land area-about $65 \%$ of the total increase in land area compared to large reactor candidate siting areas. The possibility of siting SMRs closer to population centers accounts for about $15 \%$ of the increase. Potential tolerance to higher land slopes within a smaller site footprint accounts for about $12 \%$ of the increase. Six percent of the increase can be accounted for by including military base land area and by allowing closer proximity to airports. The potential greater tolerance for SMRs for earthquake peak ground accelerations accounts for about $4 \%$ of the increase.

The step-down histogram shown in Fig. 17 for the effects of the individual SMR SSEC layers was revised in Fig. 53 to show the fraction of the overall percentage of available land suitable for SMR sites (light green) distinguished from the land suitable for large reactor sites (dark green). Since the SSEC layers are independent, the shape of the cumulative histogram is strictly determined by the order in which the SSEC layers (steps) are applied. Likewise, since the land reduction shown in each step is cumulative, the difference shown between SMRs and larger LWRs in the individual steps is dependent on the order of the steps. However, the end result at step 10 is the same no matter the SSEC layer application order. The five exclusion layers modified to reflect SMR-specific factors are highlighted in Fig. 53.

A cursory review of the potential sites by state as presented in Fig. 46 was performed. It is observed that there is significant siting potential added when considering SMRs. Every state in the contiguous United States contains candidate area sites for building SMRs where larger reactors do not meet the SSEC values established for that group of reactors. 
Table 5. SMR-only land area characterization

\begin{tabular}{|l|c|c|}
\hline \multicolumn{1}{|c|}{ Criteria } & $\begin{array}{c}\text { Increase in SMR candidate } \\
\text { area compared to large LWRs } \\
\text { (percent of total U.S. land) }\end{array}$ & $\begin{array}{c}\text { Breakdown of 11.8\% increased } \\
\text { SMR candidate Area by SSEC } \\
\text { (percent) }\end{array}$ \\
\hline Population & 1.8 & 14.8 \\
\hline Slope & 1.4 & 11.5 \\
\hline Stream Flow & 7.7 & 65.4 \\
\hline $\begin{array}{l}\text { Military bases and airport } \\
\text { proximity }\end{array}$ & 0.7 & 5.8 \\
\hline Safety shutdown earthquake & 0.5 & 4.0 \\
\hline Total & $12.1^{*}$ & $101.5^{*}$ \\
\hline
\end{tabular}

"The SMR-only land area is about $11.8 \%$ of contiguous United States or 202 million acres. Numbers add to greater than $11.8 \%$ and $100 \%$ due to double counting shared areas.

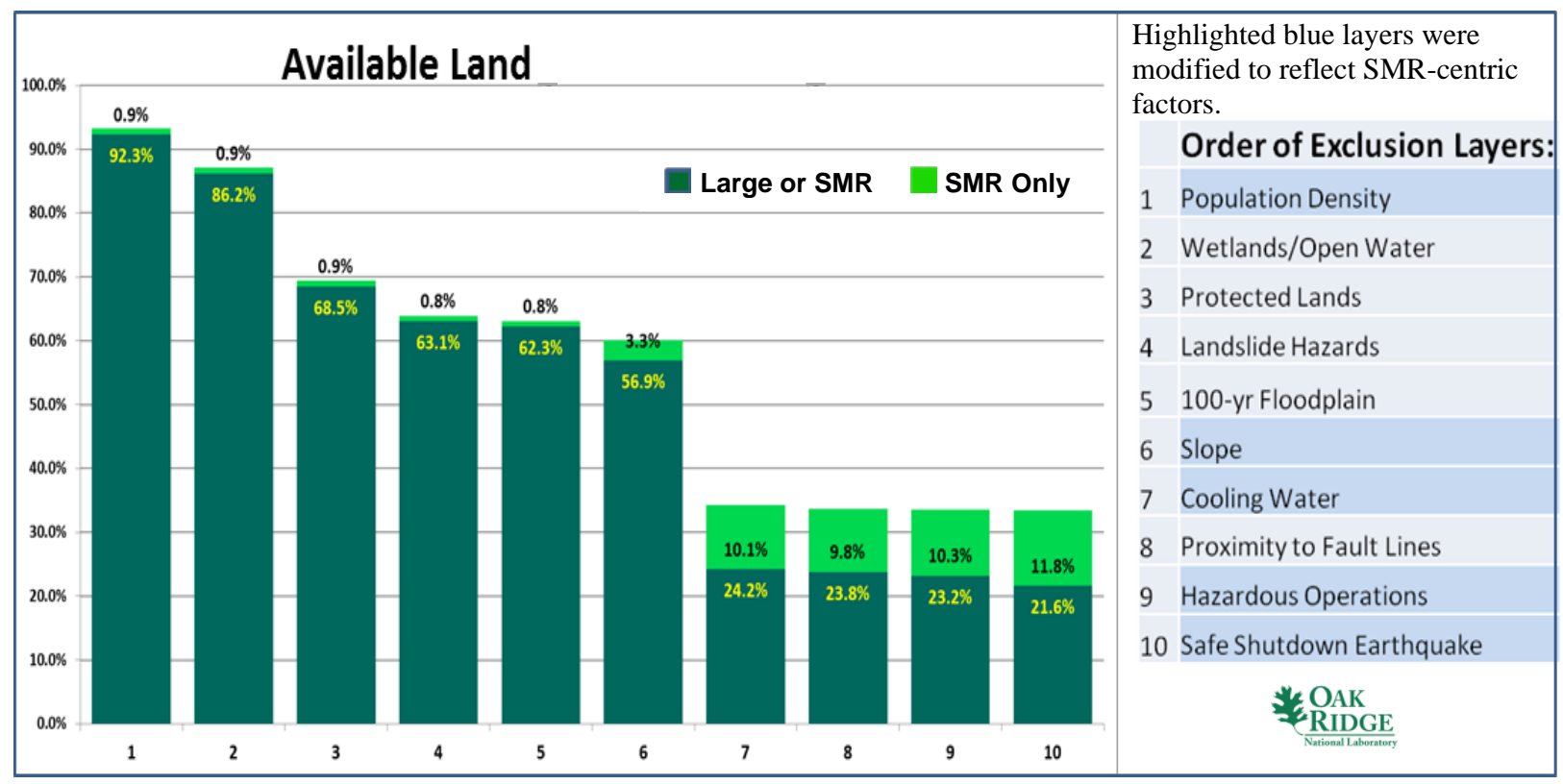

Fig. 53. SMR step-down histogram detailing effect of SMR centric SSEC values.

\subsection{Proximity to High Population (and High Electrical Demand) Areas}

The DOE Energy Information Administration (EIA) uses population data and population forecasts to predict where energy demands and subsequent installed electricity capacity is likely to grow in 22 electricity market regions. Based on EIA data, ${ }^{13}$ each individual is expected to use an average of $3.19 \mathrm{~kW}(\mathrm{e})$ of installed generation capacity in 2015 . Therefore, it is reasonable to use OR-SAGE to review similar population/electricity demand correlations.

OR-SAGE can be used to model areas of potentially higher electrical load demand typically associated with higher density population areas. Having generation capability located close to loads requires lower transmission infrastructure investments and can help minimize grid disturbances associated with wheeling power long distances. The SMR-only base map areas in Fig. 46 are overlaid onto areas with high

${ }^{13}$ Annual Energy Outlook 2012, DOE/EIA-0383(2012), June 2012. 
population density from Fig. 7 as shown in Fig. 54. This provides a national view of areas of high population/power density areas with SMR siting possibilities.

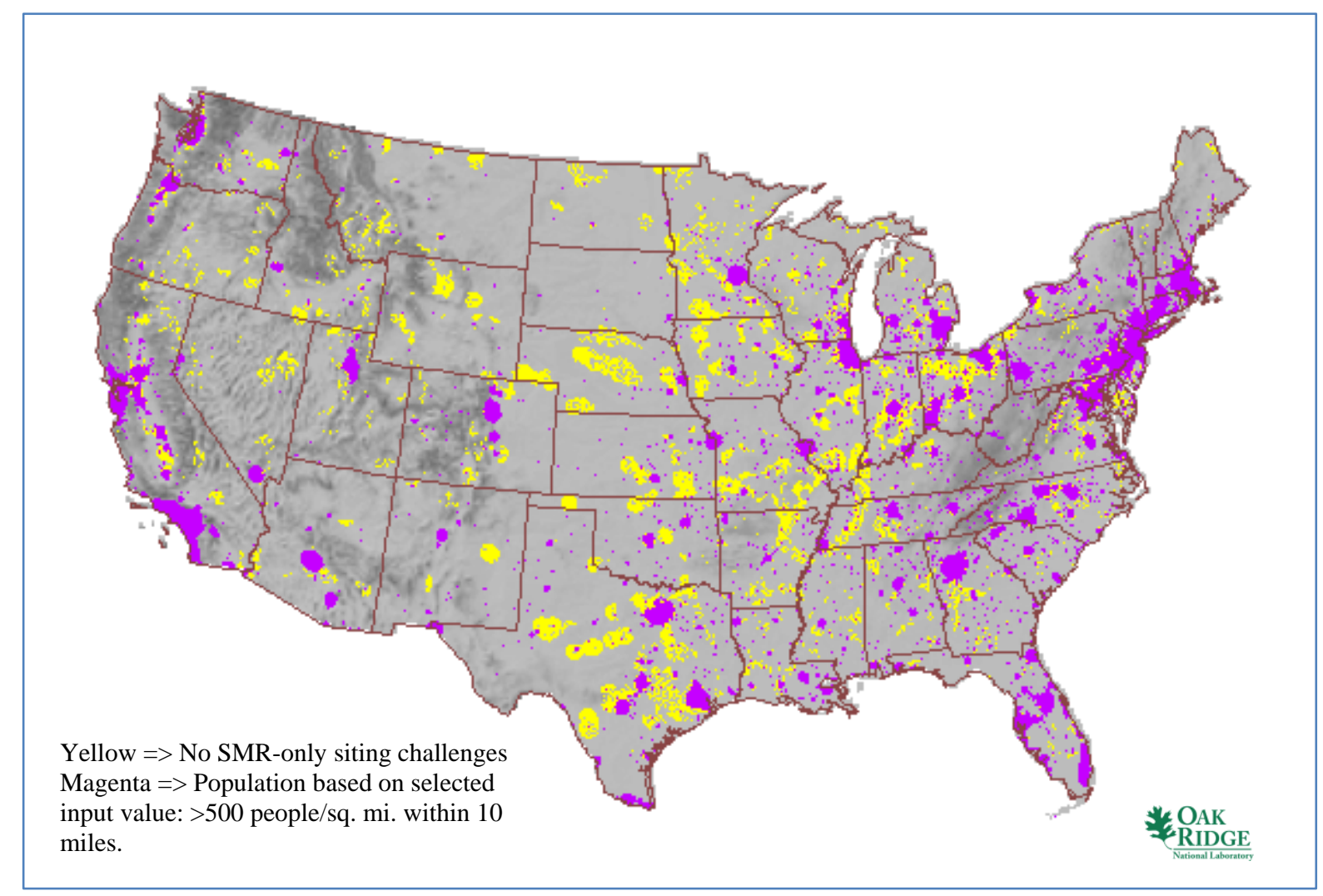

Fig. 54. SMR-only base map combined with areas of high population density (2010).

\subsubsection{Proximity to Areas of Projected High Population Growth (and Areas of High Electrical Load Growth)}

SMRs can potentially be sited closer to areas of projected population growth. Their smaller cores combined with underground siting yields a smaller source term for this class of reactors. Therefore, the potential for a release is theoretically lower and the consequences of a release are theoretically less severe. SMR-only candidate land areas together with a projection of population growth through the year 2035 are shown in Fig. 55. 


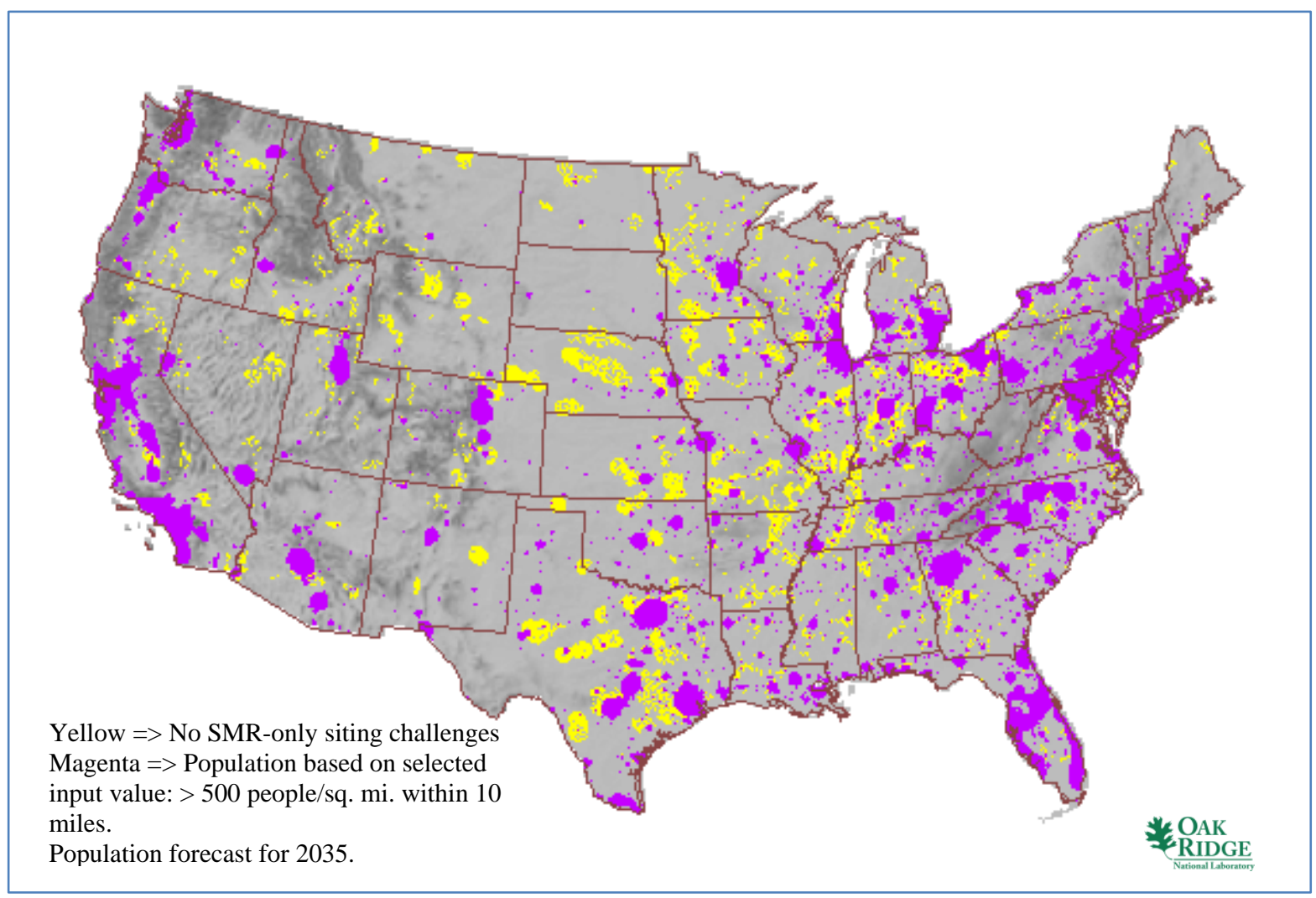

Fig. 55. SMR-only base map combined with areas of high population density (2035).

An additional illustration is provided in Fig. 56, which shows the change in population between 2010 and 2035 in red with the area suitable for siting all reactors shown in green and the SMR-only area shown in yellow for the southeastern United States. Typically, the red rings represent projected population growth outward from areas of high population density from 2010 to 2035 (increased difference - delta - in land obtained by subtracting the magenta area in Fig. 54 from that of Fig. 55). Base map areas where the red rings abut green or yellow candidate site areas could be well suited for reactor deployment from the perspective of being close to locations of expected load growth. Plant sites close to load can help reduce electrical transmission infrastructure construction and minimize the likelihood of grid-based disturbances associated with long-distance wheeling of power from one area to another.

Harder to see in Fig. 56 are areas in blue, such as the areas at the bottom left of the figure in Texas and scattered throughout the figure, where decreases in population are projected. These areas could contain suitable sites, such as brownfield industrial sites, for future nuclear site development. Areas in blue are a little more distinguishable in the close-up view of Alabama in Fig. 57. 


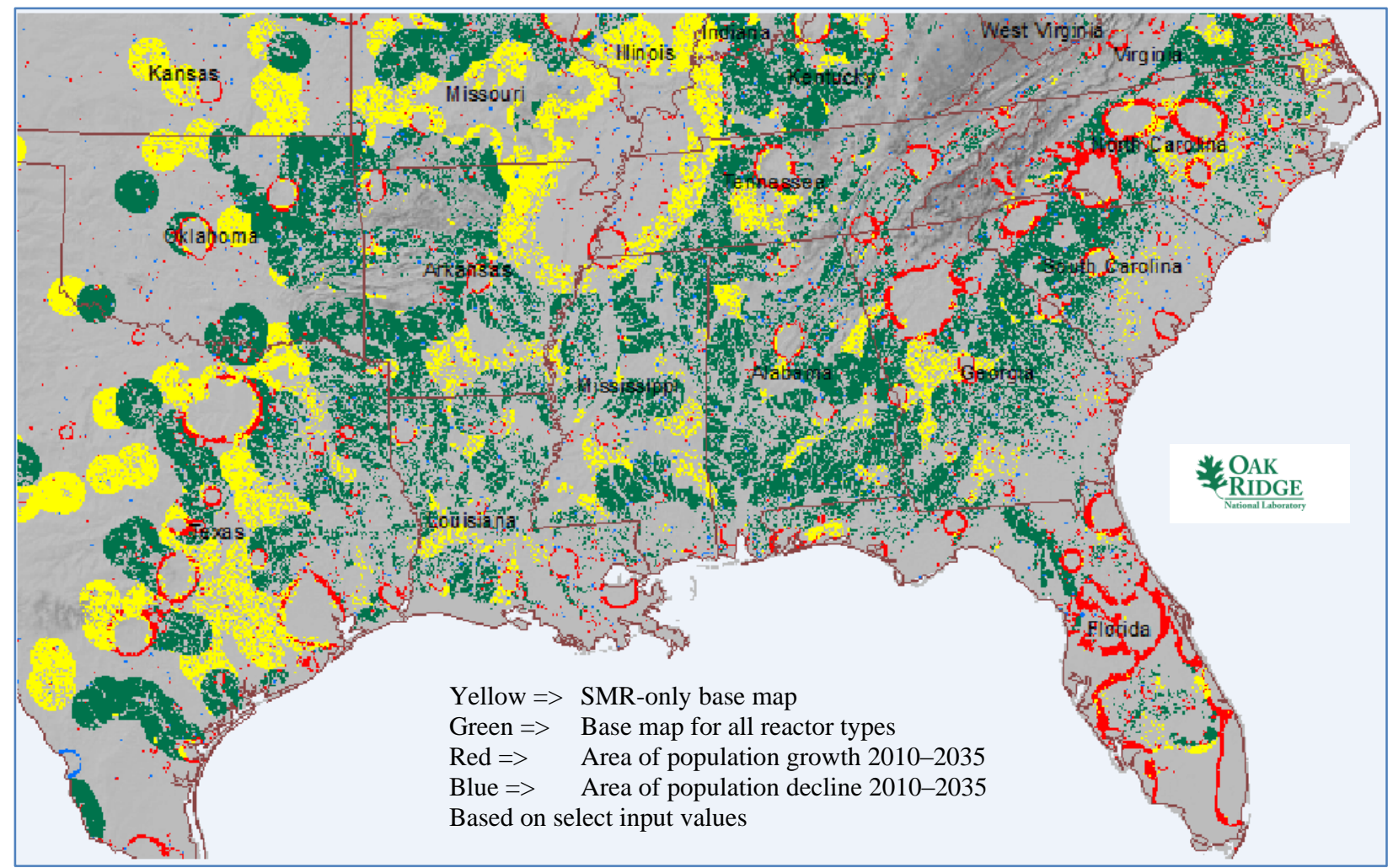

Fig. 56. Southeast SMR base map (yellow and green) with areas of high population density (2035).

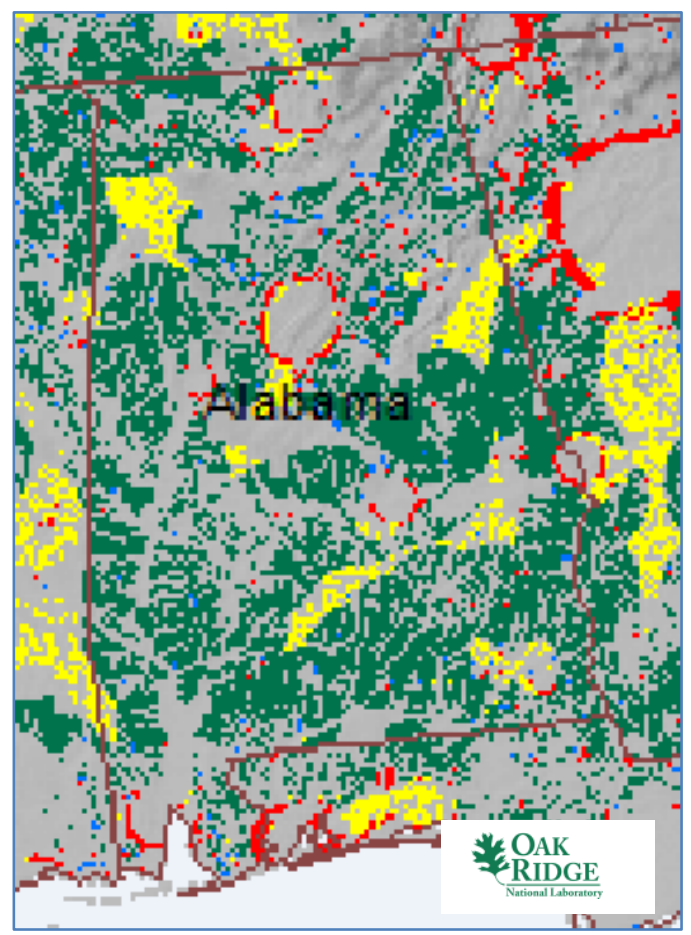

Fig. 57. Alabama SMR base map (yellow and green) with areas of high population density (2035). 


\subsubsection{Proximity to Transmission Lines}

A straight-forward analysis of proximity of SMR-only area to the existing transmission infrastructure was performed. A map of existing 110-230 kV transmission lines in the contiguous United States is shown in Fig. 25. A map of SMR-only aggregate candidate areas and 110-230 kV transmission lines with a 10-mile buffer area is shown in Fig. 58. Approximately $74 \%$ of SMR-only aggregate candidate sites are with 10 miles of existing 110-230 kV transmission lines and, as discussed in Sect. 2.2.2, 78\% of the entire SMR aggregate area is within 10 miles of current $110-230 \mathrm{kV}$ transmission lines. About $91 \%$ of the SMR-only aggregate candidate sites, and $93 \%$ of all SMR aggregated land, are within 20 miles of $110-230 \mathrm{kV}$ transmission lines. Therefore, most of the candidate area land added by the additional flexibility afforded by the SMR designs is within 20 miles of existing $110-230 \mathrm{kV}$ transmission lines.

Likewise, SMR-only aggregate candidate areas and transmission lines greater than $230 \mathrm{kV}$ with a 10 - or 20-mile buffer area can be compared. In this case, just 54\% of the SMR-only aggregate candidate sites are within 10 miles of existing power lines greater than $230 \mathrm{kV} ; 76 \%$ of the SMR-only aggregate candidate sites are within 20 miles. These values slightly exceed the statistics for all SMR aggregate candidate area where $50 \%$ of the aggregated land is within 10 miles of an available extra high-voltage transmission line and $72 \%$ of the SMR aggregated land is within 20 miles of an available extra high-voltage transmission line.

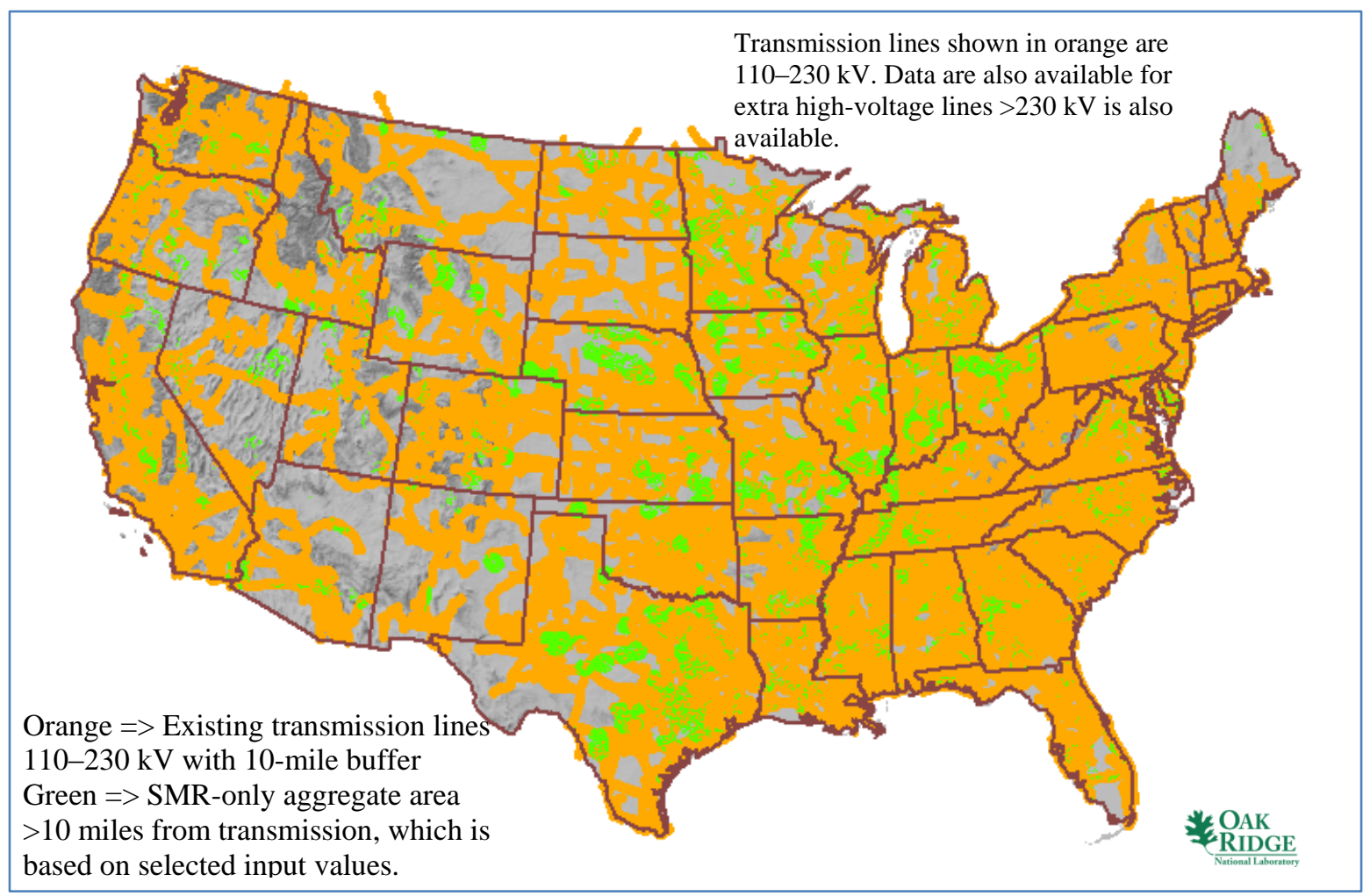

Fig. 58. Transmission lines (110-230 kV) with 10-mile buffer overlaid on SMR-only aggregate map. 


\subsection{Proximity to Transportation Resources}

Proximity of SMRs to existing rail infrastructure may also be examined in an analogous manner as done for electric transmission. Rail lines in the contiguous United States are shown in Fig. 21. A map showing the SMR-only aggregate candidate siting areas with rail lines plus a 10-mile buffer is shown in Fig. 59. Approximately $70 \%$ of all SMR-only aggregate candidate areas are within 10 miles of a rail line and, as discussed in Sect. 2.2.1, 73\% of the entire SMR aggregate area is within 10 miles of an available rail line. Approximately $84 \%$ of all SMR-only aggregate candidate areas and $88 \%$ of all SMR aggregated land are within 20 miles of a rail line. Therefore, the availability of rail transportation is similar for the SMR-only aggregate area and the entire SMR aggregate area illustrating that a large portion of potential SMR sites are within a reasonable distance of rail access.

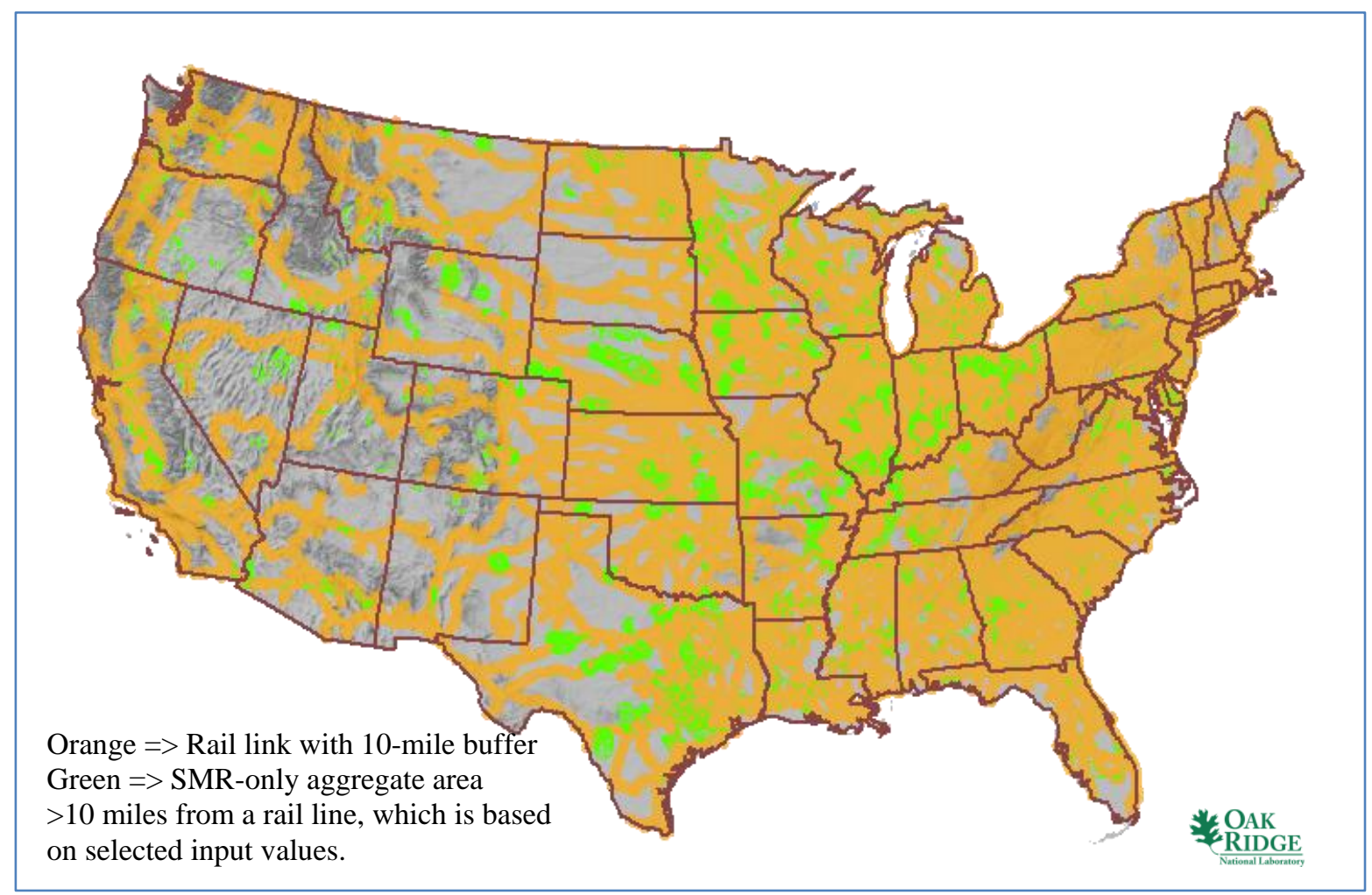

Fig. 59. Rail lines with 10-mile buffer overlaid on SMR-only aggregate map.

\subsection{Replacement of Older Coal Plants in Ohio and Nearby States}

Current SMR vendors have noted that a potential market for SMRs is the replacement of smaller, aging coal plants with a similar capacity and site footprint. In some cases, these older coal plants may have economic disadvantages associated with the addition of costly pollution control equipment. The OR-SAGE siting tool capability is illustrated in Fig. 60 , where all coal plants in Ohio and nearby states are overlaid onto a map showing candidate siting areas for large or small reactors (green area) and SMRs only (yellow area). Numerous opportunities for future replacements of coal plants with SMRs can be identified in Fig. 60. An added advantage is that the cooling water makeup requirements would essentially be a trade-off between the existing coal plant needs and the SMR cooling water makeup needs. In addition, if the coal plant is utilizing once-through cooling, downstream heating effects could be reduced with closed cycle cooling assumed for the SMR plants. 
As can be observed, there are a number of coal plants that overlay on SMR candidate areas. The next phase of work in these site suitability studies for DOE-NE will characterize a number of these coal sites across the United States more specifically identifying any challenges focusing on older and smaller plants.

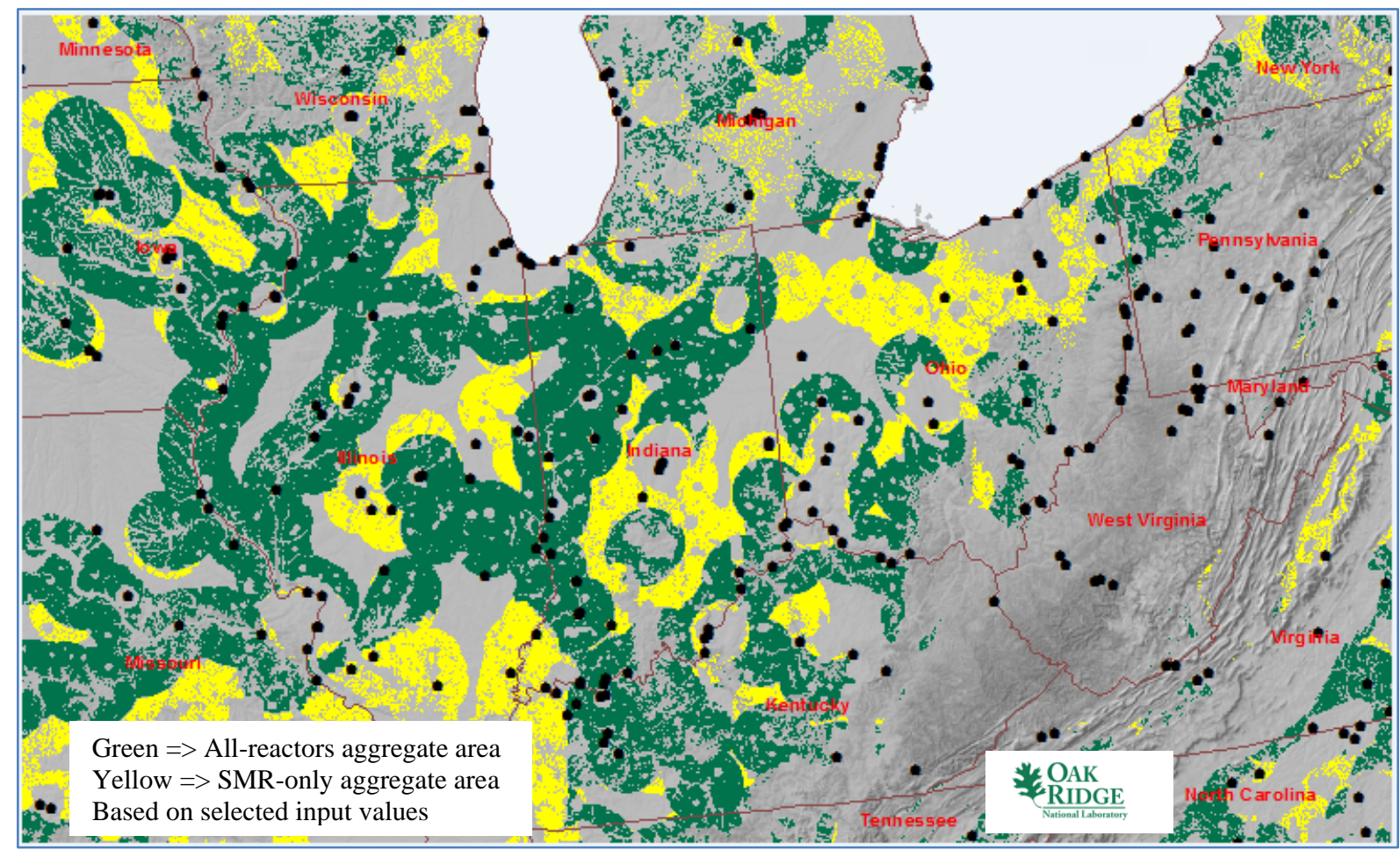

Fig. 60. SMR aggregate map colored to show the split between all (green) and SMR-only (yellow) candidate areas with all coal plant sites. 


\section{CLIMATE, FLOODING, AND FUKUSHIMA CONSIDERATIONS}

Based on events and environmental-related conditions that have impacted existing operating nuclear power plants, this section of the report discusses in general terms how OR-SAGE might model such impacts. In addition to flooding and seismic considerations, new plant designs must also address an external threat of intentional aircraft crashes. Longer term, what might the impact be related to any potential effect of global climate changes such as more severe storms, water availability, or rising ocean levels.

For example, two nuclear power stations in the Midwest experienced river flooding conditions in 2011. One of these plants delayed startup from a refueling outage because of the forecast flooding and remained shut down a year later for reasons including flood response issues. Another nuclear power station in the eastern United States experienced a seismic event in 2011 that caused peak ground accelerations at some frequencies that exceeded the station's design basis. A nuclear power station in Japan was shut down for 21 months following an earthquake in July 2007. And, of course, multiple units of the Japanese Fukushima Dai-ichi nuclear power station were severely damaged by the earthquake-generated tsunami in March 2011, after which all nuclear power stations in Japan were shut down for inspections and design reviews.

In response to the Fukushima accident in Japan, the NRC established a task force of senior staff to review the event and determine potential implications and lessons learned applicable to nuclear power plants in the United States. ${ }^{14}$ The task force also made recommendations for enhancing reactor safety, which NRC staff subsequently prioritized and, in some cases, expanded. ${ }^{15}$ Most of these recommendations pertain to concerns affecting reactors already in operation. Some, however, also pertain to environmental threats or conditions that are pertinent to planned or future reactor sites. The highest-priority recommendations affecting present reactor sites were for seismic and flood hazard evaluations. A long-term recommendation was also made to perform a 10-year confirmation of seismic and flooding hazards.

OR-SAGE supports the assessment of many conditions that could affect land suitable for siting nuclear power plants. For example, seismic data are continually being updated. EPRI, DOE, and the NRC released a new, joint seismic study in January 2012 that will help nuclear facilities in the central and eastern United States reassess seismic hazards. ${ }^{16}$ As noted by a summary report from LANL, "this study includes a new seismic source characterization model developed using a process with the goal of representing the full range of defensible data, models and methods to develop a seismic source model for different seismotectonic zones of the central and eastern United States. A set of alternatively weighted seismotectonic zones were defined based on earthquake recurrence rate, maximum earthquake magnitude, expected characteristics of future earthquakes (style of faulting, rupture orientation, depth distribution) and probability of active tectonic features." A representation of the seismotectonic and repeat large magnitude earthquake (RLME) source zones is shown in Fig. 61. This can be compared to the current SMR SSEC seismic layer shown in Fig. 16. A GIS dataset for this updated information is being prepared and will be incorporated into OR-SAGE when it is available.

\footnotetext{
${ }^{14}$ U. S. Nuclear Regulatory Commission, Recommendations for Enhancing Reactor Safety in the $21^{\text {st }}$ Century-The Near-Term Task Force Review of Insights from the Fukushima Dai-ichi Accident, July 12, 2011, http://pbadupws.nrc.gov/docs/ML1118/ML111861807.pdf.

${ }^{15}$ U. S. Nuclear Regulatory Commission, Prioritization of Recommended Actions to be Taken in Response to Fukushima Lessons Learned, SECY-11-0137, October 3, 2011, http://www.nrc.gov/reading-rm/doc-collections/commission/secys/2011/20110137scy.pdf.

${ }^{16}$ U. S. Department of Energy, Electric Power Research Institute, U. S. Nuclear Regulatory Commission, Central and Eastern United States Seismic Source Characterization for Nuclear Facilities, NUREG 2115, January 2012, http://www.ceus-ssc.com.
} 


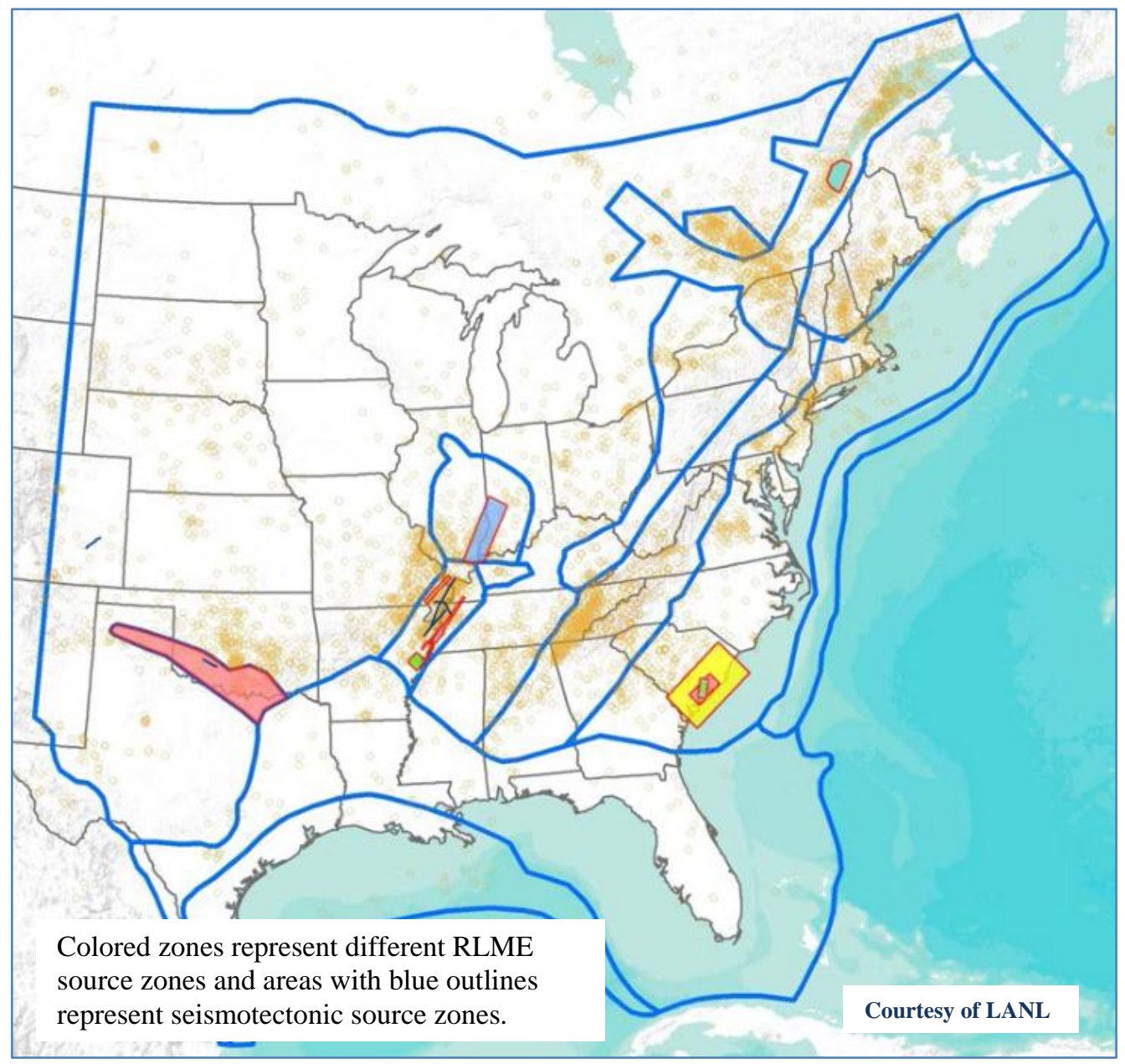

Fig. 61. Seismotectonic and RLME source zones of the central and eastern United States. ${ }^{11}$

Similarly, stream flows affected by high temperatures or drought conditions could be postulated and revised stream flow and flood plain information added to OR-SAGE as they become available. Potential effects of climate change, such as projected sea level rises throughout this century referenced by the U.S. Environmental Protection Agency ${ }^{17}$ could also be incorporated in OR-SAGE. As an illustration, a partial effect of a 4-foot rise in sea level by the year 2100 (approximately the median value in the range of EPAcited projections) was incorporated into the OR-SAGE model. A 4-foot sea level rise on land bordering the Atlantic, Pacific, and Gulf coasts of the United States produced a calculated reduction in SMR candidate site land area of just $0.01 \%$ of the contiguous United States. This magnitude of change is too small to be visible on the scale maps used in this report. Note that this is a limited assessment of sea level rise; it did not include impacts on coastal rivers and flood plains that could result in additional reductions in SMR candidate site land area.

\footnotetext{
${ }^{17}$ Future Climate Change, United States Environmental Protection Agency, http://www.epa.gov/climatechange/science/future.html\#sealevel.
} 


\subsection{Proximity to Dams}

The Fukushima accident in Japan is largely attributed to the tsunami flooding that followed the earthquake in March 2011. While the U.S. reactor sites are not generally thought to be susceptible to similar tsunami flooding, manmade lakes behind dams that power reactors utilize for makeup and cooling purposes might present a similar threat. The SMR SSEC layer avoiding the 100-year floodplain is an attempt to consider flooding potential. However, a catastrophic upstream or downstream dam break or overflow could provide another threat to reactor plant siting. Nuclear power plant environmental evaluations consider flood threats from many sources, such as tsunami, seiches, rivers, high rainfall in a watershed, and overflow of dams or failures of dams. These threats are evaluated in detail on a sitespecific basis.

For illustration purposes, the OR-SAGE tool was used to overlay an inventory of approximately 5400 dams with a maximum storage capacity greater than 5000 acre-feet from the U.S. Army Corps of Engineers (red squares) on the large reactor and SMR combined candidate siting areas shown in green in Fig. 62. Subsequently, these results were refined to show those dams that overlap the SMR aggregate map, as shown green in Fig. 63. It is possible in Fig. 63 that the dams could be upstream or downstream of the SMR aggregate land area and just outside of the aggregate map green area. Therefore, the potential effect of a dam nearby but not within the aggregate map area could also be potentially consequential. GIS applications are available that project the consequences of excess water injected into a region. Such an application could be coordinated with the OR-SAGE evaluation to further study the issue of flooding attributed to dams or to weight/score SMR candidate areas.

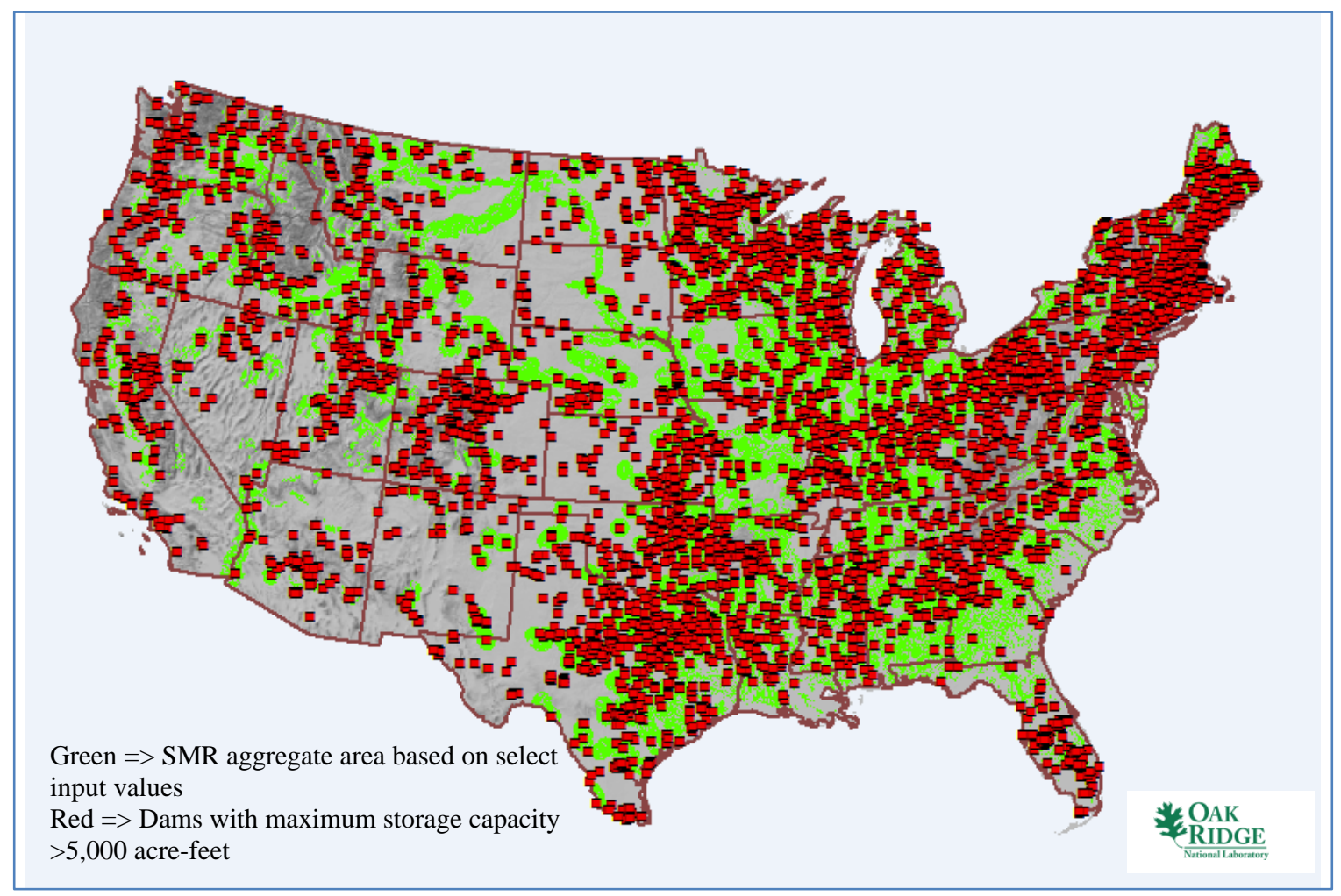

Fig. 62. SMR aggregate map and all U.S. dams with capacity of at least 5000 acre-feet. 


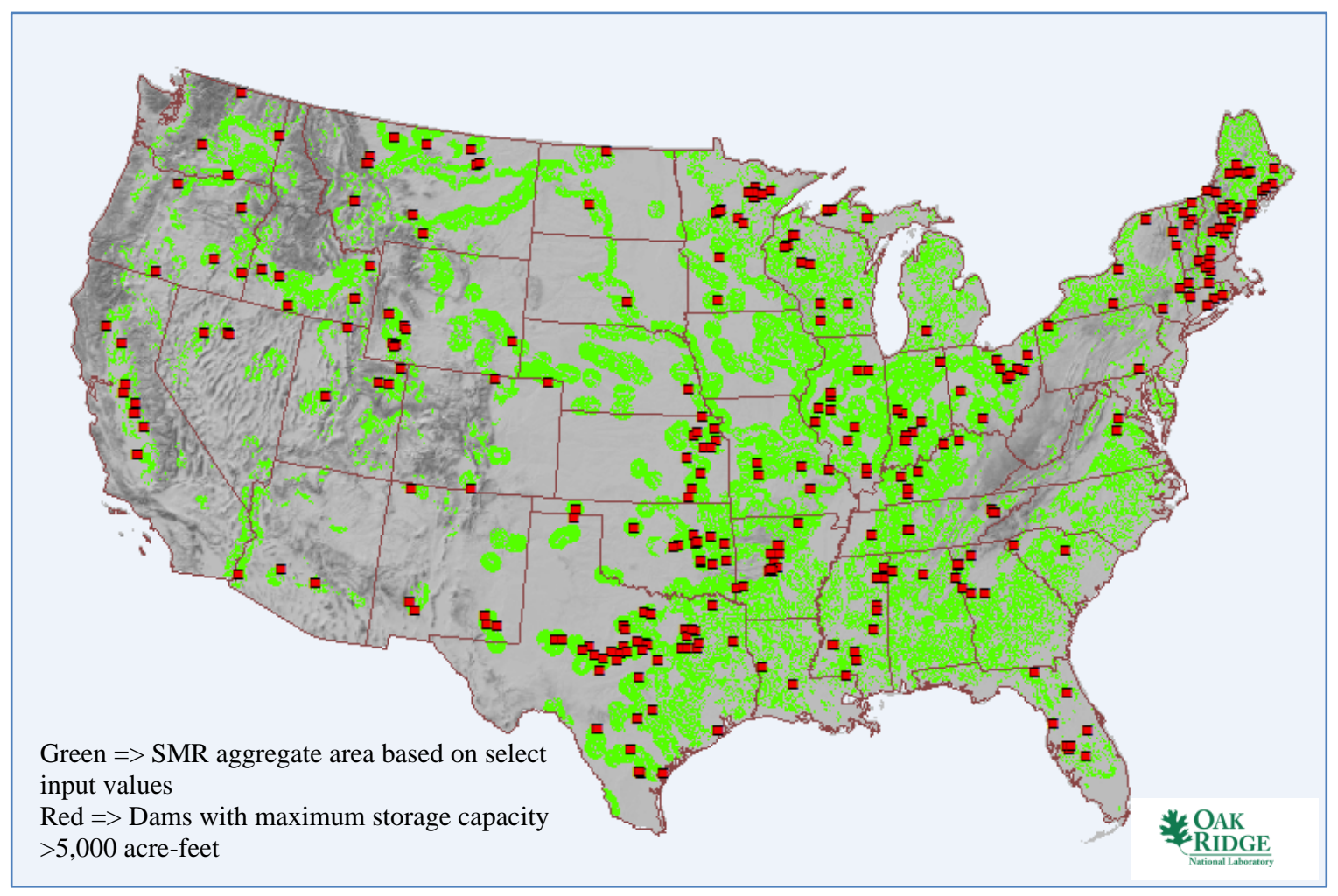

Fig. 63. Dams with capacity of at least 5,000 acre-feet that overlap the SMR aggregate map. 


\section{CHARACTERIZATION OF SINGLE-ISSUE SCREENING RESULTS}

As indicated previously, the OR-SAGE tool tracks the parameters for each of the 700 million individual 100 - by 100-m cells in the database. Therefore, it is possible to track and display cells that are tripped by one, two, or three or more SSEC criteria as a composite map. The development of the SMR composite map was discussed in Sect. 2.1 and was shown in Fig. 18 (reproduced below as Fig. 64). This is a powerful aspect to the OR-SAGE tool, because it allows areas with a limited number of siting challenges to also be characterized. Engineering solutions to areas with limited siting challenges may be available. The areas in yellow in Fig. 64 makeup 41.3\% of the contiguous United Sates and have just a single SSEC challenge. The individual SSEC causing the trip in the yellow region can be identified and evaluated.

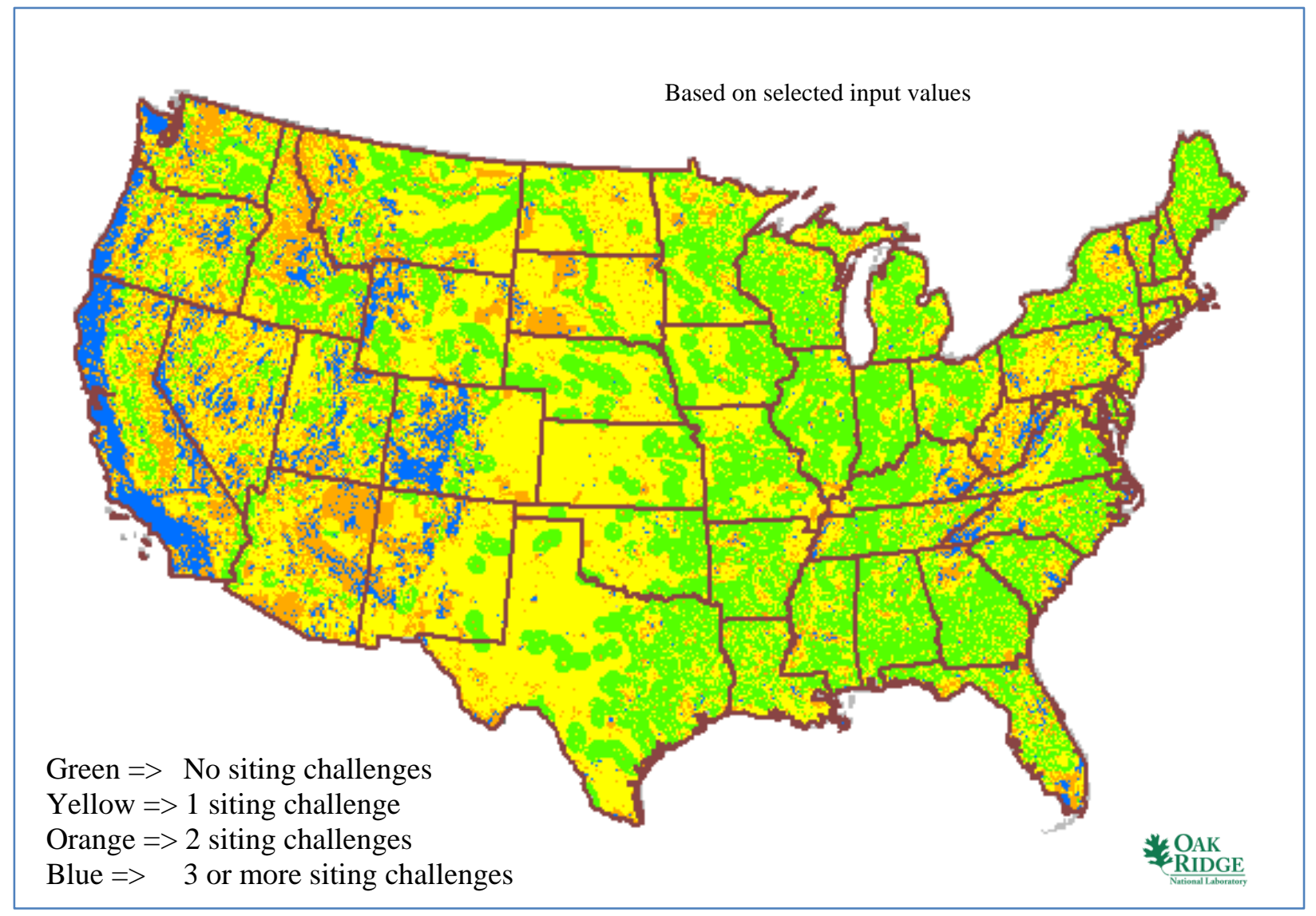

Fig. 64. Nominal, bounding SMR composite map detailing siting challenges.

\subsection{Population}

NRC siting guidance ${ }^{8}$ recommends calculating the population density within 20 miles of the site and excluding population densities of greater than 500 people per square mile. Current SMR vendors identify the ability to replace smaller, aging coal plants with an SMR having a similar capacity and footprint as an advantage of SMR iPWR designs. In order to provide this function, SMRs will need to be located closer to population centers where many of these coal plants already exist. SMRs will have a smaller source term than a large reactor, and the appropriate evacuation zone is an issue still under discussion with the NRC staff. For the purposes of this study, a 10-mile buffer was deemed appropriate for SMR siting. This value is variable within the database. The map in Fig. 65 identifies land area that is excluded based solely on the selected nominal SMR SSEC value for population. The highest concentration of population-only 
excluded land is in the northeast. Other population-excluded areas, such as southern California and coastal Florida, are excluded by more than one SMR SSEC factor. This map can be compared to the nominal SMR population SSEC layer shown in Fig. 7. The area in Fig. 65 represents 3.2\% of the contiguous United States or 55 million acres, the approximate land area of Oregon. This is $7.7 \%$ of the total SMR candidate area excluded by a single SSEC factor.

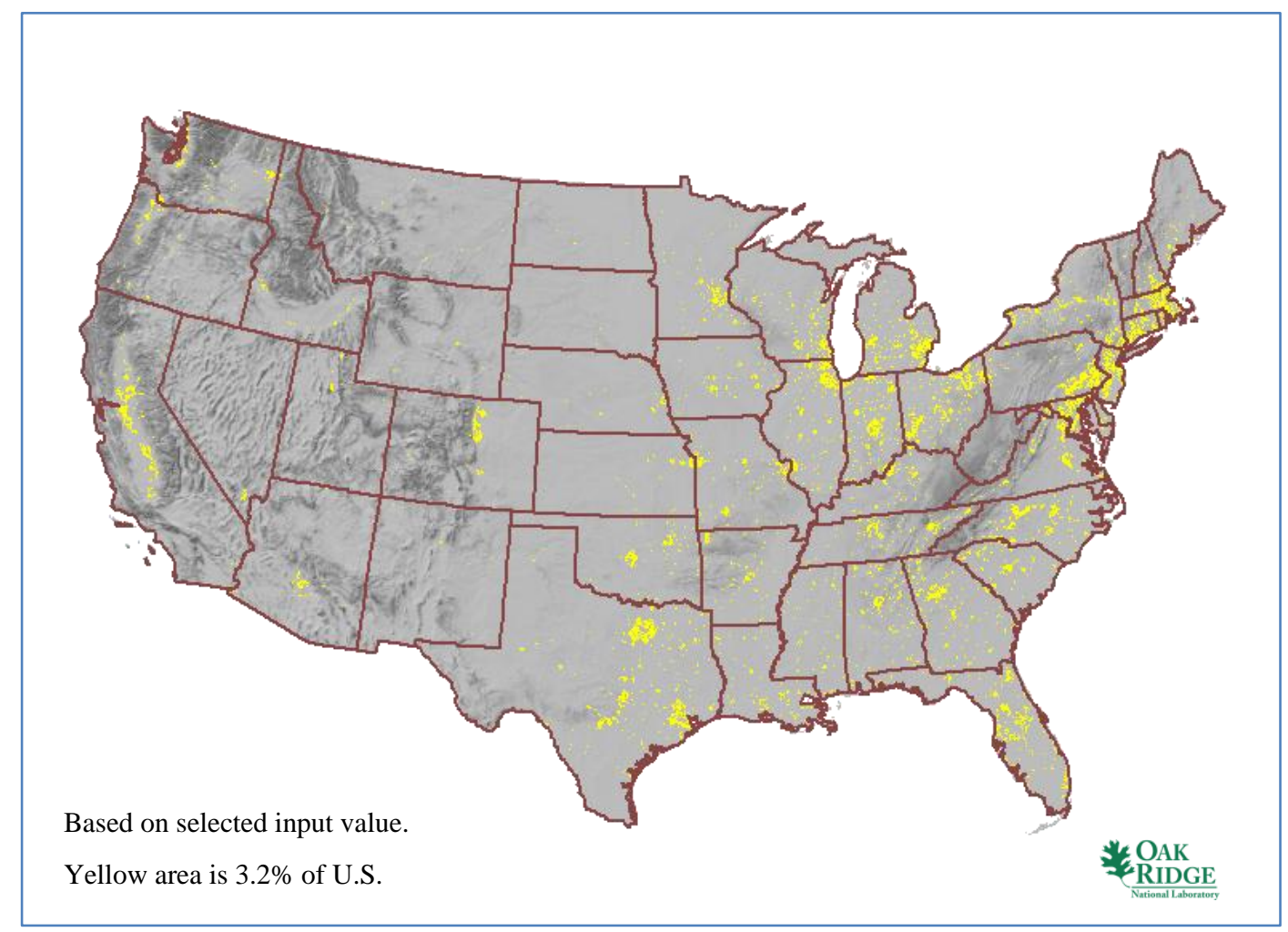

Fig. 65. Portion of the yellow area in Fig. 64 due to population only.

Based on this analysis, the ultimate decision on SMR population limits and buffering distances will have a significant effect on the available candidate areas to site near-term SMRs. This will have significant ramifications to potential customers, and likewise the SMR vendors, for an SMR design.

\subsection{Wetlands and Open Waters}

The map in Fig. 66 identifies land area that is excluded based solely on the selected nominal SMR SSEC value for wetlands and open water. The highest concentration of wetlands/open waters-only excluded land is in the north central, northeastern, and southeastern area of the country. This map can be compared to the nominal SMR wetlands and open water SSEC layer shown in Fig. 8. The area in Fig. 66 represents $4.1 \%$ of the contiguous United States or 70 million acres, the approximate land area of New Mexico. This is $9.9 \%$ of the total SMR candidate area excluded by a single SSEC factor. 


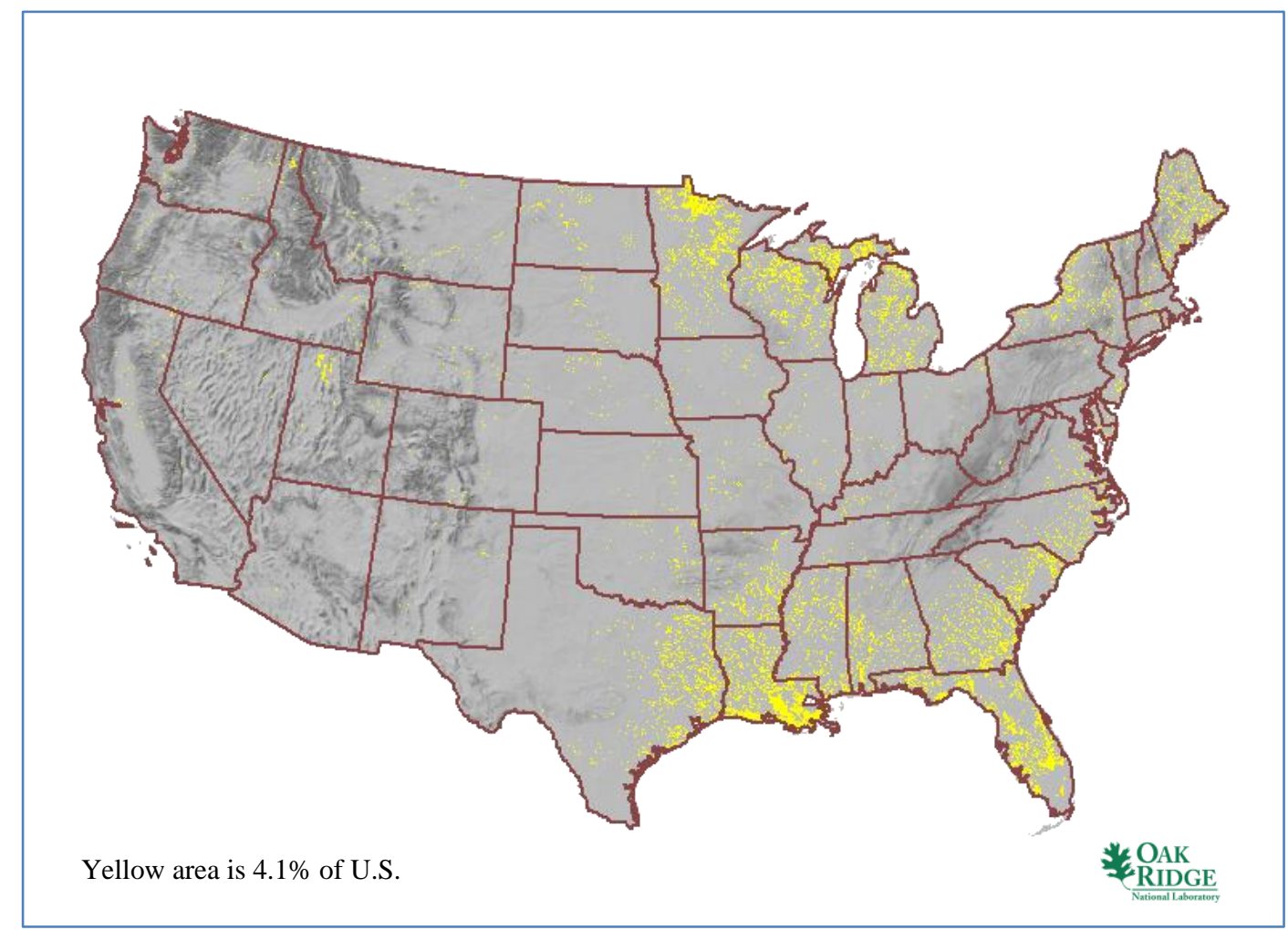

Fig. 66. Portion of the yellow area in Fig. 64 due to wetlands and open water only.

Wetlands and open waters-only excluded areas have a significant impact on the SMR candidate area land available. However, based on environmental considerations, this is not easily overcome. Therefore, further effort to refine and work with this SSEC layer is not likely to yield any increase in the SMR candidate area.

\subsection{Protected Lands}

Protected lands include national parks, national monuments, national forests, wilderness areas, wildlife refuges, wild and scenic rivers, state parks, county parks, American Indian lands, hospitals, colleges, schools, and correctional facilities. These lands are excluded based on their public nature. The map in Fig. 67 identifies land area that is excluded based solely on the selected nominal SMR SSEC value for protected lands. The protected-lands-only excluded land is reasonably distributed across the country. This map can be compared to the nominal SMR protected lands SSEC layer shown in Fig. 9. The area in Fig. 67 represents $4.7 \%$ of the contiguous United States or 80 million acres, slightly smaller than the approximate land area of Montana. This is $11.4 \%$ of the total SMR candidate area excluded by a single SSEC factor. 


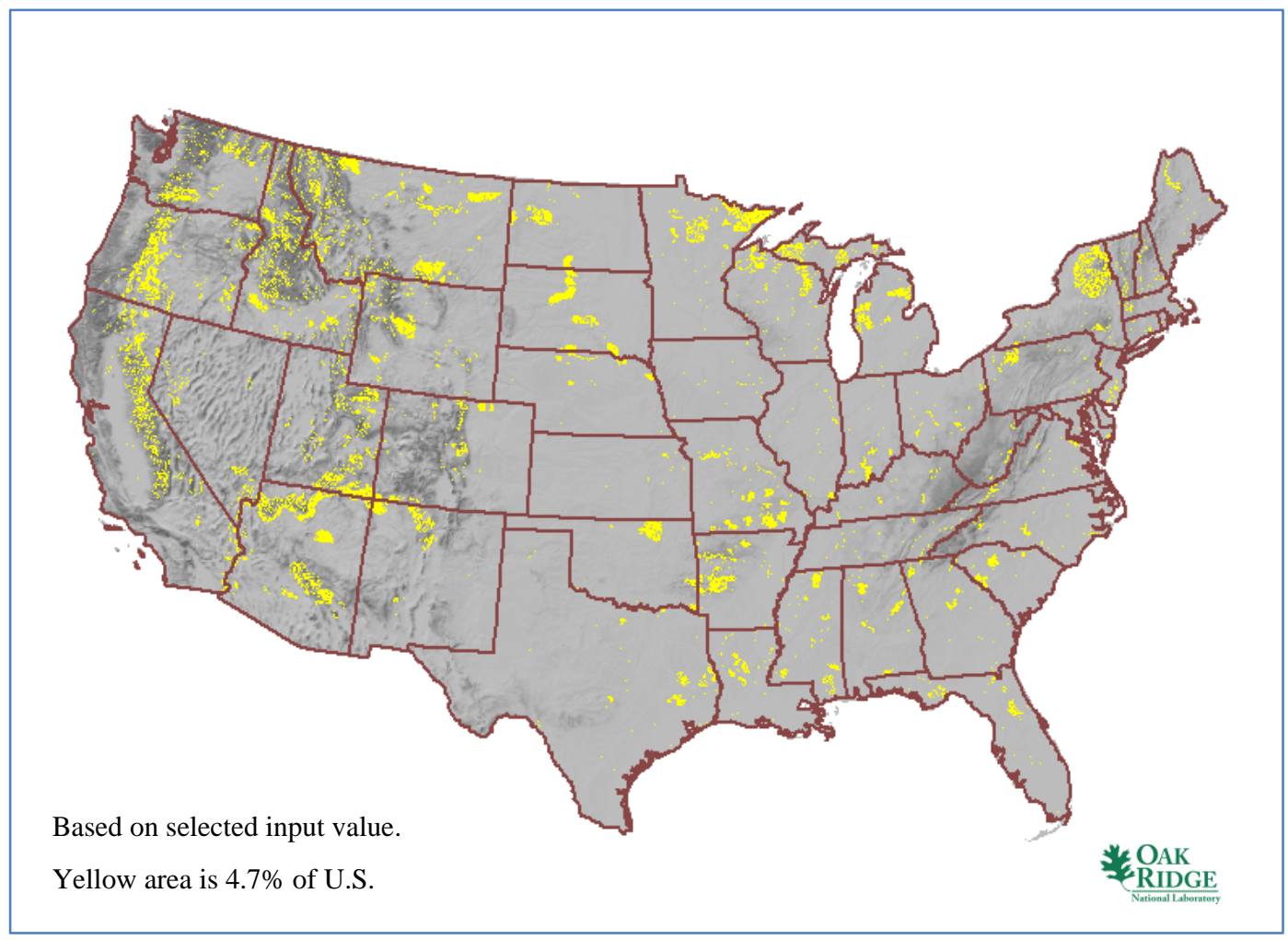

Fig. 67. Portion of the yellow area in Fig. 64 due to protected lands only.

Protected-lands-only excluded areas have a significant impact on the SMR candidate area land available. While some protected lands would likely never be considered for an SMR site, it is conceivable that some classes of protected lands may eventually be considered for an SMR site, such as American Indian land, large colleges, and correctional facilities with considerable land based on local decisions and desires for a low-pollution power source. Since these would be voluntary decisions by these entities, no further refinement of the protected lands SSEC is warranted here. Therefore, further effort to refine and work with this SSEC layer in the near-term are not likely to yield any increase in the SMR candidate area.

\subsection{Landslide Hazards}

The map in Fig. 68 identifies land area that is excluded based solely on the selected nominal SMR SSEC value for landslide hazards. The landslide-hazards-only excluded land is concentrated in the middle Atlantic states along the eastern mountain chains. This map can be compared to the nominal SMR landslide hazard SSEC layer shown in Fig. 10. The area in Fig. 68 represents 2.7\% of the contiguous United States or 46 million acres, the approximate land area of Kansas. This is $6.5 \%$ of the total SMR candidate area excluded by a single SSEC factor. 


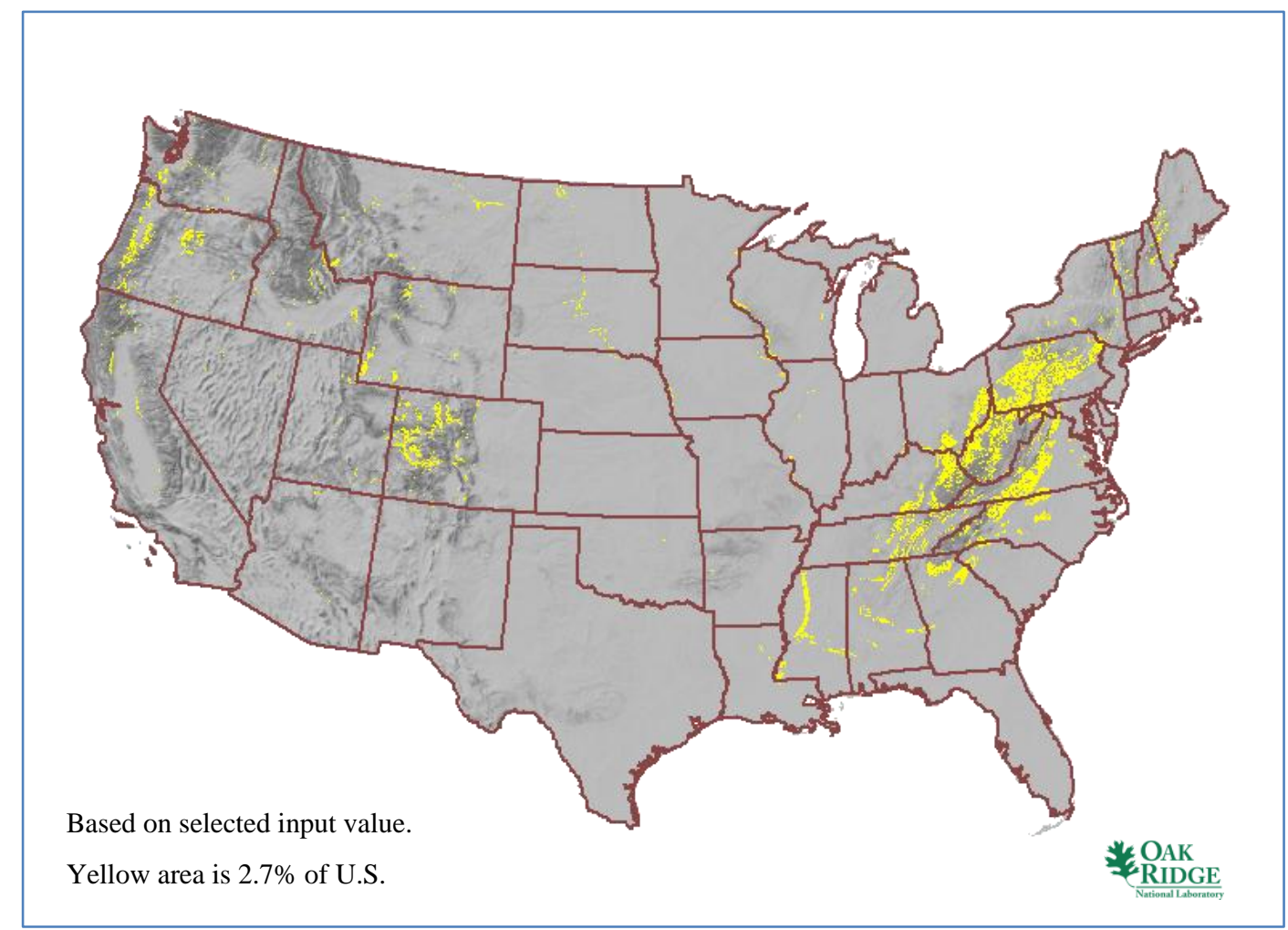

Fig. 68. Portion of the yellow area in Fig. 64 due to landslide hazards only.

Landslide-hazards-only excluded land has a moderate impact on the SMR candidate area land available. Landslide risk is determined by the USGS. Large areas of land tend to get evaluated by the USGS in mass and categorized with the same hazard treatment. Although the USGS evaluations of these broad areas are more involved and complicated than this SMR SSEC discussion indicates, individual areas would need to be evaluated more specifically for the genuine landslide risk. Therefore, land excluded based solely on landslide hazards should be retained for more detailed SMR candidate area analysis.

\section{$6.5 \quad 100-Y e a r$ Floodplain}

The 100-year floodplain SMR SSEC is included for plant investment or risk considerations. The map in Fig. 69 identifies land area that is excluded based solely on the selected nominal SMR SSEC value for 100-year floodplain. The 100-year-floodplain-only excluded land is reasonably distributed across the country. This map can be compared to the nominal SMR 100-year floodplain SSEC layer shown in Fig. 11. The area in Fig. 69 represents $0.5 \%$ of the contiguous United States or 9 million acres, twice the approximate land area of New Jersey. This is $1.2 \%$ of the total SMR candidate area excluded by a single SSEC factor. 


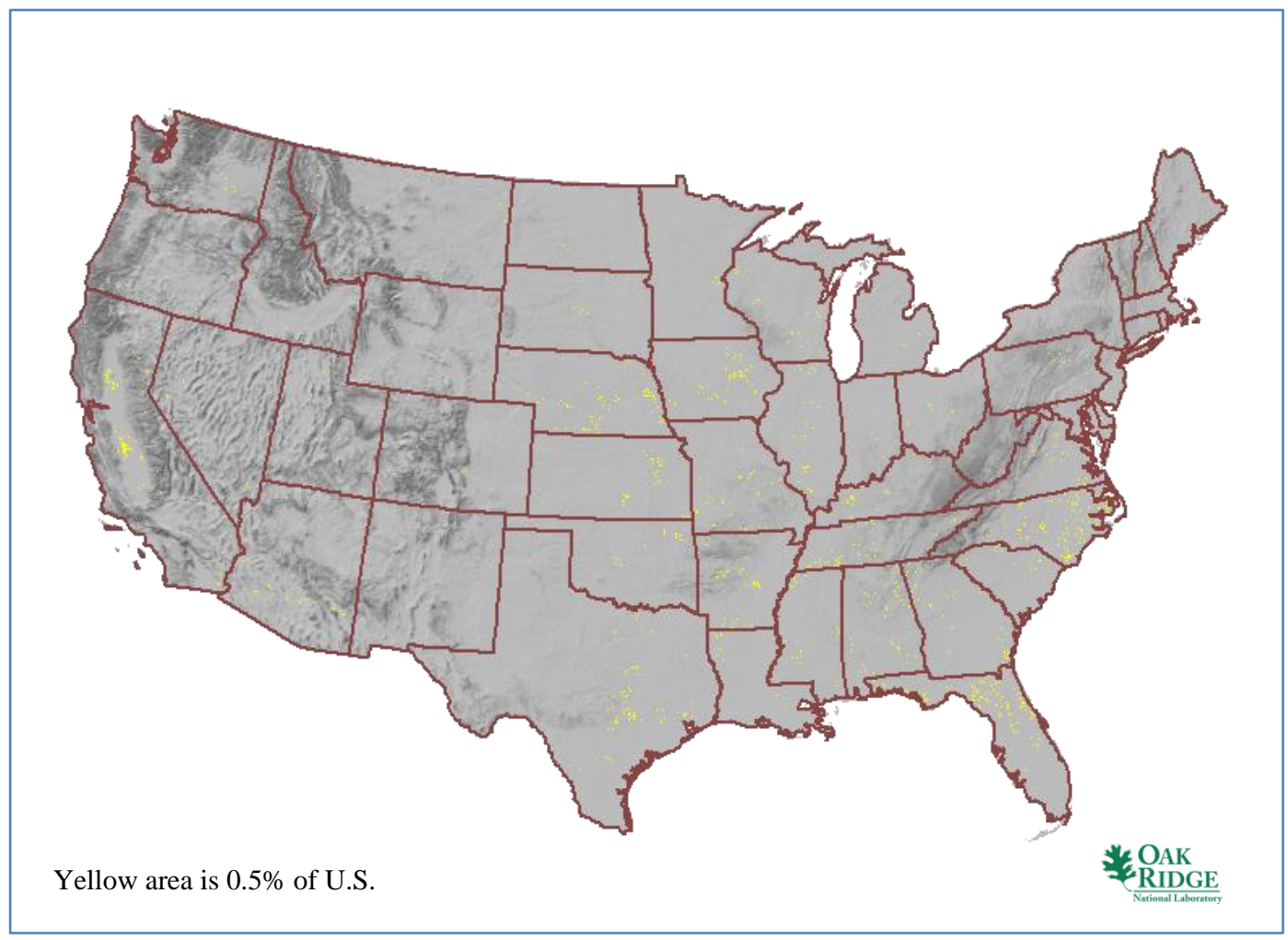

Fig. 69. Portion of the yellow area in Fig. 64 due to 100-year floodplain only.

The 100-year-floodplain-only excluded area has a minimal impact on the SMR candidate area land available. Furthermore, based on environmental considerations, this is not easily changed. Therefore, further effort to refine and work with this SSEC layer is not likely to yield any appreciable increase in the SMR candidate area.

\subsection{Slope}

Steeper slopes are avoided based on the economic cost of preparing the site for construction. Based on the smaller footprint area of the SMR designs, a value of $18 \%$ was selected vs $12 \%$ for larger reactors to allow more sites to be considered. This allows the size of the candidate areas for potential SMR siting to be expanded, recognizing that more extensive site work to prepare a relatively small site may be justifiable, and allows this to be a significant scoring factor in choosing an actual site. This value is variable within the database. The map in Fig. 70 identifies land area that is excluded based solely on the selected nominal SMR SSEC value for slope. The slope-only excluded land is reasonably distributed across the mountainous regions of the country. This map can be compared to the nominal SMR slope SSEC layer shown in Fig. 12. The area in Fig. 70 represents $1.5 \%$ of the contiguous United States or 26 million acres, the approximate land area of Pennsylvania. This is $3.6 \%$ of the total SMR candidate area excluded by a single SSEC factor. 


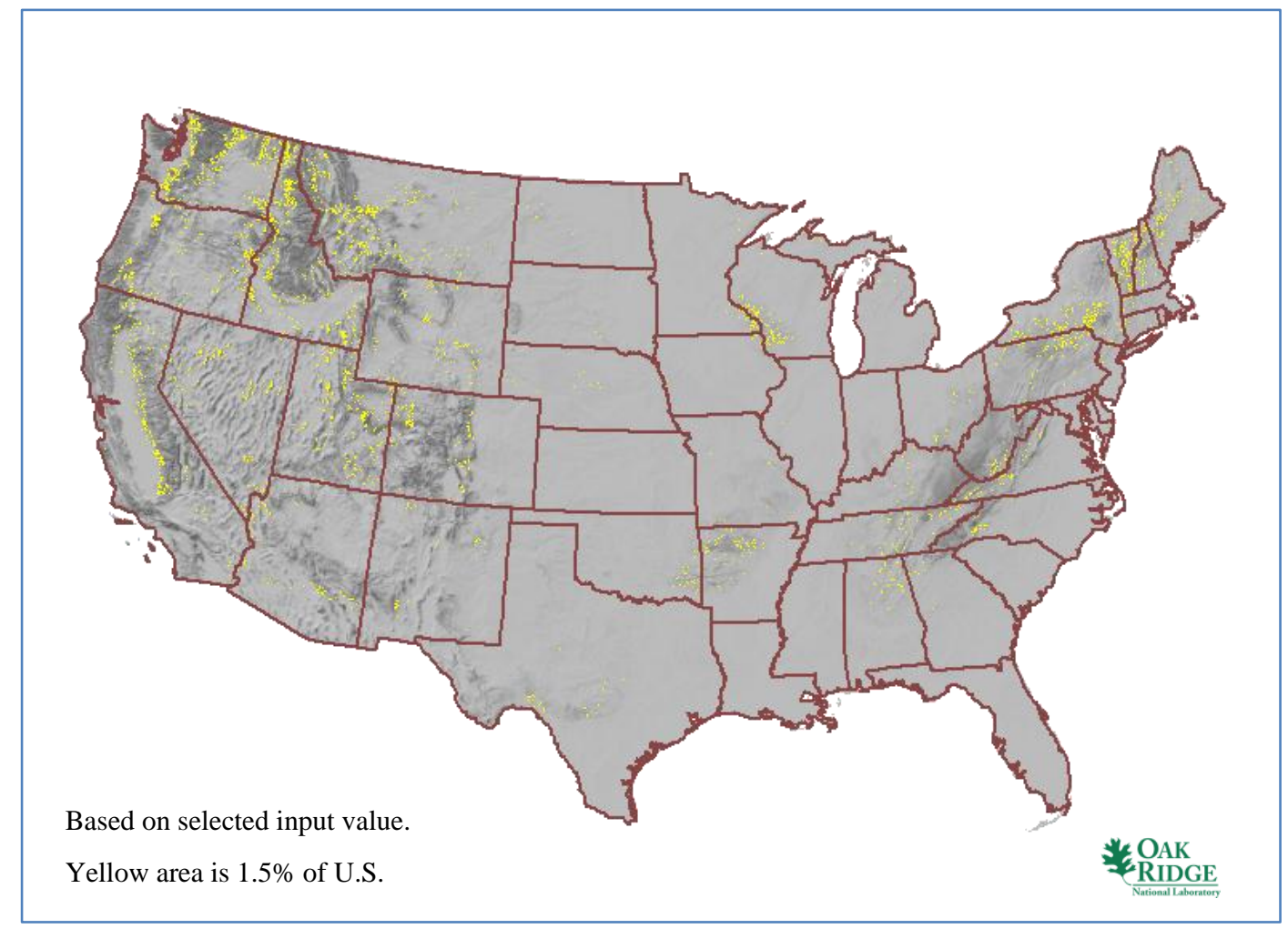

Fig. 70. Portion of the yellow area in Fig. 64 due to slope only.

The slope-only excluded area has a minimal impact on the SMR candidate area land available. However, slope is primarily an economic issue for the vendor. Therefore, land excluded based solely on slope should be retained for more detailed SMR candidate area analysis.

\subsection{Cooling Water Makeup}

Cooling water makeup requirements are based on rules of thumb of cooling water makeup required per megawatt of generation for a plant utilizing closed-cycle cooling. These rules of thumb are consistent with environmental analyses supporting site evaluations submitted to the NRC. Makeup water pipe runs of up to 20 miles were considered. The nominal makeup water value of 65,000 gpm stream flow was selected based on the bounding MW(e) rating of the near-term iPWR designs under consideration. It was assumed that cooling water makeup should be limited to taking no more than $10 \%$ of the available stream flow, and twenty miles was considered to be within reasonable proximity to a cooling water source, allowing for piping and pumps. ${ }^{4}$ Values are variable within the database.

The map in Fig. 71 identifies land area that is excluded based solely on the selected nominal SMR SSEC value for cooling water makeup. The cooling water makeup-only excluded land is concentrated in the central part of the country. This map can be compared to the nominal SMR cooling water makeup SSEC layer shown in Fig. 13. The area in Fig. 71 represents $23.3 \%$ of the contiguous United States or 399 million acres. This is $56.4 \%$ of the total SMR candidate area excluded by a single SSEC factor. 


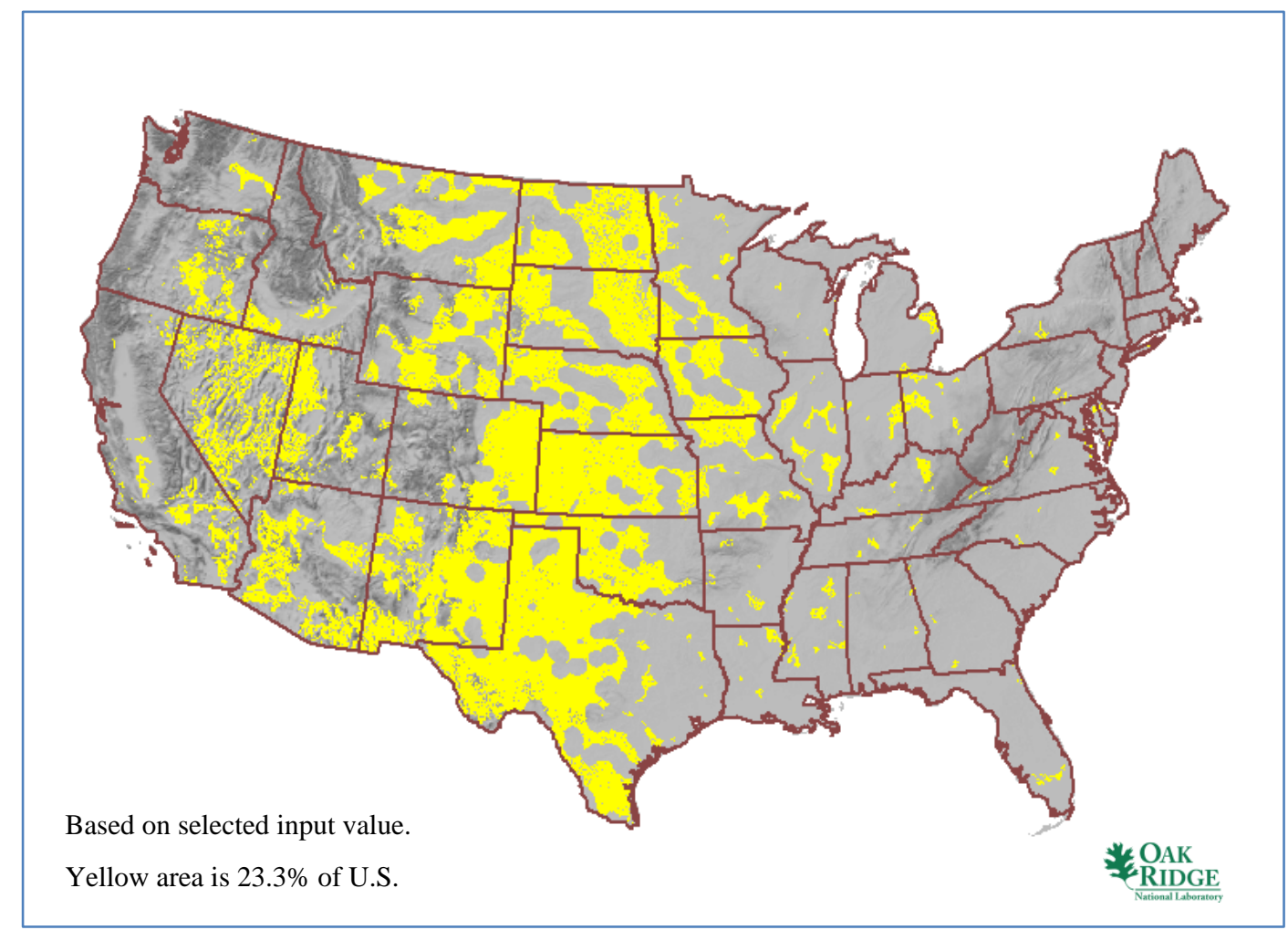

Fig. 71. Portion of the yellow area in Fig. 64 due to cooling water makeup only.

Cooling water makeup-only excluded area has far and away the most significant impact on the SMR candidate area land. Aquifers and gray water as alternate sources of cooling water makeup have a significant effect on making water available in the central part of the country. Alternate cooling water sources are explored in Chapter 3 of the report. Land excluded based solely on cooling water makeup should be retained for more detailed SMR candidate area analysis.

\subsection{Proximity to Fault Lines}

Nuclear plants must consider proximity to fault lines as a public safety issue. Based on the fault line length, a standoff distance for plant siting is recommended. ${ }^{4}$ The map in Fig. 72 identifies land area that is excluded based solely on the selected nominal SMR SSEC value for proximity to fault lines. The proximity to fault lines-only excluded land is concentrated in the western part of the country. This map can be compared to the nominal SMR proximity to fault lines SSEC layer shown in Fig. 14. The area in Fig. 72 represents $0.6 \%$ of the contiguous United States or 10 million acres, twice the approximate land area of Massachusetts. This is $1.5 \%$ of the total SMR candidate area excluded by a single SSEC factor. 


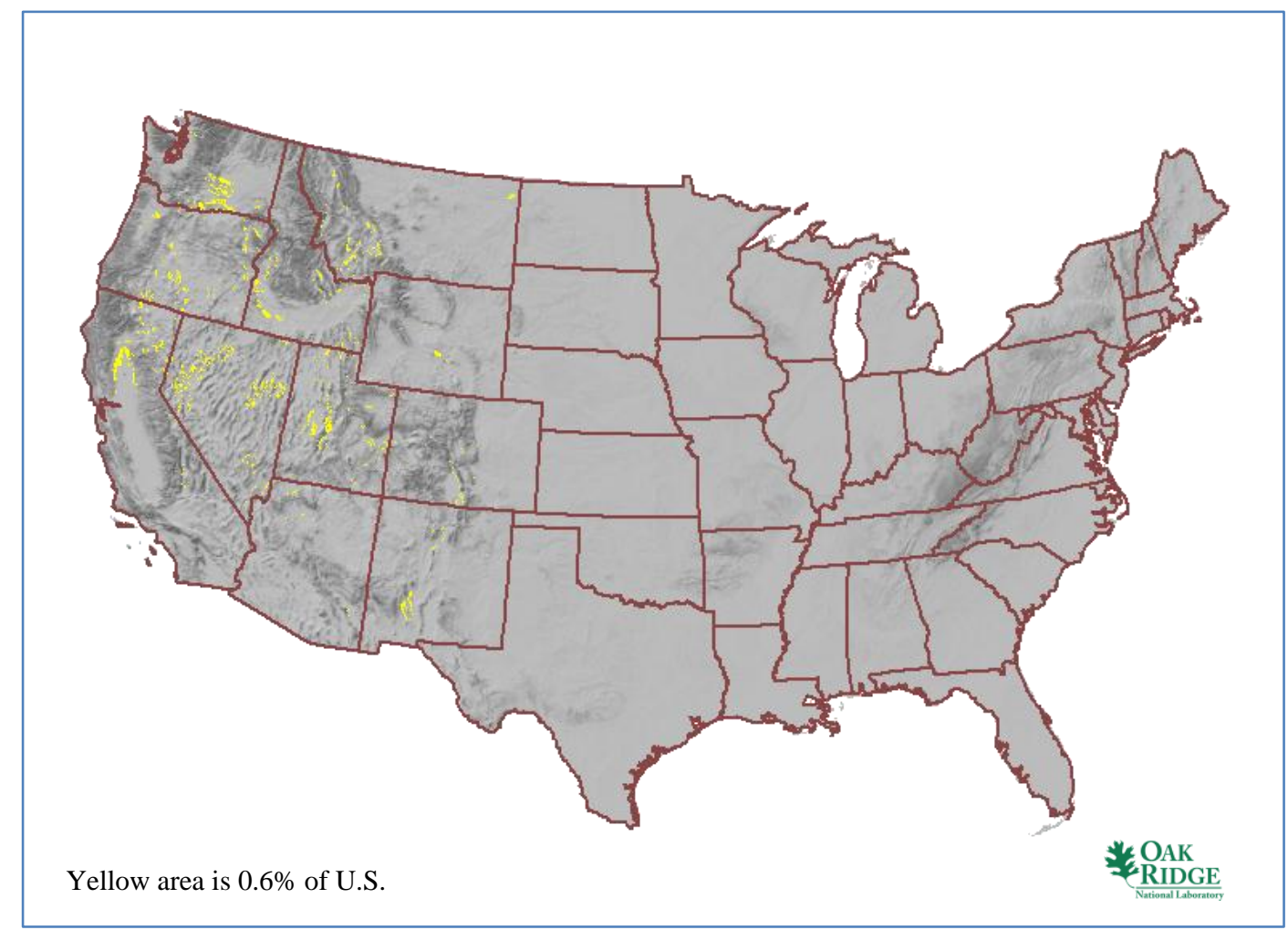

Fig. 72. Portion of the yellow area in Fig. 64 due to proximity to faults only.

The proximity to fault lines-only excluded area has a minimal impact on the SMR candidate area land available. Furthermore, the standoff distances are reasonable. Current efforts to better define faults in the central and eastern part of the country will eventually increase the amount of land excluded due to faults. Therefore, further effort to refine and work with this SSEC layer will not yield any increase in the SMR candidate area.

\subsection{Hazardous Operations}

Nuclear plants must consider proximity to hazardous operations as a public safety issue. Hazardous operations include commercial airports with a 5-mile buffer and oil refineries with a 1-mile buffer. Military bases have previously been considered under hazardous operations based on ordnance and flight operations, but the U.S. Department of Defense is looking at the possibility of using SMRs to remove some defense installations from the grid, so military bases are not excluded in this SMR study. The nominal SMR hazardous operations SSEC layer is shown in Fig. 15. However, no map of the hazardous operations-only area is provided in the report because only $0.0007 \%$ of the contiguous United States or 12 thousand acres is represented, which is not visible using report-scale maps. This is much less than $1 \%$ of the total SMR candidate area excluded by a single SSEC factor. Further effort to refine and work with this SSEC layer will not yield any appreciable increase in the SMR candidate area. This is an area that could be pursued in the future when considering more advanced high-temperature SMRs that may be colocated with hazardous chemical plants as a heat source.

\subsection{Safe Shutdown Earthquake}

Nuclear plants must consider SSE as a public safety issue. Many SMR designs are expected to call for an underground installation. In addition, the smaller structures associated with these designs are expected to allow greater flexibility in designing to higher seismic conditions. Therefore, SSE peak ground 
acceleration for this study was limited to $0.5 \mathrm{~g}$ as opposed to smaller peak ground accelerations used in other studies. This value is variable within OR-SAGE. The map in Fig. 73 identifies land area that is excluded based solely on the selected nominal SMR SSEC value for SSE. The SSE-only excluded land is concentrated in two spots - at the New Madrid seismic zone and the Charleston seismic zone. This map can be compared to the nominal SMR SSE SSEC layer shown in Fig. 16. The area in Fig. 73 represents $0.7 \%$ of the contiguous United States or 12 million acres, twice the approximate land area of Vermont. This is $1.7 \%$ of the total SMR candidate area excluded by a single SSEC factor.

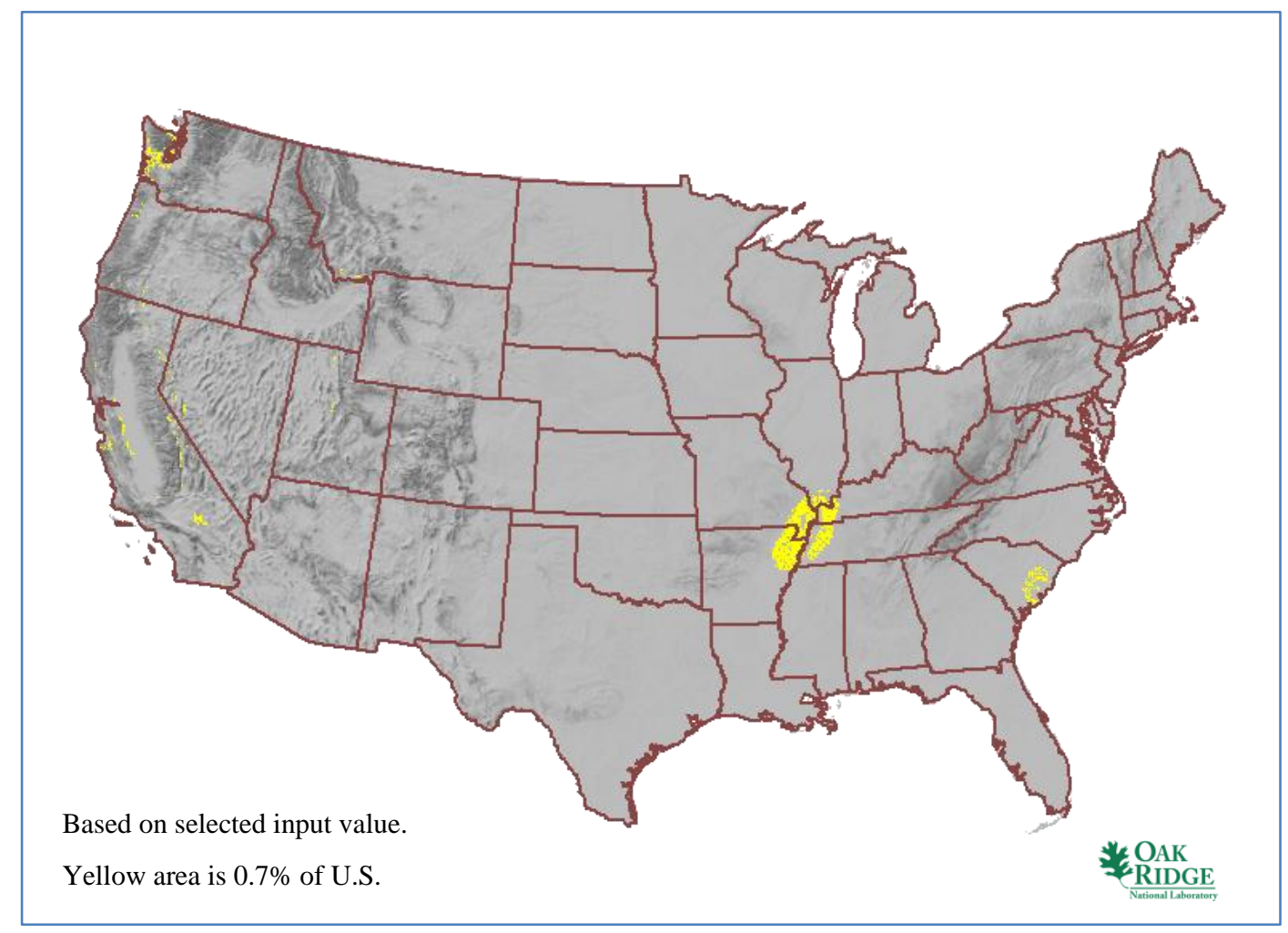

Fig. 73. Portion of the yellow area in Fig. 64 due to SSE only.

The SSE limit was adjusted as part of the detailed look at SMRs to coincide with design targets of the near-term SMR designs (iPWRs). Further adjustments to the SSE selection criteria would exceed current SMR design targets and would have a minimal impact on reducing the SSE-only excluded area and the SMR candidate area land available. Therefore, further effort to refine and work with this SSEC layer will not yield any increase in the SMR candidate area.

\subsection{Summary of SMR Single-Issue Screening Results}

The most significant contributor to the single-issue area on the nominal SMR composite map is cooling water makeup from existing stream flow. Varying values for stream flow and alternate sources of cooling water and dry cooling are explored in Sect. 2.2 and Chapter 3 of the report. Other SSEC that provide a noteworthy contribution to the single-issue area on the nominal SMR composite map and merit retention of the single-issue excluded area for more detailed SMR candidate area analysis include population and buffer, landslide hazards, and slope. These parameters involve a reasonable possibility of an engineering solution or rule-making decision affecting the screening value as well as providing a significant increase in the amount of land available for SMR candidate area. Table 6 provides a summary of the single-issue areas on the nominal SMR composite map. 
Table 6. Summary of SMR single-issue screening results

\begin{tabular}{|c|c|c|c|c|}
\hline Criteria & $\begin{array}{c}\text { United States } \\
\text { area }(\%)\end{array}$ & $\begin{array}{c}\text { Single-issue area on } \\
\text { nominal SMR } \\
\text { composite map (\%) }\end{array}$ & $\begin{array}{c}\text { Rank by } \\
\text { contribution to } \\
\text { single-issue area }\end{array}$ & $\begin{array}{l}\text { Ability to increase } \\
\text { SMR candidate area } \\
\text { by engineering or } \\
\text { rule making }\end{array}$ \\
\hline Population and buffer & 3.2 & 7.7 & 4 & Yes \\
\hline $\begin{array}{l}\text { Wetlands and open } \\
\text { waters }\end{array}$ & 4.1 & 9.9 & 3 & No \\
\hline Protected land & 4.7 & 11.4 & 2 & No \\
\hline Landslide hazards & 2.7 & 6.5 & 5 & Yes \\
\hline 100-year floodplain & 0.5 & 1.2 & 9 & No \\
\hline Slope & 1.5 & 3.6 & 6 & Yes \\
\hline $\begin{array}{l}\text { Cooling water } \\
\text { makeup }\end{array}$ & 23.3 & 56.4 & 1 & Yes \\
\hline $\begin{array}{l}\text { Proximity to fault } \\
\text { lines }\end{array}$ & 0.6 & 1.5 & 8 & No \\
\hline Hazardous operations & 0.0007 & 0.2 & 10 & No \\
\hline $\begin{array}{l}\text { Safe shutdown } \\
\text { earthquake }\end{array}$ & 0.7 & 1.7 & 7 & No \\
\hline Total & 41.3 & $100.1 *$ & & \\
\hline
\end{tabular}

* Adds to more than $100 \%$ due to rounding

The single-issue SSEC parameters cooling water makeup from existing stream flow, population and buffer, landslide hazards, and slope make up $30.7 \%$ of the country and $74.2 \%$ of the total single-issue SMR area. A total of 526 million acres of land is covered by these four SSEC parameters, which are subject to change beyond the selected SMR nominal case values.

The second and third most significant contributors to the single-issue SMR candidate area land are protected lands and wetlands/open waters. These two SSEC parameters combine for $8.8 \%$ of the country or $21.3 \%$ of the single-issue SME area. While this encompasses a noteworthy 151 million acres, the parameters are of a go-no go nature and slight adjustments to the SSEC parameter definition is unlikely to yield much of an increase in the SMR candidate siting area.

Efforts to engineer a solution around the remaining parameters listed on Table 6 provide diminishing returns.

Of course, as efforts are made to utilize more of the single-issue area for SMRs, some areas excluded by two issues will inevitably become single-issue areas. This transformation could drive factors represented in Table 6 to take on a revised relative importance for SMRs. The area excluded by two SSEC parameters represents $17 \%$ of the country. However, this was not explored further. 



\section{SUMMARY}

Using a focused set of SSEC to bound SMR candidate siting areas, approximately one-third of the contiguous United States is likely suitable for siting SMRs. When aggregated for 50-acre SMR sites, more than one-fourth of the contiguous United States remains available for SMR candidate area siting. Based on the selected SSEC criteria, 88\% of the SMR aggregated land is within 20 miles of an available rail line, 93\% of the SMR aggregated land is within 20 miles of an existing 110-230 kV transmission line, and $72 \%$ of the SMR aggregated land is within 20 miles of an existing extra high-voltage transmission line.

Smaller SMR designs based on electrical power output relative to the nominal bounding SMR power output, in terms of MW(e), can net 2 to $4 \%$ additional land for candidate area siting. However, as listed in Table 3, alternate sources of cooling water makeup can offer more than $50 \%$ of the contiguous U.S. land for SMR candidate area siting. Furthermore, dry cooling technology can provide almost $60 \%$ of the contiguous U.S. land for SMR candidate area siting, as listed in Table 4.

SMRs offer approximately 1.5 times the nuclear power plant candidate siting area that is provided by large reactors alone. ${ }^{5}$ Approximately $74 \%$ of the aggregated SMR candidate area added by the attributes of the SMR designs, or SMR-only candidate areas, are with 10 miles of existing 110-230 kV transmission lines. About $91 \%$ of the SMR-only aggregate candidate sites are within 20 miles of existing $110-230 \mathrm{kV}$ transmission lines. Approximately $70 \%$ of all SMR-only aggregate candidate areas are within 10 miles of a rail line, and $84 \%$ of all SMR-only aggregate candidate areas are within 20 miles of a rail line. Therefore, the factory-built concept envisioned for the SMR designs is very plausible as it pertains to shipping completed factory-built modules by rail.

Single siting challenge SMR areas account for $41.3 \%$ of the contiguous United Sates. Engineering solutions or other accommodations for the individual issues that "block" SMR siting may be available and could yield significant increases in available SMR candidate land areas. As listed in Table 6, the most significant contributor to the single-issue area on the nominal SMR composite map is cooling water makeup from existing stream flow. Other SSEC that provide a noteworthy contribution to the single-issue area on the nominal SMR composite map include population limitations and buffer distance, landslide hazards, and slope. These parameters offer a reasonable possibility of an engineering solution or rulemaking decision affecting the screening value as well as providing a significant increase in the amount of land available for SMR candidate area.

The next phase of work to be performed in this series of site suitability studies will be directed at two specific activities. First, while this report has principally focused on analyses looking at the continental United States and generating results as presented in national maps, the next series of analyses will focus on characterization of specific classes of potential sites that represent potential deployment options for SMRs. For example, sites at DOE facilities, DoD facilities/bases, and older, smaller coal plants (re-power these coal plants with SMRs) have been identified as possible options for deploying SMRs to match lower power requirements. The second activity will be the development of a graphical user interface (GUI) to support searches and display of results. A user will be provided options to modify the values for certain of the SMR-centric SSEC and generate new or revised maps. 



\section{DATA SOURCES}

Population: excluding all areas with population density greater than 500 people per square mile LandScan Global 2009 Population Dataset (ORNL) [30-arcsecond ( 1-km) resolution, ambient population distribution], http://www.ornl.gov/sci/landscan.

LandScan USA 2009 Population Dataset (ORNL)

Safe Shutdown Earthquake: excluding areas having a 2\% chance in 50-year return period of peak ground acceleration greater than 0.5

USGS National Seismic Hazard Mapping data (2008),

http://earthquake.usgs.gov/hazards/products/.

Tectonic Sources/Faults: excluding areas using a variable buffer distance based on the length of the fault line

USGS Quaternary Fault and Fold Database, http://earthquake.usgs.gov/hazards/qfaults/.

Wetlands: excluding areas defined as open water or wetlands through satellite remote sensing of land cover

2001 National Land Cover Dataset,

http://www.mrlc.gov/finddata.php.

Protected Land Uses: excluding managed lands and built environment (see following list)

\begin{tabular}{|c|c|c|c|}
\hline Name & Notes & Date & Link \\
\hline $\begin{array}{l}\text { National parks } \\
\text { National monuments } \\
\text { National forests } \\
\text { Wilderness areas }\end{array}$ & $\begin{array}{l}\text { National Atlas- } \\
\text { Federal Lands }\end{array}$ & $\begin{array}{l}\text { Current, } \\
\text { accessed } \\
9 / 29 / 2009\end{array}$ & http://www.nationalatlas.gov/maplayers.html \\
\hline Other parks & $\begin{array}{l}\text { Contains national, } \\
\text { state, county, } \\
\text { local parks and } \\
\text { forests }\end{array}$ & & ESRI 9.3 mapping data \\
\hline Wild/scenic rivers & $\begin{array}{l}\text { 2-mile buffer } \\
\text { added }\end{array}$ & 2008 & http://www.rivers.gov/maps.html \\
\hline Wildlife refuges & $\begin{array}{l}\text { Merged from all } \\
\text { regions }\end{array}$ & Varies & http://www.fws.gov/refuges/realty/gis.html \\
\hline $\begin{array}{l}\text { American Indian } \\
\text { reservations }\end{array}$ & & & HSIP Gold 2008 \\
\hline Hospitals & $\begin{array}{l}0.25 \text {-mile buffer } \\
\text { around points }\end{array}$ & & HSIP Gold 2008 \\
\hline Correctional facilities & $\begin{array}{l}0.25 \text {-mile buffer } \\
\text { around points }\end{array}$ & & HSIP Gold 2008 \\
\hline Schools/colleges & $\begin{array}{l}0.25 \text {-mile buffer } \\
\text { around points }\end{array}$ & & HSIP Gold 2008 \\
\hline Inventoried roadless areas & & & National Forest Service \\
\hline $\begin{array}{l}\text { Areas of critical } \\
\text { environmental concern }\end{array}$ & $\begin{array}{l}\text { Merged from state } \\
\text { data }\end{array}$ & & Bureau of Land Management \\
\hline
\end{tabular}


Slope: excluding areas with slopes greater than $18 \%$.

Digital Terrain Elevation Dataset, National Geospatial Intelligence Agency

Landslides: excluding all areas with moderate or high incidence or susceptibility to landslides

USGS Landslide Hazards Program (2002), http://landslides.usgs.gov/learning/nationalmap.

100-Year Floodplain: excluding all areas within the 100-year floodplain. Data quality and availability vary by county.

FEMA National Flood Hazard Layer (2009), http://www.msc.fema.gov.

Streamflow-Cooling Water Makeup: excluding areas further than 20 miles from streams with varying flow, depending on the makeup requirements of the energy source. Additionally allows sites within 20 miles of coastlines.

USGS/EPA National Hydrologic Dataset Plus (NHDPlus) (2008), http://www.horizon-systems.com/nhdplus

Low-flow statistics (7 day, 10 year) calculated from USGS National Water Information System (NWIS), data downloaded: 5/24/2010-5/28/2010,

http://waterdata.usgs.gov/nwis.

Hazardous Facilities: EPRI siting guidelines consider these existing facilities as avoidance criteria. Major airports have a 10-mile buffer zone; all other facilities have a 1-mile buffer.

Major Airports-Federal Aviation Administration and Bureau of Transportation Statistics (2008).

Military Bases-U.S. Census Bureau (2008),

http://www2.census.gov/cgi-bin/shapefiles/national-files.

Refineries-active facilities, HSIP Gold 2008. 